\title{
HIV stigma and social interaction : examining strategies to influence perceivers' emotional and behavioral reactions in initial encounters
}

Citation for published version (APA):

Bos, A. E. R. (2001). HIV stigma and social interaction : examining strategies to influence perceivers' emotional and behavioral reactions in initial encounters. [Doctoral Thesis, Maastricht University]. Universiteit Maastricht. https://doi.org/10.26481/dis.20011108ab

Document status and date:

Published: 01/01/2001

DOI:

10.26481/dis.20011108ab

Document Version:

Publisher's PDF, also known as Version of record

Please check the document version of this publication:

- A submitted manuscript is the version of the article upon submission and before peer-review. There can be important differences between the submitted version and the official published version of record.

People interested in the research are advised to contact the author for the final version of the publication, or visit the DOI to the publisher's website.

- The final author version and the galley proof are versions of the publication after peer review.

- The final published version features the final layout of the paper including the volume, issue and page numbers.

Link to publication

\footnotetext{
General rights rights.

- You may freely distribute the URL identifying the publication in the public portal. please follow below link for the End User Agreement:

www.umlib.nl/taverne-license

Take down policy

If you believe that this document breaches copyright please contact us at:

repository@maastrichtuniversity.nl

providing details and we will investigate your claim.
}

Copyright and moral rights for the publications made accessible in the public portal are retained by the authors and/or other copyright owners and it is a condition of accessing publications that users recognise and abide by the legal requirements associated with these

- Users may download and print one copy of any publication from the public portal for the purpose of private study or research.

- You may not further distribute the material or use it for any profit-making activity or commercial gain

If the publication is distributed under the terms of Article 25fa of the Dutch Copyright Act, indicated by the "Taverne" license above, 


\section{HIV STIGMA AND}

\section{SOCIAL INTERACTION}

EXAMINING STRATEGIES TO INFLUENCE PERCEIVERS' EMOTIONAL AND BEHAVIORAL REACTIONS IN INITIAL ENCOUNTERS

Arjan E. R. Bos 
CHA AMVIT2 VHH MOHTJA97TMA HA1DO?

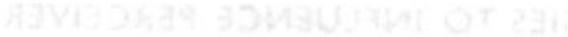

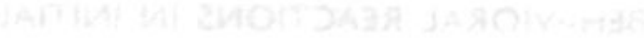




\title{
HIV STIGMA AND SOCIAL INTERACTION
}

\author{
EXAMINING STRATEGIES TO INFLUENCE PERCEIVERS' \\ EMOTIONAL AND BEHAVIORAL REACTIONS IN INITIAL \\ ENCOUNTERS
}

ter verkrijging van de graad van doctor aan de Universiteit Maastricht, op gezag van de Rector Magnificus, Prof. dr.A. C. Nieuwenhuijzen Kruseman, volgens het besluit van het College van Decanen, in het openbaar te verdedigen op donderdag 8 november 2001 om 16.00 uur

door Arjan Evert Renzo Bos 
Promotor

Prof. dr. G.J. Kok

Co-promotor

Dr.A.J.M. Dijker

Beoordelingscommissie

Prof. dr. N. K. de Vries (voorzitter)

Prof. dr. H.W. van den Borne

Prof. dr.A. H. Fischer (Universiteit van Amsterdam)

Prof. dr. H.L.G.J. Merckelbach

Prof. dr. J. B. Pryor (Illinois State University, USA)

\section{Colofon}

Vormgeving: NORA OOSTING [grafische vormgeving], Maastricht

Cover design: Josee Driessen

Printing: Unigraphic, Maastricht

ISBN 90-568|-117-7

The studies presented in this dissertation were conducted under the auspices of the Maastricht Research Institute for Prevention and Care (Health) at Maastricht University, The Netherlands. Health is part of the Netherlands School of Primary Care Research ( $\mathrm{CaRe}$ ), which has been acknowledged since 1995 by the Royal Dutch Academy of Art and Sciences (KNAW). The studies presented in this dissertation were financially supported by a grant from Stichting AIDS Fonds (grant no. 1005). 
IN MEMORY OF MISCHA 



\section{CONTENTS}

Chapter 1 HIV stigma and social interaction: A theoretical overview

Chapter 2 Public reactions to people with HIV/AIDS in the Netherlands

Chapter 3 The influence of seriousness of disease symptoms and patient's sexual orientation on emotional and behavioral reactions to ill persons

Chapter $4 \quad$ Reducing stigmatization of persons with HIV in initial encounters: The person with HIV as an 'agent of change'

Chapter 5 Interpersonal consequences of coping with HIV: Gender differences in perceivers' emotional and behavioral reactions

Chapter 6 Reducing fear of people with HIV: The impact of predictable behavior and reassuring information

Chapter $7 \quad$ General discussion

References

Notes

Summary

Samenvatting

Curriculum Vitae

Acknowledgements 


\section{CHAPTER I}

HIV STIGMA AND SOCIAL INTERACTION:

A THEORETICAL OVERVIEW 
Several years ago, a homosexual couple moved to Waardenburg, a protestant town in the Netherlands, to found a guest-house for AIDS patients. The municipal council did not object to this plan, and so it seemed that AIDS patients were to enjoy their holidays in a peaceful small village. Yet, things worked out quite differently. As soon as the plans for the guest-house had been made public, the local protestant youth responded to this plan with hostility and made the lives of both men a misery. The men were threatened and bullied, and parts of their garden were destroyed. Efforts to stop the intolerance and hostility were unavailing. Finally, the two men decided to sell their house and leave Waardenburg ("Orthodox Waardenburg", 1999). This hostility towards the foundation of a guest-house for AIDS patients is an example of HIVrelated stigmatization. ${ }^{1}$ Since the outbreak of the AIDS pandemic almost twenty years ago, people with HIV or AIDS2 have been the victim of stigmatization, prejudice and negative social reactions. For many persons with HIV, the disclosure of their serostatus has led to the loss of family ties, friendship, employment and housing; to dismissal from school; and to denial of health care and life-insurance (Chesney \& Smith, 1999; Herek, 1999; Pryor, Reeder \& Landau, 1999). How can we explain these extremely negative responses towards persons with HIV and how can we reduce HIV-related stigmatization? This dissertation examines determinants of HIVrelated stigmatization and investigates interaction strategies that persons with HIV may adopt to reduce stigmatizing reactions in initial encounters.

In this introductory chapter, I will take a closer look at the process of stigmatization. I will present a theoretical overview of the literature on stigmatization and apply relevant theoretical insights to the stigmatization of persons with HIV and AIDS. After defining stigma and discussing manifestations of stigmatization, I will focus on social interaction between stigmatized and non-stigmatized individuals. Relevant aspects of stigmatization will be discussed from both the perspective of the perceiver and the stigmatized individual. Subsequently, I will present a cognitive-emotional model of HIV-related stigmatization and discuss empirical evidence for this model. This model integrates a number of theoretical issues that have been raised in the preceding part of the introductory chapter. This chapter will conclude with an outline of the following chapters.

\section{DEFINITION OF STIGMA}

The term stigma is derived from the ancient Greeks, who used this word to refer to the marks or signs that were bumt or cut into the body of slaves, traitors or criminals. This stigma showed that the bearer of this mark was morally defective or to be avoided (Crocker, Major \& Steele, 1998; Goffman, 1963; Jones, Farina, Hastorf, Markus, Miller \& Scott, 1984). Nowadays the term stigma refers to any attribute or characteristic of a person that is deeply discrediting. This attribute is 
devalued in a particular context and calls into question the full humanity of this person. Because of this negatively valued attribute, persons are devalued, spoiled or flawed in the eyes of others (Crocker et al, 1998; Jones et al, 1984). Overt behavioral manifestations of stigmatization involve dehumanization, threat, aversion, discounting, discrediting, avoidance, social rejection and depersonalization of others into stereotypic caricatures (Dovidio, Major \& Crocker, 2000; Herek, 1999; Herek et al., 1998). However, individuals may also be stigmatized in a more subtle manner, for example by non-verbal expressions of discomfort. Such awkward reactions may occur in tensed social interactions between stigmatized and nonstigmatized individuals (Hebl, Tickle \& Heatherton, 2000).

\section{MANIFESTATIONS OF STIGMATIZATION}

\section{Behavioral expressions of stigmatization}

People may express their negative attitudes and feelings towards stigmatized individuals in different ways. In his classic account on prejudice, Allport (1954) distinguished between different levels of negative behavioral reactions: antilocution, avoidance, discrimination, physical attack and extermination. Antilocution is at stake when people only talk about their stereotypes and prejudices (predominantly with like-minded friends and occasionally with strangers). If people have stronger prejudices, they may avoid social interaction with the stigmatized individual. Avoidance does not include direct attempts to harm the stigmatized individual, in contrast to discrimination, physical attack and extermination. Discrimination concerns the active exclusion, discrediting and discounting of the stigmatized individual. Physical attack consists of even stronger negative action aimed at the stigmatized individuals, such as intimidation, threat and violence. Finally, extermination includes lynching and murder, 'the ultimate degree of violent expression of prejudice' (Allport, 1954, p. 15).

The above-mentioned expressions of stigmatization also apply to stigmatization of persons with HIV. The expression of HIV stigma may vary from one country to another, depending for example on the local epidemiology of HIV and preexisting prejudices within a culture (Herek, 1999). A meta-analysis of AIDS stigma revealed that a greater degree of stigma was expressed towards persons with AIDS than towards persons with other serious and stigmatizing diseases such as cancer (Crawford, 1996). However, the results of this study may also reflect a cultural bias, since it included mainly American studies.

It should be noted that HIV stigma may also extend to persons who are associated with persons with HIV, such as friends, family members or AIDS volunteers (Herek, 1999; Herek et al, 1998). This extension of stigma to others who are associated with a stigmatized person is referred to as courtesy stigma (Goffman, 1963) or stigma by association (Neuberg, Smith, Hoffman \& Russell, 1994). 
In general, perceivers do not simply hold hostile or accepting attitudes towards stigmatized individuals, but rather a mixture of positive and negative beliefs (Hebl et al., 2000; Katz, 1981). Social interaction with stigmatized individuals may therefore evoke ambivalence in perceivers (Katz, 1981). On the one hand, perceivers may feel a need to help or support those with a stigma. On the other hand, they may be motivated to avoid or reject the other person because of this stigma. These conflicting motivations may 'leak out' during social interaction and may result in non-verbal signs of distress and avoidant behavior.

Social interaction with persons with HIV may also arouse ambivalence in perceivers. Perceivers of persons with HIV may hold the belief that people suffering from a serious illness should receive social support, while simultaneously having a desire to avoid them. According to Crocker and colleagues (1998), information about the personal responsibility for the onset of the disease may moderate this state of ambivalence. If persons with HIV are highly responsible for the onset of their medical condition (e.g. in the case of HIV caused by unsafe sex), people tend to respond in a purely stigmatizing manner. If persons with HIV are not responsible for their HIV infection (e.g. if they have been infected with HIV due en hlond ransfusion), people are particularly inclined to respond in a prosocial manner (Crocker et al., 1998; Weiner, Perry \& Magnusson, 1700):

\section{STIGMA AND SOCIAL INTERACTION}

Social interaction between stigmatized and non-stigmatized individuals is a complex process that involves cognitive, emotional and behavioral aspects of both interaction partners (Dijker \& Koomen, 1996; Dovidio et al., 2000). In essence, the origin of stigmatization lies in the perception and cognitive representation of people with a deviant condition. These cognitions may subsequently trigger perceivers' emotional and behavioral reactions (Dijker \& Koomen, 1996; see the section on cognitive-emotional model of HIV-related stigmatization). Likewise, the individual with a stigma perceives and interprets the behavior of the perceiver, which may have an impact on the inner state (emotions and self-esteem) and behavioral responses of the stigmatized individual. Interaction patterns between stigmatized and nonstigmatized individuals depend not only on cognitions, emotions and behavior of both interaction partners, but also on the nature of their relationship (Jones et al., 1984). For example, social interaction with strangers will be based to a larger extent on stereotypic judgments than social interaction with friends (see for example Goffman, 1963, p.68).

Social interaction pattems between stigmatized and non-stigmatized individuals have received limited research attention. As Dovidio and colleagues (2000, p.11) noted, 'we know considerably more about perceivers and targets separately 
than we do about their actions together'. This knowledge about both interaction partners, however, has provided valuable insights in the needs, goals, motivations and behavior of stigmatized and nonstigmatized individuals during social interaction. In the following sections I will discuss relevant aspects of stigmatization from both the perspective of the perceiver and the stigmatized individual.

\section{THE PERSPECTIVE OF THE PERCEIVER}

This section discusses social interaction with marked individuals from the perpective of the perceiver. First, I will discuss how people perceive and categorize social stigmas. Then, attention will be paid to different functions that stigmatization may serve for stigmatizing individuals. Finally, I will focus on instrumental and symbolic attitudes towards persons with HIV.

\section{Dimensions of stigmatization}

Sociologists and social psychologists have tried to organize social stigmas into meaningful categories. Ervin Goffman (1963) offered the first categorization of social stigmas. In one of the first books on the topic of stigmatization, he distinguishes three different dimensions of social stigma: tribal stigma, abominations of the body, and blemishes of individual character. Tribal stigma refers to membership of devalued racial, ethnic or religious groups, that are familial, or passed on from generation to generation. Abominations of the body concern physical characteristics that evoke stigmatizing reactions, such as physical handicaps. Blemishes of individual character deal with devalued personality characteristics or norm-violating behavior, such as substance abuse, homosexuality, unemployment, or juvenile delinquency. Goffman (1963) provides a relatively broad classification of social stigma, and most stigmas can be classified into one (or even more) of these categories. For example, persons with AIDS in an advanced stage of the disease, may be seen as having abominations of the body (e.g. being skinny or having Kaposi's sarcoma) and a blemish of character (e.g., being homosexual).

Jones and colleagues (1984) identified six key dimensions that influence the role of stigma in interpersonal interactions (Jones et al., 1984) Concealability refers to whether the stigma is necessarily visible or can be hidden from others. A visible mark (e.g., physical disability) is readily apparent and may have an immediate impact on social interaction. In addition, persons with a visible mark may have little control over initial stigmatizing reactions of others. In contrast, stigmas that are not necessarily visible (e.g., attending psychotherapy) can be hidden from others or can be selectively disclosed. Thus, many negative consequences of a stigma can be avoided when marked individuals hide their condition (Jones et al., 1984). Furthermore, individuals with a concealable stigma have relatively more 
control over reactions of others, by carefully selecting the persons to whom they disclose their condition and by adopting certain disclosure strategies. Course concerns the way a condition changes over time and its ultimate outcome. Some conditions may become less stigmatizing over time or may even disappear (e.g., acne), other conditions are relative stable (e.g., being blind), while other conditions become more salient and stigmatizing over time (e.g., dementia). In general, people seem to respond more negatively to conditions that have a negative ultimate outcome compared to conditions that are curable and alterable (Jones et al., 1984). Disruptiveness refers to the extent to which the condition hampers social interaction. This dimension not only concerns distortion of the communication process (e.g., stuttering), but refers to any condition that makes appropriate interaction patterns uncertain. An example of disruptiveness is nervous and unpredictable behavior of persons with a mental disorder. This behavior calls attention to itself and disturbs the flow of normal interpersonal interaction (Jones et al., 1984). The dimension aesthetic qualities concerns subjective reactions to the unattractiveness of the stigma. This dimension often involves a primary affective reaction. For instance, a person with severe burn injuries may evoke strong feelings of disgust and stigmatizing behavior in perceivers, because the marks are perceived as ugly or upsetting. Another important dimension of social stigma is origin. This involves the personal responsibility of the marked individual for creating his or her own mark (Jones et al., 1984). There is strong empirical evidence that marked individuals receive stronger negative reactions when they are held responsible for the onset of their condition (see Weiner et al, 1988). For instance, a person with lung cancer will receive stronger negative reactions if this person was a heavy smoker than if the person has never smoked a cigarette at all. Finally, peril refers to the perceived danger of the stigmatizing condition to other. This perceived danger involves a variety of threatening conditions, such as contagious diseases, mental patients or persons who committed a violent crime. In general, individuals in these conditions are more easily rejected than individuals in conditions that are not perceived as dangerous.

Most of the above-mentioned dimensions are relevant to understanding perceivers' reactions towards HIV and AIDS. First of all, the dimension of peril is important to understand avoidant reactions towards persons with HIV and AIDS. Perceived contagiousness of the disease is found to be an important determinant of fear and stigmatizing reactions towards persons with HIV (Dijker, Kok \& Koomen, 1996; Herek, 1999). Second, the dimension of origin is also related to negative social reactions towards persons with HIV and AIDS. Research has shown that perceivers respond with stronger anger and stigmatization to persons with HIV who are highly responsible for the onset of their medical condition (Dijker \& Koomen, in press; Weiner et al., 1988). Third, the course dimension seems closely related to the serious nature of AIDS. Although the availability of antiretroviral therapies has prolonged the life-span of many HIV-infected individuals in westem societies, AIDS is still an incurable disease. For those who do not benefit from antiretroviral treatment, the disease may become more apparent over time and the ultimate outcome (sc., death) is very negative. Finally, dimensions like concealability and aesthetic qualities become particularly important in the 
later stages of the disease. In these stages, persons with AIDS may not be able to hide their medical condition from others, because of visible disease symptoms (e.g. weight loss or Kaposi's sarcoma). Therefore, their medical condition is readily apparent to perceivers and they may have less control over initial stigmatizing reactions of perceivers. Furthermore, some visible disease symptoms, such as Kaposi's sarcoma, may be seen by perceivers as an unaesthetic quality and may therefore intensify perceivers' stigmatizing responses. In sum, HIV contains many characteristics that are likely to evoke stigmatizing responses in perceivers. This makes it explicable why people respond in such an extremely negative way towards persons with HIV.

\section{Functions of stigmatization}

Research in the field of social stigma has identified different functions that stigmatization may serve for stigmatizing individuals (Crocker et al., 1998; Dovidio et al, 2000 ; Stangor $\&$ Crandall, 2000). These functions provide insight in some of perceivers' underlying motivations to reject stigmatized individuals. However, it should be noted that perceivers may stigmatize based on a variety of motivations and that the relative importance of certain functions may vary with the type of stigma, perceiver, target and nature of the social interaction.

\section{Control enhancement}

One function of stigmatization may be the protection of the self from harm or threat (Stangor \& Crandall, 2000). Stigmatizing individuals can enhance their control by avoiding dangerous or threatening situations. Stigmas contain information about the potential threat to perceivers (Stangor \& Crandall, 2000). The perceived threat may be instrumental (e.g., contagious disease) or symbolic (e.g., homosexuality). Instrumental threats involve threats to a material or concrete good, such as health, safety, wealth or social position, whereas symbolic threats concern beliefs, values or ideology (Stangor \& Crandall, 2000).

Control enhancement seems an important motivation for perceivers to stigmatize persons with HIV. First of all, the contagious nature of HIV may evoke a need for safety in perceivers, resulting in avoidant behavioral reactions. Second, HIV is often associated with homosexuality or drug use. Perceivers may consider these behaviors as a threat to their own values and consequently respond in a stigmatizing manner. Research in the field of HIV-related stigmatization has indeed shown that both instrumental factors and symbolic factors determine stigmatizing reactions towards persons with HIV (Herek \& Capitanio, 1998; Crandall et al., 1997; Pryor et al., 1989; Pryor et al., 1999).

\section{Existential anxiety-buffering}

Another function of stigmatization is offered by terror management theory (Greenberg, Pyszczynski \& Solomon, 1986; Solomon, Greenberg \& Pyszczynski, 1991). According to terror management theory, the awareness of one's own mortality or vulnerability can create an overwhelming existential anxiety in people. 
This anxiety motivates people to reinforce their cultural world view and reject those who violate this worldview. Perceptions of deviance or difference seem also sufficient to arouse existential anxiety (Dovidio et al., 2000). In such circumstances, stigmatization of deviant individuals is a way to provide a worldview that buffers against this anxiety (Crocker et al., 1998). Existential anxiety-buffering seems to be especially important for stigmas based on abominations of the body, because these marks immediately remind perceivers of their own vulnerability.

Existential anxiety-buffering seems to be a relevant motivation for individuals who stigmatize persons with a life-threatening disease. Social interaction with persons with HIV may remind perceivers of their own mortality and may increase a motivation to manage their existential anxiety. As a result, perceivers may reject those infected with HIV. Indeed, researchers have found that seriousness of a medical condition is related to stronger stigmatization (Crandall \& Moriarty, 1995; Dijker \& Koomen, in press). As mentioned previously, perceptions of deviance may also arouse existential anxiety in perceivers, resulting in social rejection. Persons with HIV are often associated with behavior that is perceived as deviant, such as homosexuality or drug use (Capitanio \& Herek, 1999; Herek \& Capitanio, 1999; Pryor et al., 1999; Pryor et al., 1989). Therefore, social rejection of persons with HIV can also be seen as a way for perceivers to punish and reject those who violate their cultural world views.

\section{Self-enhancement and ingroup enhancement}

At the individual level, stigmatization may serve as a self-enhancement strategy (Crocker et al., 1998; Dovidio et al., 2000). People can enhance their self-esteem through downward comparison. According to downward comparison theory (Wills, 1981), people can boost their own self-esteem by comparing themselves with others who are worse off. This downward comparison process can also take an active form, when people try to disadvantage others through stigmatization. At the intergroup level, stigmatization may enhance people's social identity (Crocker et al., 1998; Dovidio et al., 2000). According to social identity theory (Tajfel \& Tumer, 1986), people make favorable intergroup comparisons to maintain a positive social identity. Stigmatization of outgroup members is an active form of downward comparison, which affirms the superiority of one's group in relation to another group. This ingroup enhancement function may be particularly relevant to tribal stigmas, in which the mark involves a characteristic of a group (Goffman, 1963).

Self-enhancement may be one of the underlying motivations for individuals to stigmatize persons with HIV. However, this function does not explain why individuals particularly choose persons with HIV to enhance their self-esteem, After all, self-enhancement could also be realized by derogating other persons who are worse off. Ingroup enhancement seems a relevant motivation for stigmatization of members of an outgroup. Persons with HIV may be seen as an outgroup through their association with deviant behavior, such as homosexuality or drug use (Capitanio \& Herek, 1999; Herek \& Capitanio, 1999; Pryor et al., 1999; Pryor, Reeder, Vinacco \& Kott, 1989). Thus, stigmatization of persons with HIV may be a way to increase intergroup differences and show the superiority of the ingroup of the stigmatizer. 


\section{System justification}

Stigmatization may also stem from motivations to legitimize unequal group status in society (Crandall, 2000; Crocker et al., 1998; Jost \& Banaji, 1994). People of higher status groups may stigmatize people of lower status groups to justify their advantages (Crocker et al,, 1998). Systematic stigmatization based on system justification excuses negative social treatment of another group and reinforces the control of one group over the other (Dovidio et al., 2000).

Although system justification seems especially important in tribal stigmas (e.g., to justify gender or racial differences in society), it may also apply to HIV stigma. A manifestation of system justification is the response of some governments to the AIDS pandemic. The deliberate denial of the seriousness of the AIDS epidemic, the refusal to break the silence that surrounds AIDS, and the unwillingness to start adequate prevention activities and realize good care for AIDS patients, can be viewed as governments' strategies to maintain group inequalities in society.

\section{Instrumental and symbolic attitudes towards persons with HIV}

Many researchers in the field of HIV stigma have made a distinction between instrumental and symbolic attitudes towards persons with HIV and AIDS (e.g., Crandall et al., 1997; Herek \& Capitanio, 1998; Pryor, Reeder, \& McManus, 1991; Pryor et al., 1989). Instrumental attitudes involve a concern about the potential consequences of interacting with a person with $\mathrm{HIV}$ and are related to the contagious and serious nature of HIV (Herek, 1999; Pryor et al., 1989). Symbolic attitudes involve a concern about what HIV symbolizes (Pryor et al., 1989). Reactions towards persons with HIV often symbolize negative attitudes towards groups that are associated with HIV, such as homosexuals or IV drug users (Capitanio \& Herek, 1999; Herek \& Capitanio, 1998; Herek \& Capitanio, 1999; Pryor et al., 1989).

Pryor and colleagues (1989) examined instrumental and symbolic attitudes towards persons with AIDS. In their first three studies, participants had to respond to having their child in a class with a hemophiliac with AIDS. Instrumental factors (beliefs about child contracting AIDS) as well as symbolic factors (attitude towards homosexuals) determined reactions to having a child in a class with a person with AIDS. Pryor et al.'s (1989) fourth and fifth study examined participants' desire to switch class after finding out that their professor had contracted AIDS from a blood transfusion. In both studies, symbolic factors (attitude towards homosexuals) determined participants' desire to switch class. Instrumental concerns only influenced the desire to switch class in the fifth study. It appeared that instrumental concerns involved in this classroom situation were beliefs about feeling comfortable (as operationalized in their fifth study) instead of beliefs about the contagiousness of the disease (as operationalized in their fourth study). In sum, the five studies conducted by Pryor and colleagues (1989) underline the importance of both instrumental and symbolic factors. Remarkably, these studies demonstrated that people's reactions towards a heterosexual person with AIDS were influenced by their attitude towards homosexuals. This latter finding has been replicated in subsequent studies (e.g., Pryor et al., 1991). 
Herek and Capitanio (1998) also examined to what extent attitudes towards persons with AIDS were predicted by instrumental and symbolic concerns. Various facets of AIDS stigma were measured in a two-wave national telephone survey. Herek and Capitanio (1998) found that support for punitive AIDS policies, support for mandatory testing of high-risk groups, and negative affect towards homosexual persons with AIDS were primarily predicted by symbolic concerns. Avoidant behavioral intentions, however, were predicted by both instrumental and symbolic concerns.

Crandall et al. (1997) conducted a series of five studies to investigate the role of instrumental and symbolic attitudes in stigmatization of persons with HIV. They compared reactions to AIDS with reactions to a fictitious disease that had identical disease characteristics, but not the symbolic meanings associated with AIDS. Their first three studies showed that instrumental concerns, particularly the seriousness of disease, were sufficient to cause HIV-related stigmatization. Their fourth study provided evidence for symbolic factors in HIV-related stigmatization: When the fictitious disease was presented as a treatable mild medical condition, symbolic aspects (e.g. association with homosexuality) still contributed to stigmatization. Their last study indicated that HATH (heterosexuals' attitudes toward homosexuals; Larsen, Reed, \& Hoffman, 1980), a measure frequently used to demonstrate the importance of symbolic factors in HIV-related stigmatization, may be a confounded measure. Crandall et al. (1997) showed that HATH not only measures antihomosexual affect, but also general rejection of other forms of deviance. To conclude, Crandall et al. (1997) found evidence for both instrumental and symbolic attitudes towards persons with HIV. However, they demonstrated that 'when instrumental concerns are strong, symbolic attitudes may add little to the prediction of social distance' (Crandall et al., 1997, p. 117).

Recently, research on instrumental and symbolic attitudes towards persons with $\mathrm{HIV}$ has been combined with insights from the field of social cognition (Pryor et al., 1999; Reeder \& Pryor, 2000). Reeder and Pryor (2000) argued that knowledge from social cognitive research could contribute to better understanding of the cognitive representation and underlying process of instrumental and symbolic attitudes. Researchers in the field of social cognition have proposed dual-process models to describe the cognitive processes involved in person perception (e.g., Brewer, 1988; Fiske \& Neuberg, 1990, see for a review Smith \& DeCoster, 2000). Basically, these dual-process models assume that both automatic and more controlled processes are involved in the perception of others, and that thoughtful information processing is employed only when people have enough motivation and cognitive resources. In a similar vein, Reeder and Pryor (2000) proposed a two-stage model of reactions towards persons with HIV. They suggested that the initial reaction towards persons with HIV involves relatively automatic and associative processing. However, if people have enough time, motivation and cognitive resources, they may engage in more controlled processing and adjust their initial reaction. Reeder and Pryor (2000) argued that symbolic attitudes are likely to play a role in the first automatic stage, because of their associative nature. Instrumental attitudes, however, are more likely to come into play in the second adjustment stage, because these attitudes require more thoughtful processing (e.g., weighing 
the pros and cons of interpersonal contact with a person with HIV). Pryor et al. (1999) reported initial evidence for this assumption.

\section{THE PERSPECTIVE OF THE STIGMATIZED INDIVIDUAL}

Stigmatization may have serious consequences for social relationships, psychological well-being and physical health of stigmatized individuals. This poses a challenge for stigmatized persons to cope with and adapt to these severe reactions. Further, persons with an invisible stigma may have the dilemma as to whether or not to disclose their stigma to others. This section focuses on these problems, challenges and dilemmas for stigmatized individuals.

\section{Consequences of stigmatization}

Stigmatization may have far-reaching negative consequences for stigmatized individuals. First of all, stigmatization may have social consequences. Stigmatization may lead to the disruption of relationships with acquaintances, relatives or friends. In addition, the stigma may hamper the development of new relationships. Thus, the social network of stigmatized persons may become reduced and some stigmatized persons may even face social isolation. Research of Crandall and Coleman (1992) shows that persons with HIV who feel stigmatized indeed experience alienation and the disruption of their relationships. Second, stigmatization may also have psychological consequences. Stigmatization is a painful process and may arouse negative emotions in stigmatized individuals, such as anxiety, depression or hostility (Jones et al., 1984). Further, the awareness that one's identity is devalued in the eyes of others may also be a threat to one's self-esteem (Crocker et al., 1998). However, although the self-esteem may be threatened, this does not necessarily lead to low self-esteem (Crocker \& Major, 1989; Crocker et al., 1998), because stigmatized individuals may engage in strategies to maintain or enhance their self-esteem (see for example Tice, 1993; Tajfel \& Tumer, 1986). Crandall and Coleman (1992) found that stigmatized persons with HIV report feelings of anxiety and depression. The psychological impact of HIV-related stigmatization is also documented by other researchers (e.g. Leary \& Schreindorfer, 1998). Third, stigmatization may also have health consequences. The disruption of interpersonal relations, for example, may limit the number of potential social support providers. In the case of HIV, fear of stigmatization may have another negative impact on the health of persons with HIV. People may hesitate or resist to be tested for HIV, because they are afraid to become stigmatized (Leary \& Schreindorfer, 1998). This may result in delays of treatment and care for persons with HIV (Chesney \& Smith, 1999). Since persons with HIV seem to benefit from early treatment with antiretroviral therapy, this procrastination of HIVtesting may have negative health consequences. 
Obviously, social stigma is a very stressful life event for persons who possess such a mark. This raises the question of how stigmatized individuals cope with and adapt to being stigmatized. Before going into details of this, it should be noted that coping responses depend on the stressor and vary across individuals. Therefore, the aim of this section is merely to provide an overview of possible strategies that stigmatized people may use to cope with their stigma.

Researchers in the field of coping have frequently made a distinction between problem-focused and emotion-focused forms of coping (Folkman, Lazarus, Gruen, $\&$ Delongis, 1986; Lazarus \& Folkman, 1984; Maes, Leventhal \& De Ridder, 1996). Problem-focused coping strategies are responses directed at the stressor itself, whereas emotion-focused coping strategies are directed at the internal state caused by the stressor. In a recent chapter on coping with stigma, Miller and Major (2000) have used this distinction between problem- and emotion-focused coping to classify different coping strategies that stigmatized individuals may use to reduce stigmatizing responses and maintain or enhance their self-esteem.

\section{Problem-focused coping}

Miller and Major (2000) have argued that stigmatized individuals can target their efforts to reduce stigmatization towards the self, towards others or towards the situation. Problem-focused strategies aimed at the self include, for example, concealment or disguise of the stigma (e.g., a blind person wearing sunglasses) or eliminating the stigmatized condition (e.g., plastic surgery for persons with burn injuries). Other-oriented strategies consist of ways to reduce stigmatization in others (e.g., campaigns to gain acceptance for certain stigmatized groups). Stigma reduction efforts aimed at the situation involve the avoidance of situations which are prone to stigmatization (e.g., avoidance of cafeterias by obese persons) or seeking stronger affiliation with similar others (e.g., social support groups).

Basically, the three above-mentioned strategies may also be used by persons with HIV. First, many persons with HIV in western societies may have the option to conceal their medical condition from others. However, as I will argue later, this may also have its drawbacks. Second, stigma reduction strategies targeted towards others may also be employed by persons with HIV. For example, AIDS organizations have developed mass-media campaigns aimed at stigma reduction (see for example Kok, Kolker, De Vroome \& Dijker, 1998). Persons with HIV may also attempt to influence stigmatizing behavior of others in interpersonal contact. This approach is the focus of the experiments reported in this dissertation. Third, persons with HIV may also avoid situations that are likely to expose them to stigmatization or they may seek affiliation with other persons with HIV (e.g. participate in 'HIV vereniging'). Structural avoidance of certain situational contexts, however, does not seem to be a desirable option.

\section{Emotion-focused coping}

Stigmatized individuals also have different ways to minimize negative emotions and protect their self-esteem from stigma-related stressors (Crocker et al., 1998; 
Miller \& Major, 2000). First of all, stigmatized individuals may use social comparisons as a way to protect self-esteem and regulate the emotions associated with the stigma (Crocker \& Major, 1989; Miller \& Major, 2000). Stigmatized individuals are usually in a disadvantaged position compared to others. Comparing one's position with other persons who are better off may entail a threat to one's selfesteem. However, engaging in downward comparisons may enhance self-esteem and regulate emotional reactions (Miller \& Major, 2000; Wills, 1981). Second, stigmatized individuals can protect their self-esteem by attributing negative outcomes to external causes (Crocker et al., 1998; Miller \& Major, 2000). Research in the field of attributions and emotions (Weiner, 1985) has shown that negative outcomes are less likely to lead to negative emotions when they are attributed to external causes (e.g., the stigmatizing individual) than to internal causes (e.g., the self). Third, stigmatized individuals may disengage their self-esteem from a particular stigmatizing context and increase the importance of the self in other contexts in which they are not disadvantaged (Crocker et al., 1998; Miller and Major, 2000). In this way, the self-concept of stigmatized individuals will suffer less when they are the target of stigmatization. To my knowledge, the above-mentioned emotion-focused ways of coping with stigma have never been investigated for stigmatized persons with HIV. Research on coping with HIV has primarily focused on coping with the medical condition itself and with the emotional consequences of being infected with HIV (e.g., Fleishman \& Fogel, 1994).

\section{The dilemma of disclosure}

Persons with an invisible stigma may have the choice between concealment and disclosure of their stigma. This choice may place the person in a difficult dilemma. Obviously, concealment seems an effective strategy to avoid stigmatizing reactions and may be particularly an option in short-term contact and casual interactions (Jones et al., 1984). However, non-disclosure may also have its drawbacks. First, the concealment of a stigma implies that those individuals will not receive social support from others. Research suggests that people cope better with stressful events if they can discuss their personal difficulties with somebody else (Derlega, Lovejoy \& Winstead, 1998; Lane \& Wegner, 1995; Larson \& Chastain, 1990; Pennebaker, 1990). Second, the concealment of the stigma may be a stressful event in itself, because one is constantly 'on stage' trying to hide this condition for others (Hebl et al., 2000). Research on thought suppression has shown that people who try to suppress unwanted thoughts may experience a rebound effect of such thoughts later (Wegner, 1994). Smart and Wegner (2000) extended these ideas to the concealment of stigmas and investigated whether stigma concealment was related to stronger preoccupation with the stigma. Indeed, they found that people who actively tried to conceal their stigma showed more intrusions of these thoughts.

Disclosure of an invisible stigma may have its drawbacks as well. First, people with a stigma may lose control over important information about themselves when they inform others about the stigma. Informed others may break confidentiality and pass on this information about the stigma (Goffman, 1963). Hence, 
people with an invisible stigma may unwantedly become the target of gossip or stigmatization in a larger social context. Second, informed others may treat the marked individual differently after stigma disclosure. For example, they may break up social contact, show lack of understanding or display overprotection. In sum, people need to decide carefully to whom they disclose their stigma and need to anticipate how another person will respond to this information.

Persons with HIV may also face the dilemma of disclosure. For many persons with HIV in western societies their medical condition is not apparently visible 3 . Research indicates that many persons with HIV selectively disclose their serostatus to others (Derlega et al., 1998, p. 149). In general, persons with HIV seem to disclose their serostatus to their primary sexual partner and friends. Family members and co-workers are less likely to be informed about their HIV infection (Hays, McKusick, Pollack, Hilliard, Hoff \& Coates, 1993; Mansergh, Marks \& Simoni, 1995; Stempel, Moulton \& Moss, 1995). Disclosure of serostatus is generally higher among symptomatic persons than asymptomatic persons (Mansergh et al., 1995). In general, persons with HIV report the least favorable reactions towards HIV disclosure from primary sexual partners and male family members (Mansergh et al., 1995; Stempel et al., 1995). Derlega et al. (1998) investigated reasons for HIV disclosure and nondisclosure among forty-two persons with HIV, predominantly African Americans. This study showed that a large number of persons disclose their serostatus, because they feel close to that other person and expect supportive, caring or consoling reactions. Reasons for nondisclosure included fear of stigmatization, expectations of unsupportive reactions and emotional protection of others (e.g. prevent people from worrying about them).

Persons with HIV not only have to decide to whom they disclose their serostatus, but also need to think carefully to what extent they want to confront others with their suffering. Silver, Wortman and Crofton (1990) called this the self-presentational dilemma of ill persons. On the one hand, patients have to confront others with their suffering in order to receive supportive reactions. On the other hand, they run the risk of social rejection when they convey distress. Silver et al. (1990) investigated this self-presentational dilemma for female breast cancer patients. They found that perceivers responded negatively towards patients who conveyed high levels of distress and coped poorly with their disease, and towards patients who did not provide any coping information. Conversely, perceivers reacted positively to patients who indicated that they were coping well with their disease. Interestingly, participants also responded positively towards patients who displayed a balanced form of coping, in which patients conveyed distress but simultaneously indicated that they were coping well with their disease. Schwarzer and Weiner (1991) investigated the effects of patients' coping with HIV on perceivers' emotional and behavioral reactions, using a vignette methodology. They found that perceivers responded with stronger pity towards a target with AIDS who engaged in active coping, as compared to passive coping. However, the interpersonal consequences of coping with HIV have received limited research attention and will be the central focus of the studies reported in Chapter 5 . 


\section{A COGNITIVE-EMOTIONAL MODEL OF STIGMATIZATION OF PERSONS WITH HIV}

Many researchers in the field of HIV stigma addressed perceivers' instrumental and symbolic attitudes towards persons with HIV (e.g., Crandall et al., 1997; Herek \& Capitanio, 1998; Pryor et al., 1999). This line of research has primarily focused on the relative importance of both attitude functions in HIV-related stigmatization, and has relatively neglected the specific content of cognitive factors involved in stigmatization of persons with HIV. Further, this approach has not given attention to possible emotional reactions that mediate attitudes and behavioral reactions. However, research in the field of stereotyping and stigmatization increasingly recognizes the role of emotions in reactions to different social groups (Dovidio et al., 2000; Dijker et al., 1996; Dijker \& Koomen, in press; Dijker \& Raeijmaekers, 1999; Mackie \& Hamilton, 1993; Weiner et al., 1988). This section will present a cognitive-emotional model of stigmatization of persons with HIV. This model is based on Dijker and Koomens' cognitive-emotional model of stigmatization of handicapped and ill persons (Dijker \& Koomen, 1996), which extends Weiner's attribution-emotional model of stigmatization (Weiner, 1993, 1996; Weiner et al., 1988). The proposed cognitive-emotional model of stigmatization of persons with HIV seeks to integrate important theoretical concepts put forward by other investigators in this field and focuses on the contribution and specific content of cognitions and emotions in the process of stigmatization.

Weiner and colleagues (Weiner, 1993, 1996; Weiner et al., 1988) have paid explicit attention to the role of emotions in the process of stigmatization. Weiner's attribution-emotion model of stigmatization assumes that two central emotional reactions, pity ${ }^{4}$ and anger, motivate social rejection of marked individuals. Anger motivates hostility and stigmatizing behavior towards marked individuals. In contrast, pity motivates prosocial behavior and is related to a reduction of stigmatization. Weiner assumes that both emotional reactions are determined by beliefs about personal responsibility for the onset of the deviant condition (Dijker \& Koomen, in press; Weiner et al., 1988). If persons are highly responsible for the onset of their condition (e.g., obesity due to excessive eating without exercise), people tend to respond with less pity, stronger anger and stronger stigmatization. However, if individuals have low personal responsibility for the onset of their condition (e.g., obesity due to glandular dysfunction) people respond with stronger pity, less anger and less stigmatization. This concept of personal responsibility is similar to the stigma dimension origin (Jones et al., 1984).

From the above-mentioned attribution-emotional perspective, Weiner et al. (1988) investigated reactions towards different stigmatized groups, including persons with AIDS. In their first experiment, Weiner et al. (1988) compared several stigmas on a range of dependent variables. They found that stigmas with a mentalbehavioral origin (e.g., AIDS) were perceived as being more onset-controllable than physically based stigmas (e.g., Alzheimer's disease). Furthermore, stigmas with a mental-behavioral origin elicited less pity, less helping and more anger than physically based stigmas. In their second study, Weiner et al. (1988) manipulated information about onset responsibility for ten stigmas (manipulation for AIDS: blood 
transfusion vs. leading a promiscuous life) and measured the same range of dependent variables. Information about personal responsibility for the onset of AIDS influenced participants' emotional and behavioral reactions. If the target was highly responsible for contracting AIDS, participants reported stronger blame, less pity and less liking. However, if the person with AIDS had no onset responsibility, participants responded with less blame, stronger pity and stronger liking.

Other researchers have also found evidence for the assumption that attributional factors are involved in stigmatization of persons with HIV. Peters, Den Boer, Kok and Schaalma (1994) investigated stigmatization of persons with AIDS in a field experiment, using Weiner's attribution theory. They found that attributional factors accounted for a significant amount of the variance in emotional reactions and helping behavior towards persons with AIDS. However, their research also revealed that other factors, such as attitude towards homosexuals and perceived risk of infection, contributed to public reactions to persons with AIDS. In another field study, Dijker et al. (1996) investigated public reactions to people with AIDS. They found that blaming, which is similar to the concept of personal responsibility, was related to stronger anger, less pity and less willingness to have personal contact with a person with AIDS. In line with Weiner's attribution-emotion model, pity was related to stronger willingness and irritation to less willingness to engage in personal contact with persons with AIDS. Dijker et al's (1996) field study revealed that other cognitive factors (risk perceptions and attitude towards homosexuals) and emotional factors (fear) were also related to willingness to have personal contact with a person with AIDS.

As the latter studies indicate, the attribution-emotion model seems too limited to explain the whole process of stigmatization of ill persons (and other deviant conditions). In fact, Weiner assumes that beliefs about personal responsibility are a central cognitive construct in motivating stigmatizing responses towards ill persons. However, other cognitive factors may also determine emotional and behavioral reactions towards ill persons. Furthermore, perceivers do not only experience pity or anger when they are confronted with ill persons, but may also experience other emotional reactions such as fear.

Research on illness representations (Bishop, 1991a; 1991b) has revealed that lay people generally categorize and interpret diseases on two dimensions, namely contagiousness and seriousness of a disease, and that AIDS is categorized among the contagious and serious diseases. Contagiousness of disease refers to Jones et al's (1984) dimension of peril. Seriousness of disease contains elements of the dimensions peril, course and aesthetic qualities (Jones et al., 1984). Both illness cognitions are important components of instrumental attitudes towards persons with HIV (Pryor et al., 1989; Crandall et al., 1997; Herek \& Capitanio, 1998) and seem to influence perceivers' emotional and behavioral reactions.

Perceived contagiousness of disease seems to be related to stronger fear and less willingness to have contact with ill persons. Bishop (1991b) found that willing24 ness to interact with ill persons was a direct function of the perceived contagiousness of a disease. Furthermore, Dijker and Raeijmaekers (1999) found that contagiousness of disease influenced fear responses if close physical contact with a seriously ill person was expected. Research in the field of HIV stigma has revealed 
that perceived contagiousness influences stigmatizing responses to persons with HIV (Bishop, Alva, Cantu \& Rittiman, 1991; Dijker et al., 1996; Peters et al., 1994). In addition, evidence has been found for the role of fear in interpersonal contact with persons with HIV. For example, Dijker, Koomen and Kok (1997) found that participants reacted with more fear to a target with AIDS than to a healthy target. Furthermore, Dijker et al. (1996) found that risk perceptions of HIV infections were related to fear responses, and that fear responses influenced willingness to have personal contact with persons with HIV.

Perceived seriousness of disease seems related to relatively stronger feelings of both fear and pity and stronger stigmatization. Crandall and Moriarty (1995) investigated the influence of several stigma-related factors on social rejection of ill persons and found that illness severity contributed to stronger negative reactions. However, this study does not show how illness severity influences social rejection of ill persons. A possible explanation may be the mediating role of emotions. Batson and colleagues found that watching another person in distress may evoke both empathy and distress in perceivers, depending on their perspective (Batson, 1987; Batson, Early \& Salvarani, 1997). Empathy can be defined as a prosocial emotion that is similar to pity, whereas the concept of distress seems comparable to fear. Both emotional states have opposite effects on behavioral reactions, since fear triggers a need to avoid the other person and pity evokes a motivation to help the other person. Recent studies on stigmatization of ill persons indicate that seriousness of a medical condition elicits both fear and pity in perceivers (Dijker \& Koomen, in press, exp. 2; Dijker \& Raeijmaekers, 1999). Thus, it seems that seriousness of disease arouses emotional ambivalence in perceivers (see Katz, 1981). Crandall et al. (1997) have specifically examined the contribution of illness severity in HIV stigma. They demonstrated that the stigma attached to HIV was also related to its severity.

Another cognitive factor that may influence stigmatizing responses is norm-violating behavior. This concept is closely related to Goffman's dimension of 'blemishes of individual character' (Goffman, 1963). Furthermore, with regard to HIV stigma, this concept resembles symbolic attitudes towards persons with HIV (Pryor et al., 1989; Crandall et al., 1997; Herek \& Capitanio, 1998). Dijker and Koomen (1996) have argued that personal responsibility for the onset of a deviant condition may be contaminated with norm-violating behavior. For example, persons with HIV who are highly responsible for the onset of their disease, have often also engaged in behaviors that may be perceived by others as norm violating (e.g., homosexual behavior). In contrast, persons with HIV who are irresponsible for the onset of their disease (e.g., infected through blood transfusion), have often not engaged in norm violating behavior. Recently, Dijker and Koomen (in press) have demonstrated that norm violation is negatively related to pity and positively related to anger (Experiments 2 and 3)5. Furthermore, they showed that norm violation influenced emotional and behavioral reactions towards ill persons, independent of personal responsibility (Dijker \& Koomen, in press). Research on stigmatization of persons with HIV has revealed that people's attitude towards homosexuals, which resembles the concept of perceived norm violation, is related to stigmatization of persons with HIV (Dijker et al., 1996; Herek \& Capitanio, 1999; Peters et al., 1994; Pryor et al., 1989). Furthermore, Dijker et al. (1996) 


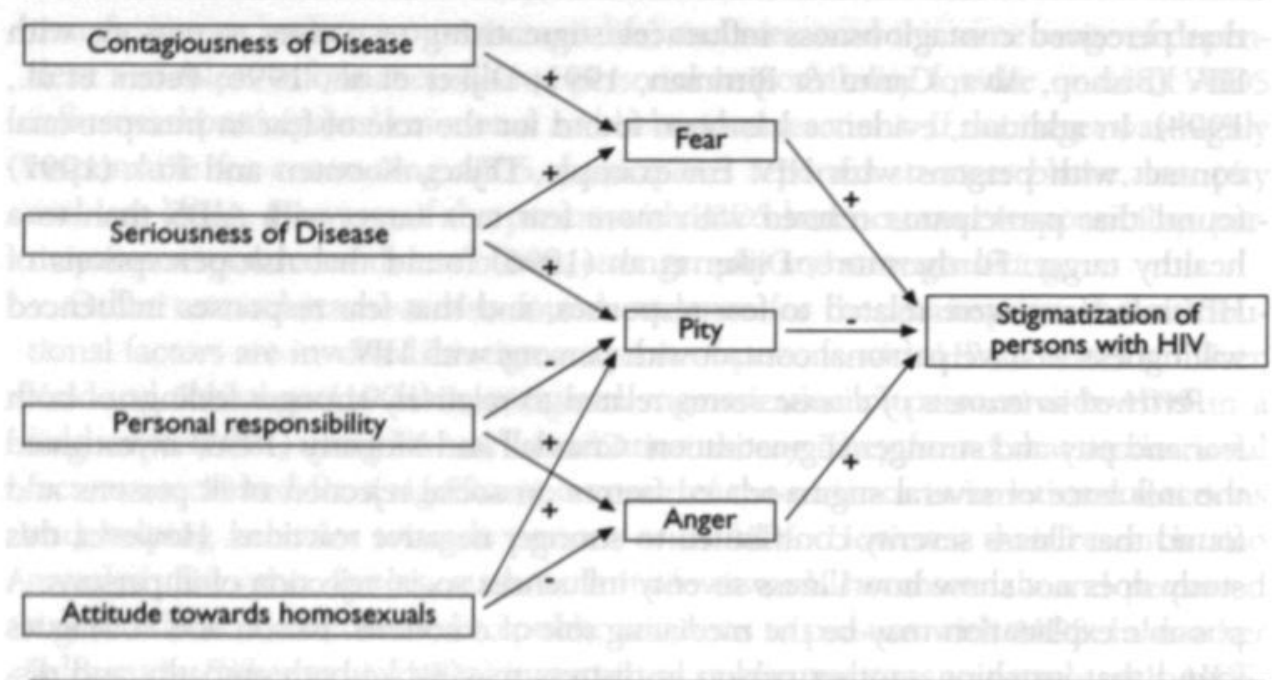

Figure I.I A cognitive-emotional model of stigmatization of persons with HIV

have shown that attitude towards homosexuals is positively related to pity, and negatively related to anger for persons with AIDS.

Dijker and Koomen (1996) have extended Weiner's attribution-emotion model of stigmatization with other cognitive and emotional factors that influence stigmatizing reactions towards ill and handicapped persons. Based on the above-mentioned theoretical considerations, Dijker and Koomen (1996) included three additional cognitive factors in their model, namely perceived contagiousness of disease, perceived seriousness of disease and norm violating behavior. Furthermore, they argued that, in addition to pity and anger, emotions like fear and 'schadenfreude' mediate the relationship between cognitive factors and behavioral reactions towards ill persons (Dijker \& Koomen, 1996).

In this dissertation I use an adapted version of Dijker and Koomen's (1996) model to explain stigmatization of persons with HIV (see Figure 1.1)6. Basically, this model assumes that the origin of HIV-related stigmatization lies in the perception and cognitive representation of persons with HIV. These cognitions trigger emotional reactions, which subsequently influence behavioral reactions towards persons with HIV. In line with Weiner's attribution-emotion model (Weiner, 1993, 1996; Weiner et al., 1988), I assume that personal responsibility for the onset of the disease is related to less pity and stronger anger. Subsequently, pity causes a reduction of stigmatizing responses, whereas anger leads to stronger stigmatization. In addition, we predict that attitude towards homosexuals, which can be seen as a measure of perceived norm violation, is related to stronger pity and less anger, which in turn influence stigmatizing responses. Furthermore, I expect perceived contagiousness to arouse fear responses. In turn, fear causes stronger stigmatization of persons with HIV. Finally, I predict that seriousness of disease causes stronger fear and stronger pity, which both have an opposite effect on stigmatizing responses. 


\section{OVERVIEW OF THIS DISSERTATION}

The present dissertation aims to examine stigmatization of persons with HIV, using the cognitive-emotional model of HIV-related stigmatization as theoretical framework. The first part of this dissertation (chapters 1 to 3 ) focusses on determinants of HIV-related stigma-tization, whereas the second part (chapters 4 to 6) examines interaction strategies to reduce stigmatization of persons with HIV. The stigma reduction experiments in chapters 5 and 6 investigate strategies that persons with HIV may adopt in initial encounters with strangers, in order to reduce negative emotional and behavioral reactions, and increase prosocial reactions.

Chapter 2 describes the results of a national telephone survey on public reactions to people with HIV in the Netherlands (Study 2.1). Since the introduction of highly active antiretroviral therapy (HAART) in 1996, the medical treatment of $\mathrm{HIV}$ in western societies has improved. As a consequence, people's representation of AIDS may have changed from a life-threatening disease to a more chronic disease. The introduction of HAART may also have changed public reactions towards persons with HIV and AIDS. Therefore, it seemed essential to assess present-day public reactions to people with HIV/AIDS in the Netherlands. Another aim of this study was to measure how knowledge about HAART is related to these public reactions. The final goal of this national survey was to investigate determinants of willingness to have personal contact with people with HIV/AIDS.

Chapter 3 examines the influence of seriousness of disease symptoms and patient's sexual orientation on emotional and behavioral reactions to ill persons (Study 3.1). Students received a vignette about a new colleague, having a disease (HIV or cancer) that differed in seriousness (low or high). An additional manipulation was target's sexual orientation (homosexual or heterosexual). Participants were asked to read this vignette carefully and answer questions about their emotional and behavioral reactions to the imagined cooperation with the target.

Chapter 4 provides a brief overview of different strategies that might be used to reduce stigmatization of persons with HIV. This chapter will review social psychological research on changing attitudes towards stigmatized persons and discuss society-level strategies that are commonly used to reduce HIV-related stigmatization. I will then focus on interaction-level strategies and argue that stigmatized individuals may intentionally influence perceivers' emotional and behavioral reactions in initial encounters, by adopting certain interaction strategies. Finally, an outline is given of the experimental studies on interactional stigma-reduction strategies reported in this dissertation.

Chapter 5 examines the interpersonal consequences of coping with HIV in three different studies. Special attention will be given to gender differences in emotional and behavioral reactions to patients' coping. The effects of patient's coping behavior have received limited research attention in the context of interaction with strangers. Therefore, the aim of Study 5.1 was to investigate which coping strategies of persons with HIV and cancer are preferred by healthy perceivers, and which strategies are not appreciated. Students received a vignette containing information about a new colleague, having a disease (HIV or cancer) that differed in seriousness (low or high). Using a free response format, partici- 
pants indicated which coping strategies they prefered and which they did not prefer. Study 5.2 examined the effects of two ways of coping ('conveying distress' and ' active coping') and a control condition ('no information about coping') on perceivers' emotional reactions. In addition, seriousness of disease (low or high) and personal responsibility for contracting HIV (low or high) were also manipulated. Students read a vignette about a new colleague and answered questions about their emotional reactions to the imaginary cooperation with the target. Study 5.3 replicated Study 5.2 in a realistic experimental setting with additional behavioral measures. The participants in this third study had been recruited from the local community, in order to be better able to generalize the results. They were invited to come to the laboratory for a study on 'cooperation and first impressions'. Upon arrival, participants listened to a taped interview with their prospective interaction partner, in order to form a first impression. This interview contained the manipulation of health status (healthy or HIV) and coping with HIV (conveying distress, active coping, no information about coping). Subsequently, participants filled in a questionnaire about their emotional and behavioral reactions towards the cooperation. Next, participants were taken to another room where physical distance, a behavioral expression of stigmatization, was measured.

Chapter 6 focuses on fear reduction strategies that persons with HIV may employ in initial contact with strangers. Study 6.1 investigated the impact of predictable behavior, an implicit nonverbal strategy, on fear reduction. Female students were led to believe that they were to cooperate with a male target that was either healthy or infected with HIV. Prior to the alleged cooperation, participants secretly watched the target on a monitor while he was preparing for the task in a predictable or unpredictable way. After that, participants were asked to complete a questionnaire containing questions about their emotional and behavioral reactions towards the cooperation. Study 6.2 examined the impact of reassuring information, an explicit verbal strategy, on fear reduction. In this study, female students listened to a taped interview with a healthy target or a target with HIV, who provided either reassuring or non-reassuring information. Apart from that, the procedure and dependent variables were similar to the study on predictable behavior.

Chapter 7 summarizes and discusses the main findings of the six studies that are reported in this dissertation. Attention will be given to the theoretical, methodological and practical implications of these studies ${ }^{7}$. 
CHAPTER 2

\section{PUBLIC REACTIONS TO PEOPLE WITH HIVIAIDS IN THE} NETHERLANDS

\section{Published as:}

Bos, A. E. R., Kok, G., \& Dijker, A. J. (2001). Public Reactions to People with HIVIAIDS in the Netherlands. AIDS Education and Prevention, 13, 219-228. 
Throughout the past two decades a large number of people with HIV/AIDS have been the victim of negative public reactions and stigmatization. For example, people with HIV/AIDS have been fired from their jobs or have experienced the disruption of relationships with family members and friends (Crandall \& Coleman, 1992; Herek, 1999). AIDS-related stigmatization does not only have detrimental consequences for personal and social relationships of people with HIV/AIDS, but may also counteract HIV prevention. Fear of stigmatization may be associated with delays in HIV testing for people at risk (Chesney \& Smith, 1999) and may result in concealment of one's seropositive status from others (Herek, 1999), which could both lead to the further spread of HIV.

\section{Determinants of AIDS-related stigmatization}

Why do people respond negatively to persons with HIV/AIDS? Research on AIDSrelated stigmatization has identified several factors that determine stigmatizing reactions towards persons with HIV/AIDS. First, perceived contagiousness of the disease is related to feelings of fear and stigmatization (Dijker, Koomen $\&$ Kok, 1997; Dijker \& Raeijmaekers, 1999; Herek, 1999; Herek \& Capitanio, 1998a). Although HIV/AIDS is not contagious in normal social interaction, some people still think that HIV can be transmitted through everyday contact. Second, perceived responsibility for becoming HIV-infected is associated with stigmatization of persons with HIV/AIDS (Crocker, Major \& Steele, 1998; Herek, 1999; Weiner, Perry \& Magnusson, 1988). People tend to respond with less pity, stronger anger and more stigmatization to HIV-infected individuals that are to a high degree responsible themselves for their infection (for example, due to unsafe sexual behavior). The concept of personal responsibility is closely related to blaming patients for their HIV-infection. Research by Dijker, Kok \& Koomen (1996) has shown that blaming is negatively related to pity and positively related to anger and stigmatization. Third, negative reactions towards people with HIV/AIDS often symbolize negative attitudes towards groups associated with HIV/AIDS, such as homosexuals (Crandall, Glor \& Britt, 1997; Herek \& Capitanio, 1998a; Pryor, Reeder \& Landau, 1999). A negative attitude towards homosexuals is related to stronger anger and stronger stigmatization, while a positive attitude towards homosexuals is related to stronger feelings of pity and less stigmatization (Dijker et al., 1996).

\section{Public reactions towards people with HIVIAIDS}

Public reactions to people with HIV/AIDS may vary in different societies, depending for example on preexisting prejudices within cultures and the local epidemiology of HIV (Herek, 1999). A 1997 national telephone survey in the United States revealed that AIDS stigma still persists in the United States, although extreme neg- 
ative public reactions had diminished throughout recent years (Herek, 1999; Herek \& Capitanio, 1998b). However, compared to a similar survey in 1991 (Herek \& Capitanio, 1993), a larger number of Americans overestimated the risk of HIV transmission through casual contact and blamed people with HIV/AIDS for their medical condition. This might imply that public health campaigns in the United States have insufficiently addressed these issues in recent years.

Public reactions to people with HIV/AIDS have been investigated for the last time in the Netherlands in 1994 (NSS/Marktonderzoek, 1994). This national survey revealed that most people in the Netherlands do not respond with strong negative reactions to persons with HIV/AIDS. Only five percent of the respondents reported very strong feelings of fear and 31 percent a little. Moreover, five percent of the respondents indicated to have very strong feelings of anger and 29 percent a little. Further, as much as 38 percent of the respondents reported very strong feelings of pity and 49 percent a little. Finally, this national survey revealed that 15 percent of the respondents found it unacceptable to have close personal contact with a person with AIDS.

More recent information about public reactions towards people with HIV/AIDS is not available for the Netherlands. However, since mid 1996, the medical treatment of HIV in westem societies has much improved. The introduction of highly active antiretroviral therapy (HAART) received a great deal of attention in the Dutch media, with many news papers and television programmes reporting on the relative success of HAART in prolonging the life-span of people with HIV/AIDS. The new and more effective HIV treatments may have changed people's representation of HIV/AIDS from a lethal disease to a more chronic, lifethreatening, but potentially manageable disease (Gagnon \& Godin, 2000; Kelly, Otto-Salaj, Sikkema, Pinkerton \& Bloom, 1998). As a consequence, public reactions to people with HIV/AIDS may have changed accordingly.

Information about current public reactions towards people with HIV/AIDS is an essential component of the development of campaigns aimed at stigma reduction. AIDS educational campaigns will be more effective if they are based on wellfounded theories and empirical data (Bartholomew, Parcel, Kok \& Gottlieb, 2001). The present study was conducted as part of the development of a new Dutch campaign aimed at stigma reduction. Because of the recent developments in HIV treatment, it seemed essential to assess current public reactions to people with HIV/AIDS in the Netherlands.

\section{Study 2.1}

The aim of this study was threefold. First, to assess present-day public reactions to people with HIV/AIDS in the Netherlands and to discuss the findings in the light of the available 1994 data (NSS/Marktonderzoek, 1994). The second aim of this study was to examine the relationship between knowledge about HAART and cognitive, emotional and behavioral reactions to people with HIV/AIDS. We expected people with knowledge about HAART to report less negative reactions towards persons with HIV/AIDS than people without knowledge about HAARI. 
The third aim of this study was to investigate determinants of willingness to engage in personal contact with people with HIV/AIDS. In line with previous research (Dijker et al., 1996), we predicted that higher risk perceptions and stronger blaming would be related to less willingness to engage in personal contact, whereas a positive attitude towards homosexuals would be associated with stronger willingness to have personal contact with persons with HIV/AIDS. Further, we expected feelings of fear and anger to be related to less willingness to have personal contact, and feelings of pity to be related to more willingness to have personal contact. Finally, we expected older people, lower-educated people and men to be less willing to have personal contact compared to younger people, higher-educated people and women (Herek, 1999).

\section{METHOD}

\section{Procedure and respondents}

A national telephone survey was conducted in July 1998. Respondents were drawn at random from a database of the Dutch National Telephone Company (PTT), which contains almost all telephone numbers in The Netherlands. The random sampling was conducted by means of a computer programme that is commonly used to draw random samples. The sample did not contain telephonenumbers of businesses and institutions. A letter was sent to 1200 households in advance, announcing that the University Telephone Service was to contact them for a ten-minute interview about 'diseases and medicines'. In order to avoid nonresponse among those with a negative attitude towards people with AIDS, the subject of AIDS was not explicitly mentioned in this letter. Approximately one week later the research group selected was contacted by telephone. The first respondent at home, aged 16 years or older, was asked to participate in the telephone survey. In the beginning of the interview, compassion was measured for patients who suffer from various serious diseases (cardiovascular diseases, cancer, AIDS or asthma). After this, the interview focussed exclusively on AIDS.

A total of 1042 households could be reached and 751 interviews were completed, yielding a response rate of 72 percent. Reasons for non-response were recorded: most non-responders (52\%) were not interested in a telephone survey and a smaller group (11\%) didn't have the time to participate.

\section{Measures}

First, compassion for patients with cardiovascular diseases, cancer, AIDS or asthma were each measured using a single item (e.g. 'To what extent do you feel compassion for AIDS patients?') on a 3-point scale ( $1=$ no compassion, $2=$ a little 
compassion, 3 = strong compassion). After this, cognitive, emotional and behavioral reactions towards people with HIV/AIDS were measured, using identical measures as Dijker, Kok and Koomen (1996) and NSS/Marktonderzoek (1994). Cognitive reactions refer to risk perceptions, blaming and attitude towards homosexuals, emotional reactions concern fear, pity and anger, and behavioral reactions focus on willingness to have personal contact with people with HIV/AIDS. Risk perceptions were measured using five items (e.g. 'Imagine that someone is shaking hands with a person with HIV/AIDS. To what extent does this person run the risk of getting infected with HIV?'), measured on a 3 -point-scale ( $1=$ no risk, 2 = small risk, 3 = large risk). These five items were combined into a risk perception scale (Cronbach's alpha $=.83$ ). Blaming was measured using one item ('People with HIV/AIDS have to blame themselves for it') on a 3-point scale ( $1=$ disagree, 2 = disagree/agree, 3 = agree). Attitude towards homosexuals was measured using one item ('What is your general attitude towards homosexuals?') on a 5-point scale ( $1=$ highly negative, $5=$ highly positive). Emotional reactions (fear, pity and anger) were each measured using a single item (e.g., 'When I think about people with HIV/AIDS, I feel anger') on a 3-point scale ( $1=$ not at all, $2=$ a little, 3 = very strong). Willingness to have personal contact was measured using a single item ('To what extent do you find it acceptable to have personal contact with someone with AIDS') on a 4-point scale ( $1=$ highly unacceptable, 4 = highly acceptable). Knowledge about HAART was measured with two questions. First, respondents were asked if they had heard about HAART, a new approach to the treatment of HIV/AIDS. If respondents answered affirmatively, they were asked to give a short description of HAART, which was later assessed by one of the researchers. Respondents who were able to give a good description, were classified as persons with knowledge about HAARI. Other respondents were classified as persons without knowledge about HAARI. Finally, background variables were recorded (gender, age and level of education).

\section{RESULTS}

\section{Sample characteristics}

Of the 751 respondents, 42 percent was male and 58 percent was female. The average age of these participants was 48 , ranging from 16 to 91 . Thirty-eight percent had a low, 34 percent a medium and 28 percent a high level of education.

\section{Public reactions to people with HIVIAIDS}

Risk perceptions were quite realistic: most of the respondents held the belief that HIV could not be transmitted by shaking hands with people with HIV/AIDS 


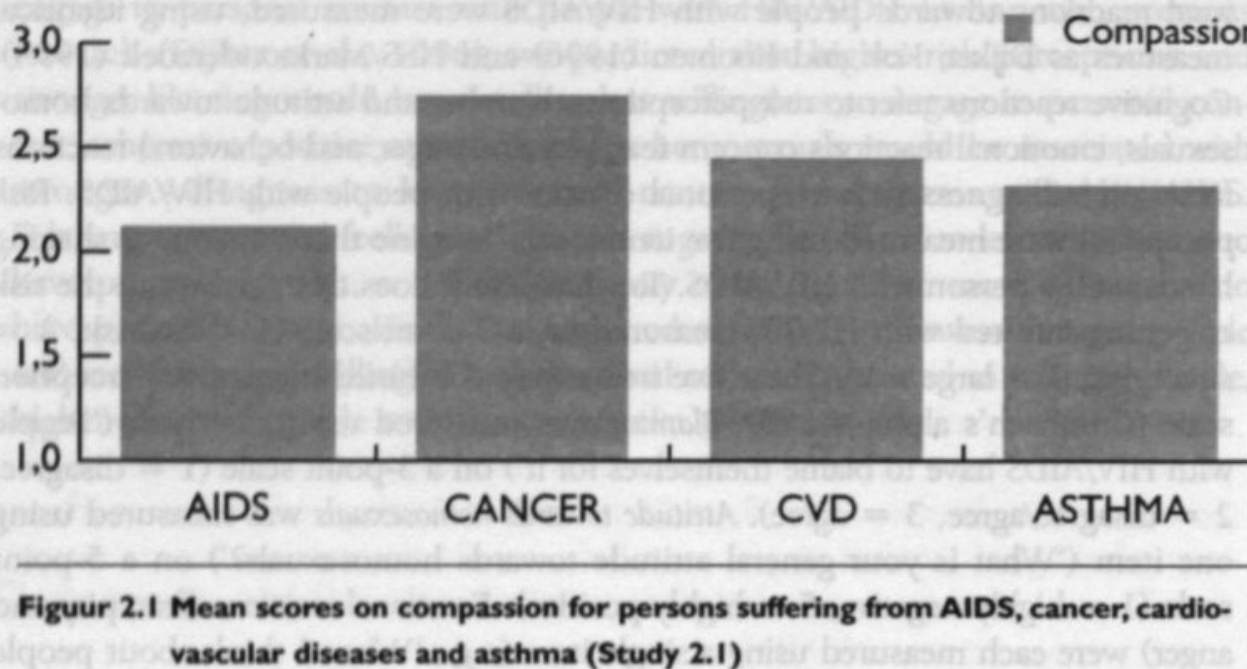

vascular diseases and asthma (Study 2.1 )

(91\%), kissing a person with HIV/AIDS on the cheek (88\%), sharing an office with a person with HIV/AIDS (87\%), sharing a drinking glass with a person with HIV/AIDS (77\%), or being served by a waiter with HIV/AIDS (74\%). Blaming was reported by a small number of respondents: 11 percent held the opinion that people with HIV/AIDS have to blame themselves for it. A small minority of respondents ( 13 percent) held a negative attitude towards homosexuals. Only 5 percent of the respondents reported very strong and 21 percent a little fear. Eight percent of the respondents indicated that they feel very strong anger and 22 percent a little anger. Forty-one percent of the respondents reported very strong pity and 47 percent a little pity. Ten percent of the respondents found it unacceptable to have personal contact with people with HIV/AIDS.

Figure 2.1 shows the mean scores on compassion for persons suffering from AIDS, cancer, cardiovascular diseases and asthma. Although public reactions towards people with HIV/AIDS seem to be moderately positive, feelings of compassion for AIDS patients were lower $(M=2.12)$ than feelings of compassion for patients suffering from other serious diseases, like cancer $(M=2.73, t(745)=$ $22.87, p<.001)$, cardiovascular diseases $(M=2.43, t(743)=10.44, p<.001)$, and asthma $(M=2.31, t(744)=6.36, p<.001)$.

\section{Knowledge about HAART}

Of the respondents, 39 percent had knowledge about HAART. T-tests were conducted to investigate differences between respondents with and respondents without knowledge about HAART on the following variables: risk perceptions, blaming, attitude towards homosexuals, fear, pity, anger and willingness to have personal contact (see Table 2.1). Respondents with knowledge about HAART 
Table 2.1 Mean scores on cognitive, emotional and behavioral reactions to people with HIVIAIDS as a function of knowledge about HAART (Study 2.1)

\begin{tabular}{lccc}
\hline & \multicolumn{3}{l}{ Knowledge about HAART } \\
\cline { 2 - 4 } & No & Yes & T-value \\
\hline Risk perceptions & & 1.12 & $2.70^{* *}$ \\
Blaming & 1.19 & 1.62 & 1.75 \\
Attitude towards homosexuals & 1.71 & 3.83 & $1.99^{*}$ \\
Fear & 3.66 & 1.25 & $2.40^{*}$ \\
Pity & 1.34 & 2.30 & 0.15 \\
Anger & 2.30 & 1.36 & 1.30 \\
Willingness to engage in personal contact & 1.42 & 3.25 & $6.88^{* * *}$ \\
\hline
\end{tabular}

Note $* p<.05, * p<.01, * * * 0.001$

Table 2.2 Intercorrelations and descriptive statistics for risk perceptions, blaming, attitude towards homosexuals and emotional factors (Study 2.1)

\begin{tabular}{lcccccccccc}
\hline & M & SD & $N$ & 1 & 2 & 3 & 4 & 5 & 6 \\
\hline I. Risk perceptions & 1.16 & .33 & 690 & - & .08 & $-.22^{* *}$ & $.23^{* * *}$ & -.10 & $.16^{* * *}$ \\
2. Blaming & 1.67 & .67 & 745 & & - & $-.22^{* *}$ & .03 & $-.15^{* * *}$ & $.12^{*}$ \\
3. Attitude towards homosexuals & 3.72 & 1.15 & 745 & & & - & -.09 & $.21^{* *}$ & -.08 \\
4. Fear & 1.31 & .56 & 749 & & & & - & $.13^{* *}$ & $.23^{* * *}$ \\
5. Pity & 2.30 & .66 & 741 & & & & & - & .02 \\
6. Anger & 1.39 & .64 & 738 & & & & & -
\end{tabular}

Note ${ }^{*} \mathrm{p}<.01$, two-tailed. ${ }^{* *} \mathrm{p}<.001$, two-tailed

reported lower risk perceptions $(t(687)=2.70, p<.01)$, a more positive attitude towards homosexuals $(t(743)=1.99, p<.05)$, less fear $(t(746)=2.40, p<$ $.05)$ and stronger willingness to have personal contact with people with HIV/AIDS $(t(725)=6.88, p<.001)$, compared to respondents without knowledge about HAARI. Both groups did not differ on the other variables ${ }^{8}$. 


\begin{tabular}{|c|c|c|c|}
\hline \multirow[b]{2}{*}{ Predictors } & \multicolumn{3}{|c|}{ Regression equation } \\
\hline & 1 & 2 & 3 \\
\hline Risk perceptions & $-.37+4$ & & $-.29=$ \\
\hline Blaming & $-.17^{* 010}$ & & $-.12^{* \neq *}$ \\
\hline Attitude towards homosexuals & $.23 *$ & & $.20 * 1$ \\
\hline Fear & & $-.18^{\text {*atk }}$ & $-.10^{* *}$ \\
\hline Pity $=0$ & & $.16 * 0$ & .05 \\
\hline Anger & & $-.11^{* * *}$ & -.06 \\
\hline Gender & macinco is & mogutatest & .02 \\
\hline 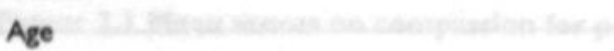 & 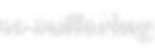 & mantonat & $-.08 *$ \\
\hline Level of education & & & $.16^{* 0 *}$ \\
\hline $\mathbf{R}^{2}$ & .28 & .07 & .32 \\
\hline Model F & $85.41+$ & $18.51 \%$ & 32.71 \\
\hline 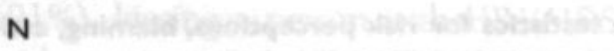 & 668 & 708 & 651 \\
\hline
\end{tabular}

Note ${ }^{*} p<.05$, two-tailed. ${ }^{* *} \mathrm{p}<.01$, two-tailed. ${ }^{* *} \mathrm{p}<.001$, two-tailed. Coefficients are standardized regression weights (Betas).

\section{Determinants of willingness to have personal contact with people with HIVIAIDS}

Table 2.2 gives an overview of the intercorrelations between risk perceptions, blaming, attitude towards homosexuals and emotional reactions. Risk perceptions were related to stronger fear $(r=.23)$ and stronger anger $(r=.16)$. Blame was related to stronger anger $(r=.12)$ and less pity $(r=-.15)$. A positive attitude towards homosexuals was related to stronger pity $(r=.21)$.

Three different regression analyses were performed to measure the contribution of cognitions, emotions and person variables in predicting willingness to have personal contact with people with HIV/AIDS (see table 2.3).

First, we regressed willingness to have personal contact on risk perceptions, blaming and attitude towards homosexuals. Risk perceptions $(B=-.37)$ and blaming ( $B=-.17$ ) were related to less willingness to have personal contact, whereas a positive attitude towards homosexuals was related to stronger willingness to engage in personal contact $(B=.20)$. Together, these factors explained 28 percent of the variance. Second, willingness to have personal contact was regressed on emotional factors. Fear $(B=-.18)$ and anger $(B=-.11)$ were related to less willingness to engage in personal contact, whereas pity $(B=.16$ ) was related to stronger willingness to have personal contact. However, emotional fac- 
tors only explained 7 percent of the variance. Finally, willingness to have personal contact was regressed on risk perceptions, blaming, attitude towards homosexuals, emotional factors and background variables. Together, these factors explained 32 percent of the variance. In comparison with the second regression equation, pity and anger no longer contributed to willingness to engage in personal contact. Background variables were related as follows: older people were less willing to have personal contact $(B=-.08)$ and people with a higher level of education were more willing to engage in personal contact $(B=.16)$. The gender of the respondent was not related to willingness to engage in personal contact with people with HIV/AIDS?.

\section{DISCUSSION}

The aims of the present study were to assess present-day public reactions to people with HIV/AIDS in the Netherlands, to examine how knowledge about HAART is related to public reactions to people with HIV/AIDS and to investigate determinants of willingness to engage in personal contact with people with HIV/AIDS. Public reactions to people with HIV/AIDS seem to be moderately positive in the Netherlands. Stigmatizing responses were reported by a relatively small number of people. This pattern of results largely corresponds with previous favourable findings of NSS/Marktonderzoek (1994). Compared to the 1994 study, slight improvements were found on some stigma measures. For example, a smaller proportion of people considered personal contact with a person with HIV/AIDS as unacceptable. Although it appears that most people in the Netherlands do not respond negatively to people with HIV/AIDS, respondents reported less compassion for AIDS patients than for patients suffering from other serious diseases. This relative lack of compassion may also be experienced as stigmatizing by people with HIV/AIDS and may also have a negative impact on their well-being.

Consistent with our predictions, respondents with knowledge about HAART reported less negative reactions towards people with HIV/AIDS than respondents without knowledge about HAARI. However, due to the correlational nature of our study, we are unable to draw conclusions about the causal relationship between knowledge about HAART and public reactions to people with HIV/AIDS. On the one hand, it might be possible that knowledge about HAART leads to less negative reactions towards people with HIV/AIDS. On the other hand, people with a positive attitude towards people with HIV/AIDS might be more interested in information about HIV/AIDS and therefore be better informed about HAART.

The present study also examined determinants of willingness to have personal contact with people with HIV/AIDS. In general, cognitive and emotional factors contributed to the willingness to engage in personal contact with people with HIV/AIDS (cf. Dijker et al., 1996). Specifically, risk perceptions, blaming and fear 
were associated with less willingness to have personal contact, whereas a positive attitude towards homosexuals was related to more willingness to have personal contact. Further, older and lower-educated people were less willing to engage in personal contact with people with HIV/AIDS. Our results demonstrate that emotional factors contribute to willingness to have personal contact with people with HIV/AIDS. However, cognitive factors (risk perceptions, blaming and attitude towards homosexuals) have a stronger influence on willingness to have personal contact than emotional factors. This might explain why pity and anger did not significantly contribute to willingness to have personal contact in the final regression equation.

One methodological limitation of the present study should be noted. Due to the limited duration of each interview, a large number of our constructs were measured using single items. Single-item measures may contain nuances of meaning and undertone that have unintended effects on respondents' responses (Eagly \& Chaiken, 1993, p.79). However, Jaccard, Weber, and Lundmark (1975) demonstrated that single-item measures can be as reliable as multiple-item measures, if the single item taps an overall evaluation of the attitude object. Our single-item measures were constructed in such a way that they involved the central aspect of the particular construct. In addition, it should be noted that most of our single-item measures have been used in previous studies (Dijker, Kok and Koomen, 1996; NSS/Marktonderzoek, 1994) yielding similar results, thus suggesting that these measures were indeed reliable and valid.

The present study has provided useful information for the development of new Dutch educational campaigns dealing with the issue of AIDS stigma. The moderately positive representation of people with HIV/AIDS in the Netherlands, seems to require a two-way AIDS educational approach. On the one hand, mass-media campaigns could be used to maintain (or improve) moderately positive public reactions to people with HIV/AIDS. Among other things, these AIDS educational campaigns should reinforce knowledge about HIV transmission through casual contact. Negative reactions towards persons with HIV/AIDS may recur if knowledge about HIV transmission declines, as suggested by the negative influence of risk perceptions on people's willingness to have contact with people with HIV/AIDS. However, our results indicate that these mass-media campaigns should also focus on ways to intensify people's involvement with HIV/AIDS and increase feelings of compassion for people with HIV/AIDS. In addition to AIDS educational activities aimed at the population in general, it may be useful to develop and execute specific stigma-reduction interventions. These interventions should be aimed mainly at situations where people with HIV/AIDS experience unsupportive or stigmatizing reactions (for example, at the workplace). Our analysis of willingness to have personal contact with people with HIV/AIDS indicates that these interventions should be particularly targeted at lower-educated and older people, and must address, among other things, people's knowledge about HIV transmission in everyday contact. 


\section{CHAPTER 3}

THE INFLUENCE OF SERIOUSNESS OF DISEASE SYMPTOMS AND PATIENT'S SEXUAL ORIENTATION ON EMOTIONAL AND BEHAVIORAL REACTIONS TO ILL PERSONS

\section{Published as:}

Bos, A. E. R., Dijker, A. J., \& Koomen, W. (1999). The Influence of Seriousness of Disease Symptoms and Patient's Sexual Orientation on Emotional and Behavioral Reactions to III Persons. Gedrog \& Gezondheid, 27, 29-35. 


\section{INTRODUCTION}

Stigmatized persons (are believed to) possess an attribute or characteristic which is discrediting (Crocker, Major \& Steele, 1998). This attribute or characteristic defines the person as 'deviant, flawed, limited, spoiled or generally undesirable' (Jones, Farina, Hastorf, Markus, Miller \& Scott, 1984). As a result of this negatively valued attribute, persons are rejected in certain social contexts and meet with negative emotional reactions such as fear or anger. An illness can be seen as an example of such an attribute (Dijker \& Koomen, 1996). Research has shown that stigmatization can have detrimental consequences for the psychological wellbeing of stigmatized individuals such as ill persons (Crocker et al., 1998), Therefore, it is important to understand the factors involved in the process of stigmatization of ill persons.

\section{Seriousness of disease}

Crandall and Moriarty (1995) investigated the influence of several stigma-related factors on social rejection of ill persons. They found that illness severity and behavioral causality independently contribute to more negative reactions to ill persons. Although this study indicates that seriousness of disease may play a role in social interaction with ill persons, it is not clear how seriousness influences people's tendency to reject ill persons.

A possible explanation for the effect of seriousness on social rejection might be the mediating role of emotions. Batson and colleagues (Batson, 1987; Batson, Early \& Salvarani, 1997) showed that watching another person in distress might cause empathy (which is quite similar to the emotion pity) or personal distress (which resembles the emotion fear). Emotional reactions like pity or fear have different behavioral consequences. Pity seems to be related to more prosocial behavior (Batson et al., 1997) and less stigmatization (Weiner et al., 1988). Feelings of fear seem to be related to more stigmatization (Dijker, Koomen $\&$ Kok, 1997) and to an action tendency to avoid the feared object (Frijda, 1986). Based on the above mentioned studies we can assume that perceivers may experience emotional ambivalence during interaction with seriously ill persons. Specifically, they may feel negative emotions (e.g. fear) when they are confronted with seriously ill persons and may have the desire to avoid them. At the same time, perceivers may experience positive emotions (e.g. pity) and may be motivated to provide social support to these persons.

\section{Gender differences in the perception of homosexual persons versus heterosexual persons}

Stigmatization of persons with AIDS seems closely connected with attitudes toward groups that are already stigmatized, such as homosexuals (Pryor, Reeder, Vinacco, \& Kott, 1989). Research indicates that gender differences play a role in 
the stigma of homosexuality. A meta-analysis of Kite and Whitley (1996) reveals that men generally hold more negative attitudes toward homosexual persons than women do. A possible explanation for these gender differences might be men's more rigid adherence to gender roles, in which homosexuality is less acceptable (Kite $\&$ Whitley, 1996). In general, men seem to react more negatively to ill persons than women do (Dijker, Koomen \& Kok, 1997).

\section{Study 3.1}

The effect of seriousness of disease and patient's sexual orientation on emotional reactions and stigmatization was examined in a vignette study, in which these factors were manipulated. For exploratory reasons, type of disease was manipulated as well. We hypothesized that respondents would experience more emotional ambivalence toward persons in the high than the low seriousness condition. That is, we expected that people would experience more pity (hypothesis la) and more fear (hypothesis lb) when the disease symptoms of the ill person are more serious. In line with previous research (Crandall $\&$ Moriarty, 1995), we expect that seriousness of disease is related to more stigmatizing responses (hypothesis 2). Finally, we expect that homosexuals will evoke more irritation (hypothesis 3a) and will receive more stigmatizing reactions (hypothesis $4 \mathrm{a}$ ) than heterosexuals. Further, we expect that male respondents will indicate more irritation (hypothesis $3 \mathrm{~b}$ ) and stigmatization (hypothesis $4 \mathrm{~b}$ ) than female respondents. In addition, we predict an interaction effect between gender of the participant and sexual orientation of the target: men will report most irritation (hypothesis 3c) and stigmatization (hypothesis 4c) when they are confronted with a homosexual target.

\section{METHOD}

\section{Participants and design}

Participants were 271 students of senior secondary vocational education, 96 men and 169 women. The gender of six participants was unknown. The mean age of the participants was 18.0 years $(S D=1.55)$. Five participants were excluded from the data analysis, because of indicating not having participated seriously. Participants were randomly assigned to the cells of a 2 (seriousness: Low vs. high) x 2 (sexual orientation target: Homosexual vs. heterosexual) $\times 2$ (disease: HIV vs. cancer) experimental design. Gender of participant was added as a fourth factor in the design. 
The experiment was conducted during class in the presence of the teacher and the experimenter. The experimenter explained that every participant would receive a scenario and several questions about a situation in a particular workplace. It was pointed out that participants should read the scenario carefully and try to imagine this situation. Eight different versions of the booklet were distributed at random. After the data collection participants were debriefed.

\section{Scenario}

The booklet first provided a detailed description of the situation. Participants had to imagine that their company, a commercial business, had merged with another company and that they would have to share their office and collaborate with Peter, who used to work for the other company. A colleague, acquainted with Peter, would provide some information about Peter. After this introduction participants read the manipulated information about their new colleague. This manipulation consisted of information about sexual orientation of the target (homosexual vs. heterosexual), type of disease (HIV vs. cancer) and seriousness of the physical condition of the target (low seriousness vs. high seriousness). Seriousness of disease symptoms was manipulated in such a way that it would be realistic that seriously ill targets would still appear at work. The manipulation of seriousness of disease symptoms consisted of the presence or absence of symptoms that could apply to both HIV and cancer. In the low seriousness condition the following information was provided: Peter feels pretty well. Sometimes he feels a little bit tired, but in general he feels well. Peter has no disease symptoms. Respondents in the high seriousness condition received the following information: Peter regularly feels miserable and often feels tired. In addition, he suffers from nightsweating and diarhoea. Peter is very skinny. It is clear that his physical condition is bad.

\section{Dependent variables}

After reading the scenario, participants answered, among others, questions about their emotional and behavioral reactions to the imagined cooperation with the target. All answers were measured on 7 -point scales ( $1=$ not at all, $7=$ very much). Our analysis of the emotional reactions will focus on three different emotions: Fear (measured by combining the scores of the two items 'nervous' and 'tense', Cronbach's alpha $=.79$ ), pity and irritation (the latter two measured with a single item). Participants received four items about stigmatizing reactions (e.g. "Would you prefer to keep some distance from Peter?'). The four stigmatization items were combined into one stigmatization scale (Cronbach's alpha $=.86$ ). The last page of the questionnaire contained a manipulation check ('Indicate to what extent Peter suffers from disease symptoms'). Finally, we asked how serious the participants filled in the questionnaire and we asked them to fill in their gender and age. 


\section{Manipulation check}

The effectiveness of the manipulation of seriousness was checked by a 2 (seriousness of disease symptoms) $\times 2$ (type of disease) $\times 2$ (sexual orientation of tanget) $\mathrm{x}$ 2 (gender of respondent) analysis of variance (ANOVA) on our manipulation check. This analysis revealed a significant main effect for seriousness $(F(1,262)=$ $123.43, p<.001$ ), confirming the success of the manipulation. Respondents in the high seriousness condition believed that the target suffered more from disease symptoms $(M=5.13)$ than respondents in the low seriousness condition $(M=$ 3.20). Further, a significant main effect of gender of participant was found, $F(1$, $262)=11.10, p<.01$. Male participants thought that the target suffered more from disease symptoms $(M=4.58)$ than female participants $(M=3.92)$. No other significant main effects or interaction effects were found.

\section{Emotional reactions}

A 2 (seriousness of disease symptoms) $\times 2$ (disease) $\times 2$ (sexual orientation of target) $\times 2$ (gender of respondent) multivariate analysis of variance (MANOVA) was performed on fear, pity and irritation. This MANOVA revealed a significant multivariate main effect of seriousness of disease symptoms on emotional reactions, $F(3,247)=6.91, p<.001$. In line with hypothesis $1 \mathrm{a}$, we found a significant univariate effect of seriousness of disease symptoms on pity, $F(1,249)=$ $19.87, p<.001$. Respondents in the high seriousness condition reported more pity $(M=4.80)$ than respondents in the low seriousness condition $(M=3.88)$. Hypothesis $1 \mathrm{~b}$ was not entirely confirmed, because there was no significant univariate effect of seriousness of disease symptoms on fear, $F(1,249)=3.03, p=$ .08 . Nevertheless, the results indicated a trend in the predicted direction: respondents in the high seriousness condition reported more fear $(M=3.37)$ than respondents in the low seriousness condition $(M=2.97)$. A positive correlation between 'fear' and 'pity' ( $r=.22, p<.001)$ gives more support for the idea that people experience ambivalent emotional reactions when they are confronted with ill persons.

In line with hypothesis $3 \mathrm{a}$, we found a significant main effect of target's sexual orientation on emotional reactions, $F(3,247)=2.73, p<.05$. Univariate analyses revealed that respondents reported more irritation toward a homosexual target $(M=1.93)$ than a heterosexual target $(M=1.50), F(1,249)=6.03, p<.05$. Hypothesis $3 \mathrm{~b}$ was also confirmed, since we found a significant main effect of gender of participant on emotional reactions, $F(3,247)=5.19, p<.01$. Male respondents reported more irritation $(M=1.96)$ than female respondents $(M=$ $1.50), F(1,249)=8.75, p<.01$. There was no significant main effect for type of disease on emotional reactions $(F(3,247)=.91$, n.s. $)$. In line with hypothesis $3 c$, the MANOVA revealed a significant interaction between gender of participant and target's sexual orientation on emotional reactions, $F(3,247)=3.19, p<.05$. 
Table 3.I Mean irritation scores as a function of target's sexual orientation and gender of participant (Study 3.1)

Target's sexual orientation

Homosexual Heterosexual

\begin{tabular}{cccc}
$\begin{array}{c}\text { Gender of participant } \\
\text { Male }\end{array}$ & M & 2.38 & \\
& SD & 1.78 & 1.57 \\
& $N$ & 50 & 1.17 \\
Female & & & 46 \\
& M & 1.48 & 1.53 \\
& SD & .99 & 1.02 \\
\hline
\end{tabular}

Univariate analyses showed that this interaction effect is only found for irritation, $F(1,249)=11.75, p<.01$. Table 3.1 shows that this interaction on irritation is caused by male respondents who reported most irritation toward a homosexual target.

\section{Stigmatization}

A 2 (seriousness of disease symptoms) $\times 2$ (type of disease) $\times 2$ (sexual orientation of target) $\times 2$ (gender of participant) ANOVA was conducted on the stigmatization scale. This ANOVA revealed a significant main effect of seriousness of disease symptoms, $F(1,260)=3.95, p<.05$. Respondents in the high seriousness condition reported more stigmatizing responses $(M=2.83)$ than respondents in the low seriousness condition $(M=2.50)$, thereby confirming hypothesis 2 . Furthermore, type of disease had a significant effect on stigmatization, $F(1,260)$ $=7.78, p<.01$. Respondents reported more stigmatizing reactions to a target with HIV $(M=2.86)$ than to a target with cancer $(M=2.47)$.

In line with hypothesis 4a, target's sexual orientation had a significant effect on stigmatization, $F(1,260)=11.72, p<.01$. Homosexual targets were more stigmatized $(M=2.90)$ than heterosexual targets $(M=2.40)$. Furthermore, the predicted gender effect was found (hypothesis $4 \mathrm{~b}$ ): male participants stigmatized to a larger extent $(M=3.33)$ than female participants $(M=2.31), F(1,260)=45.24$, $p<.001$. Hypothesis $4 c$ was also confirmed, since the ANOVA revealed a significant interaction effect between gender of participant and target's sexual orientation, $F(1,260)=15.90, p<.001$. The means of this interaction effect revealed that male respondents reported relatively high stigmatizing reactions to a homosexual target (see Table 3.2). 
Target's sexual orientation

Homosexual

Gender of participant

Male

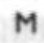

SD

N

Female

$\begin{array}{lc}M & 3.93 \\ \text { SD } & 1.72 \\ N & 49\end{array}$

49

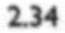

.99

90

\section{Heterosexual}

1.10

44

2.26

1.03

\section{DISCUSSION}

This study shows that ill persons may receive more stigmatizing reactions when their physical condition deteriorates. This is in line with findings of Crandall \& Moriarty (1995), who also found that illness severity is related to stronger stigmatization. In addition, we investigated the effect of seriousness of disease on emotional reactions to ill persons. The results indicate that perceivers may experience ambivalent or conflicting feelings when they are confronted with ill persons. On the one hand, seriousness of disease symptoms arouses pity in perceivers, an emotion that is related to prosocial behavior. On the other hand, seriousness of disease seems related to increased feelings of fear, an emotional reaction that corresponds with a tendency to avoid the other person. This last effect however was only marginally significant. Recently, Dijker and Koomen (1998) did find that seriousness of a medical condition leads to an increase of feelings of pity and fear.

Our study also revealed that gender of the perceiver and sexual orientation of the target influence emotional and behavioral reactions to (ill) persons. Firstly, male respondents reported more irritation and stigmatizing reactions than female respondents. Secondly, homosexual targets evoked more irritation and stigmatizing reactions than heterosexual targets. Finally, in line with research of Kite and Whitley (1996), we found that men reacted more negatively to homosexual persons than do women. These findings show that such factors should be taken into account in research on negative reactions to patient groups that are associated with homosexual behavior, such as persons with HIV.

It is difficult to measure emotional reactions and stigmatization of ill persons in 'real life'. Scenarios are controlled imitations of real life and can be considered as a useful way to investigate negative emotional and behavioral reactions. In this study, we carefully tried to make the scenario as realistic and vivid as possible. Nevertheless, it might still be possible that people experience other (stronger) 
emotions or behave differently when they are really confronted with an ill person.

Finally, two remarks should be made about the generalizability of our results. First of all, the target in our study was a colleague, who would share the same room with the respondent. It might be possible that people react differently when the familiarity with the target or the physical distance to the target is less close. Secondly, the sample consisted of students of senior secondary vocational education. It is unclear whether people of a different age or with a different level of education would experience similar emotional and behavioral reactions. It might be useful to replicate this study with other scenarios and other samples. 


\section{CHAPTER 4}

REDUCING STIGMATIZATION OF PERSONS WITH HIV IN INITIAL ENCOUNTERS: THE PERSON WITH HIV AS AN

'AGENT OF CHANGE' 


\section{INTRODUCTION}

Initial contact with persons with HIV may trigger negative emotional and behavioral reactions in healthy perceivers. Such initial responses may have important consequences for the development of further social interaction patterns. For example, perceivers may have a strong desire to break up social interaction and avoid further contact. Furthermore, if perceivers feel discomfort but do not want to respond in a prejudiced manner, social interaction may become awkward and strained (Crocker et al., 1998; Hebl et al., 2000). It is important, therefore, to investigate how emotional and behavioral reactions towards persons with HIV can be influenced in initial encounters. Research in the field of social reactions towards handicapped persons (Hastorf et al., 1979; Belgrave \& Mills, 1981; Belgrave, 1984) indicates that stigmatized individuals can ease and improve social interaction with non-stigmatized individuals by adopting certain interaction strategies. Interaction strategies for reducing HIV stigma have received limited research attention and are therefore the central focus of the studies reported in the following chapters.

This chapter gives a brief overview of social psychological research on changing attitudes towards stigmatized individuals. Attention will be paid to changing stereotypes and the pros and cons of personal contact with members of stigmatized groups. This is followed by a more extensive introduction of the concept of interaction strategies and a discussion of the scarce literature in this field. The remainder of this chapter focuses exclusively on reducing stigmatization of persons with HIV. I will first discuss society-level strategies to reduce stigmatization of persons with HIV. Then I will introduce the experimental studies on interaction strategies to reduce stigmatization of persons with HIV.

\section{CHANGING ATTITUDES TOWARDS STIGMATIZED INDIVIDUALS}

Social psychological research on changing attitudes towards stigmatized individuals has predominantly focused on changing stereotypes of stigmatized groups and on the advantages and disadvantages of personal contact with members of the stigmatized group (Batson et al., 1997; Biernat \& Dovidio, 2000). In this section both approaches will be discussed. 
Stereotypes of stigmatized groups are difficult to change (Biernat $\&$ Dovidio, 2000; Kunda \& Oleson, 1995). However, research on social cognition and intergroup relations has proposed approaches to change and reduce stereotypes of outgroups. In the present paragraph I will pay attention to conscious suppression of stereotypes and the provision of stereotype-inconsistent information.

A number of researchers have investigated whether conscious suppression of stereotypes can influence people's attitudes and behavior towards stereotyped targets. Conscious suppression of stereotypes, however, may have drawbacks. Macrae, Bodenhausen, Milne and Jetten (1994) found that suppressing stereotypic thoughts can produce unintended rebound effects, with these suppressed stereotypes becoming even more accessible than if people had never suppressed them at all. Furthermore, Macrae, Bodenhausen, Milne and Wheeler (1996) found that conscious stereotype suppression may also result in less attention being given to stereotype-inconsistent information, because of the attention allocated at stereotype suppression. Recently, other researchers have argued that people may succeed in suppressing stereotypes without incurring rebound effects, if they are highly motivated to suppress these stereotypic thoughts and are practiced at suppressing (Biernat \& Dovidio, 2000; Monteith, Sherman \& Devine, 1998). Kawakami and colleagues (2000) investigated in three studies whether stereotype activation can be reduced by training in the negation of stereotypic associations (Kawakami, Dovidio, Moll, Hermsen \& Russin, 2000). They demonstrated that people are able to reduce stereotype activation for specific categories (skinheads or racial categories) after an extensive amount of training.

Another line of research has investigated whether exposure to stereotype-inconsistent information may change stereotypes. The provision of stereotype-inconsistent information may also take a wrong turning. If people encounter group members who violate the group stereotype, they tend to 'subtype' this individual. This means that perceivers place this person in a subcategory and regard this individual as an exception of the group. The additional attributes of this stereotypeinconsistent groupmember are used to justify this subtyping and the stereotype of the group as a whole is unchanged (Kunda \& Oleson, 1995). Exposure to counter-stereotypical group members may result in stereotype change when stereotype-disconfirming attributes are present among a large number of group members, because many inconsistent group members cannot be regarded as a subtype (Kunda \& Oleson, 1995; Weber \& Crocker, 1983). Recently, Kunda and Oleson (1997) have argued that exposure to counter-stereotypical individuals may gradually change stereotypes, as long as they do not differ too extremely from people's preexisting stereotypes.

Research on stereotype change has contributed to our knowledge of stigma reduction. For example, research on stereotype suppression suggests that people may become even more preoccupied with a target's stigma when they try to suppress prejudiced thoughts in social interaction. Furthermore, knowledge about the effects of stereotype-inconsistent information may have implications for the presentation of information about stigmatized individuals in stigma reduction 
campaigns. However, most research on stereotype change concerns basic laboratory research that has been conducted from a social cognitive point-of-view. Therefore, this line of research seems to have limited implications for the development of interaction strategies to influence perceivers' emotional and behavioral reactions in real social interaction.

\section{PERSONAL CONTACT WITH MEMBERS OF STIGMATIZED GROUPS}

Another research area that has received considerable attention of social psychologists is the impact of personal contact with members of stigmatized groups on attitudes towards this group. This line of research builds on the contact hypothesis of Gordon Allport (1954). The contact hypothesis proposes that under certain circumstances interpersonal contact between members of different groups can reduce prejudice and negative intergroup attitudes. Throughout the years, the conditions under which interpersonal contact with outgroup members leads to more positive intergroup attitudes have been further specified (Amir, 1976; Brewer \& Miller, 1984; Cook, 1978; Stephan, 1985). Interpersonal contact with members of a stigmatized group may change prejudice towards the group when the contact is 'sustained and intimate, between members of equal status who share important goals, and supported by the institution within which it occurs' (Herek \& Capitanio, 1997, p. 2). Interpersonal contact with members of stigmatized groups may provide opportunities to have positive contact experiences, reduce outgroup homogeneity and disconfirm stereotypic thoughts. However, as noted previously, contact with counter-stereotypical group members may also lead to subtyping. Working together on common goals may lead to recategorization, which means that people from different groups see themselves as part of one larger social group. The common in-group identity model of Gaertner and colleagues (Gaertner, Dovidio, Anastasio, Bachman \& Rust, 1993; Gaertner, Mann, Murrell \& Dovidio, 1989) suggests that recategorization may reduce existing prejudices and that attitudes towards former outgroup members may become more positive.

Apart from the above-mentioned positive consequences of the contact hypothesis, there are also some drawbacks. If interpersonal contact is perceived as negative, people's prejudices may be confirmed or even strengthened. Furthermore, it seems impossible to arrange optimal contact experiences for large numbers of group members.

Recently, some researchers have investigated whether positive attitudes towards stigmatized groups can also be realized without direct contact experiences. Wright and colleagues (1997) examined the extended contact hypothesis, which proposes that knowledge of another ingroup member having close contact with an outgroup member can also lead to positive intergroup attitudes. The positive impact 
of extended contact on intergroup attitudes was supported in a series of four different studies (Wright, Aron, McLaughlin-Volpe, \& Ropp, 1997). In one of these studies, participants took part in a laboratory study that was similar to the classic Robbers Cave studies (Sherif et al., 1961). The participants were divided into two groups. First, ingroup solidarity and liking was created. Then, intergroup competition tasks were conducted to create rivalry and conflict between both groups. Subsequently, two members of the rival groups participated in a friendshipmaking procedure. After this, both persons informed the members of their own group about their experiences with the member of the other group. The participants filled in questionnaires at several moments during the laboratory study. The results show that prejudice towards the outgroup was reduced after group members heard about the positive contact experience of one member of their group. Evidence for the extended contact hypothesis was also found in other studies (e.g., Pettigrew, 1997).

Herek and Capitanio (1997) investigated the effects of direct and vicarious contact with persons with AIDS on AIDS-related stigma, using data from a two-wave national telephone survey on AIDS stigma. Direct contact was defined as knowing a person with HIV or AIDS. Vicarious contact was operationalized as the selfreported influence of Magic Johnson's HIV disclosure through mass media. Respondents reporting personal contact with a person with HIV or AIDS, manifested lower stigma scores than those who had no personal contact. Vicarious contact only had a small effect on attitudes of those who initially manifested strongest stigma. The limited impact of Magic Johnson's announcement is consistent with other studies on the HIV disclosure of this popular basketball player (see Kalichman, 1994).

Batson and colleagues (1997) examined whether feeling empathy for one member of a stigmatized group could improve attitudes towards the group as a whole. Participants listened to a taped interview of a member of a stigmatized group (a young woman with AIDS, a homeless man and a convicted murderer). In the low-empathy condition, participants were asked to take an objective perspective and remain detached. In the high-empathy condition, participants were asked to imagine how the stigmatized person felt and how it had affected the life of this person. After listening to the interview, participants completed a questionnaire about their empathy for the stigmatized individual and their attitudes towards the group as a whole. All studies demonstrated that inducing empathy for a member of a stigmatized group led to more positive attitudes towards the group. In the case of murderers, however, no evidence was found for improved attitudes towards convicted murderers immediately after listening to the interview, but strong evidence for improved attitudes was found 1-2 weeks later. Finlay and Stephan (2000) conducted a similar study, using African Americans as target group. In their study, white participants read vignettes about everyday discrimination against African Americans. The results demonstrated that inducing empathy for African Americans reduced differences in evaluations between whites and African Americans. In sum, the work on the extended contact effect and empathy as a way to change attitudes towards stigmatized groups are promising and may have implications for the development of future stigma reduction programs. 
In this section it was contended that positive contact experiences with members of stigmatized groups may reduce prejudice and improve attitudes towards these groups. The contact hypothesis proposes several necessary conditions under which contact with stigmatized members may lead to more positive outgroup attitudes. However, in everyday life, stigmatized and nonstigmatized members do not interact with one another under such optimum conditions. Furthermore, these conditions may be especially effective for tribal stigmas concerning, for example, devalued ethnic or religious groups. However, the likelihood of positive contact experiences will probably be lower for stigmas that concern abominations of the body or involve peril or unaesthetic qualities. In these cases, it seems especially relevant to 'break through' in initial social interaction (Goffman, 1963, p. 69) or to ease social interaction between stigmatized and nonstigmatized members. Stigmatized individuals may reduce such negative responses in initial contact by adopting certain interaction strategies. In the following chapter, research on interaction strategies is reported that aims to ease the social interaction and reduce awkward moments in social interaction.

\section{INTERACTION STRATEGIES}

Research on stigma reduction has given limited attention to targets of stigmatization as agents of change (Eberhardt \& Fiske, 1996). Eberhardt and Fiske (1996) explained that, in general, stigmatized persons do not control the resources to reduce stigmatization and may not be seen as agents who can influence their stigmatizing environment in a meaningful way. However, stigma reduction strategies that focus exclusively on the perceiver (e.g., stereotype suppression or provision of stereotype-inconsistent information) have not always been an unqualified success and it seems time to investigate to what extent targets of stigmatization can influence stigmatizing responses. Research on stigmatization of handicapped people has indicated that stigmatized individuals can foster positive social reactions in initial encounters by adopting certain interaction strategies. This research will be discussed below.

Perceivers may experience discomfort and uncertainty in their contacts with handicapped persons. Discomfort with handicapped persons may arise from a variety of reasons, such as being confronted with one's own vulnerability, uncertainty about appropriate behavior, or unattractiveness of the physical deformity. Such considerations may determine the social interaction between handicapped persons and non-handicapped perceivers. There is empirical evidence that handicapped persons can reduce feelings of discomfort and uncertainty in perceivers, by adopting certain interaction strategies in initial encounters. In a series of three studies, Hastorf and colleagues (1979) investigated whether acknowledgment of a handicap would be a successful interaction strategy. Participants watched videotapes of two handicapped persons they were to work with in a second session. 
One of both persons acknowledged his handicap, pointed out that he realized that people were afraid to talk about the handicap and encouraged people to ask questions about it. Conversely, the other person did not acknowledge the handicap. After watching the videotapes, participants rated both persons on an impression scale and a number of other questions. They were also asked to choose the handicapped person they preferred to work with in the second session. In all three studies, the handicapped person who acknowledged his handicap was preferred to the other handicapped person. Even if handicapped persons are nervous when acknowledging their handicap, people seem to respond to them positively. The acknowledgment strategy has also proven to be useful for other stigmatized individuals, such as persons who stutter (see Hebl et al., 2000).

Belgrave and Mills (1981) have demonstrated that acknowledgment of a handicap must take place in a meaningful context. They investigated the acknowledgment of a handicap under different circumstances. Participants reported increased desire for social interaction for handicapped persons who first requested for assistance and then acknowledged their handicap, or for handicapped persons who miscued their pencil in the sharpener and then acknowledged their handicap. However, the mere acknowledgment of a handicap did not result in increased desire for social interaction. In general, acknowledgment may be a useful interaction strategy for disruptive, visible stigmas, because it may reduce awkwardness in social interaction. However, this strategy may work counterproductive for controllable stigmas such as HIV (see Hebl et al., 2000). Persons with HIV are often held responsible for the onset of their medical condition, as a result of which acknowledgment of their condition might evoke anger or stigmatizing behavior in perceivers.

Belgrave (1984) investigated a number of other interaction strategies that might be useful for handicapped persons. She proposed that people may also avoid social interaction with handicapped persons, because they assume that handicapped persons are emotionally preoccupied with their disability. Belgrave (1984) examined the impact of a number of non-preoccupation strategies on perceivers' preference for social interaction. She found that showing interest in others, participating in activities that are typical of non-handicapped persons, and engaging in athletic activities increased preference for social interaction with handicapped persons. To conclude, research on interaction strategies of stigmatized persons has predominantly focused on handicapped persons and has paid relatively little attention to other stigmatized groups, such as persons with HIV.

\section{SOCIETY-LEVEL STRATEGIES TO COMBAT STIGMATIZATION OF PERSONS WITH HIV}

Since the beginning of the AIDS pandemic, different society-level strategies have been employed to improve public reactions towards people with HIV and AIDS. 
Some governments have adopted nondiscriminatory policies and other legislative measures to protect the rights of persons with HIV. In the United States, for instance, persons with HIV have been included in the Americans with Disabilities Act (Burris, 1999; Devine, Plant \& Harrison, 1999), thus protecting them from discrimination in various aspects of life. Although such legislation may eliminate some of the most overt forms of stigmatization, it may have limited power to combat more subtle types of stigmatization (Devine et al., 1999).

Furthermore, mass-media campaigns have attempted to influence people's attitudes and behavior towards persons with HIV by means of mass-media campaigns. In the Netherlands, two mass-media campaigns have explicitly focused on improving attitudes towards persons with HIV and AIDS (see Kok et al. (1998) for the content of these campaigns). Mass-media campaigns may be useful to raise people's awareness or reinforce social norms, and may serve as an umbrella for other intervention activities (Kok et al., 1998). However, they may be less appropriate to change attitudes and behavior towards persons with HIV (Kok et al. 1998; McGuire, 1985). Additionally, the effectiveness of such campaigns is difficult to measure and the effect of such campaigns on people's actual behavior towards persons with HIV is also unknown. Finally, it is often unclear to what extent mass-media campaigns are based on theoretical principles, such as the social psychological literature described above, or on empirical data (Kok et al., 1998).

Despite the above mentioned limitations, society-level strategies seem to be most appropriate to break the silence that surrounds AIDS, eliminate extreme forms of stigmatization, and foster a more tolerant view of persons with HIV in general. In this way, society-level strategies also create important conditions for improved social interaction between persons with HIV and their social environment. However, such strategies in itself do not seem to be the most effective way to reduce tension and stigmatization in social interaction. Conversely, stigmatizing responses in social interaction may be better tackled at the interaction-level.

\section{INTERACTION-LEVEL STRATEGIES TO REDUCE STIGMATIZATION OF PERSONS WITH HIV}

In everyday life, persons with HIV encounter different situations in which they meet relative strangers (e.g., at the workplace, in the neighborhood). In such situations people's reactions are to a large extent based on first impressions and stigmatizing responses are likely to occur. These first impressions seem to have important consequences for the development of further interaction patterns.

54 However, initial personal contact with persons with HIV may arouse feelings of fear or ambivalence in perceivers. Also, people may feel awkward in their social interactions with people with HIV and may wish to avoid them. This raises the question of how these negative responses can be diminished in initial encounters 
with relative strangers. As argued previously, one possibility is the use of interaction strategies in social interaction, using the person with HIV as an agent of change. Interaction strategies for reducing HIV stigma have received limited attention. Dijker, Koomen and Kok (1997) examined the impact of predictable behavior as a means to reduce fear towards persons with HIV. Participants were given a vignette which contained information about a colleague, who was either healthy or infected with HIV. Further, information was provided about the predictability of his behavior (low vs. medium vs. high predictability). The results show that participants were less willing to have indirect physical contact with a target with HIV than a healthy person, when this target displayed unpredictable behavior. The impact of predictable behavior, however, has never been replicated in a real-life setting. Furthermore, no other interaction strategies have been investigated for persons with HIV so far. Thus, it seems useful to investigate the impact of interaction strategies that persons with HIV may adopt to influence perceivers' emotional and behavioral reactions in initial encounters.

This dissertation examines the impact of different interaction strategies on perceivers' emotional and behavioral reactions towards persons with HIV. Chapter 5 will go into detail of the impact of patient's communication about coping as a means to reduce stigmatization and increase feelings of pity. Previous research on the interpersonal consequences of coping has revealed that patient's coping behavior may have a positive impact on emotional and behavioral reactions of relative strangers (Schwarzer \& Weiner, 1991; Silver, Wortman \& Crofton, 1990). Schwarzer and Weiner (1991) found that active coping of persons with AIDS was related to stronger feelings of pity. Silver, Wortman and Crofton (1990) investigated the role of coping self-presentation on reactions towards female breast cancer patients. They found that a balanced coping portrayal, consisting of a combination of conveying distress and active coping, was related to stronger social support provision and no increase in stigmatization. Active coping self-presentation was also related to prosocial responses, whereas no information about coping and conveying large amounts of distress had negative interpersonal consequences. In Chapter 5, three studies examine the impact of patient's coping on perceivers' emotional and behavioral reactions. Study 5.1 explores what coping strategies of ill persons are preferred by healthy perceivers. Study 5.2 examines the impact of 'conveying distress' and 'active coping' on perceivers' emotional reactions, using a vignette methodology. Finally, Study 5.3 replicates the latter study in a realistic context, using additional measures and participants from the general population.

Chapter 6 focuses on interaction strategies to reduce fear of people with HIV. So far, only Dijker, Koomen and Kok (1997) have investigated this topic. They examined the role of predictable behavior of persons with HIV in reducing feelings of anxiety and stigmatization, using a vignette methodology. They found that students of senior secondary vocational education reported less willingness to engage in indirect physical contact with a person with HIV than with a healthy target if this person showed impulsive and unpredictable behavior. If the target person displayed self-controlled and predictable behavior, indirect physical contact with a person with HIV or a healthy target was found equally preferrable. Chapter 6 investigates the fear-reducing effects of two different interaction strate- 
gies. Study 6.1 replicates Dijker et al.'s vignette study in a realistic experimental context and examines whether predictable behavior, an implicit behavioral strategy, can reduce participants' fear in initial encounters. In a similar interaction context, Study 6.2 investigates the fear-reducing properties of providing reassuring information, an explicit verbal strategy. 


\section{CHAPTER 5}

INTERPERSONAL CONSEQUENCES OF COPING WITH HIV: GENDER DIFFERENCES IN PERCEIVERS' EMOTIONAL AND BEHAVIORAL REACTIONS

Submitted for publication as:

Bos, A. E. R., Dijker, A. J., \& Koomen, W. (2001). Interpersonal Consequences of Coping with HIV: Gender Differences in Perceivers' Emotional and Behavioral Reactions. Manuscript submitted for publication. 


\section{INTRODUCTION}

Persons who suffer from a life-threatening disease may face a so-called self-presentational dilemma (Silver, Wortman \& Crofton, 1990). On the one hand, they have to convey distress to motivate others to give social support. On the other hand, patients may receive negative emotional or behavioral reactions when they confront others with their suffering. This dilemma of whether or not to communicate distress to others, may present an especially strong conflict for persons with HIV, a medical condition that is associated with relatively extreme negative emotional reactions and stigmatization. These negative social responses, resulting from both distress communication and the nature of HIV, may have detrimental consequences for personal and social relationships (Herek, 1999; Leary \& Schreindorfer, 1998) and may also have a negative impact on the psychological well-being of persons with HIV (Bennett, 1990; Crandall \& Coleman, 1992: Herek, 1999).

Why do people stigmatize persons with HIV? Research in the field of illness cognition has revealed that lay people generally interpret diseases in terms of contagiousness and seriousness (Bishop, 1991a, 1991b), and that HIV is grouped among the contagious and serious medical conditions. Both illness cognitions seem to have a negative impact on perceivers' emotional and behavioral reactions. Perceived contagiousness of disease is related to stronger feelings of fear and stronger stigmatization (Dijker, Koomen \& Kok, 1997; Dijker \& Raeijmaekers, 1999; Herek, 1999). Perceived seriousness of disease is associated with relatively stronger feelings of both fear and pity (Dijker \& Koomen, in press) and stronger stigmatization (Crandall, Glor \& Britt, 1997; Crandall \& Moriarty, 1995). Another factor that determines emotional and behavioral reactions to persons with HIV is personal responsibility for contracting the HIV infection. Higher personal responsibility (e.g. HIV caused by unsafe sex versus HIV caused by blood transfusion) is related to less feelings of pity, stronger feelings of anger and stronger stigmatization (Crocker, Major \& Steele, 1998; Weiner, Perry \& Magnusson, 1988). Finally, negative reactions towards persons with HIV often symbolize negative attitudes towards groups that are associated with HIV, such as homosexuals or intravenous drug users (Herek \& Capitanio, 1998; Pryor, Reeder, Vinacco \& Kott, 1989; Reeder \& Pryor, 2000).

\section{Interpersonal consequences of coping with HIV}

Research in the field of health psychology has shown strong interest in the way persons with chronic and life-threatening diseases cope with their medical condition (Dunkel-Schetter, Feinstein, Taylor \& Falke, 1992; Fleishman \& Fogel, 1994; Lazarus \& Folkman, 1984; Maes, Leventhal \& De Ridder, 1996). The impact of coping strategies on disease progression (e.g., Mulder, De Vroome, Van Griensven, Antoni \& Sandfort, 1999; Reed, Kemeny, Taylor, Wang \& Visscher, 1994) and psychological health outcomes (e.g., Fleishman \& Fogel, 1994) have been attentively investigated as well. However, researchers have paid little atten- 
tion to patients' coping as a means to receive supportive reactions (Schreurs \& De Ridder, 1997) or to minimize stigmatizing responses. As was pointed out before, the interpersonal consequences of patients' coping behavior may have a strong impact on patients' psychological and social well-being. The present paper tries to add more insight to this relatively unexplored research area.

Persons with HIV face the challenge to sollicit supportive responses and to minimize negative social reactions. Research on helping behavior suggests that perceivers have to notice signals of distress, before they can recognize a need for help. In particular, clear distress cues increase the likelihood that perceivers interpret the situation as requiring assistance and may lead to more help (see Schroeder, Penner, Dovidio \& Piliavin, 1995). However, if victims convey too much distress, perceivers tend to reject and stigmatize them (Coates, Wortman $\&$ Abbey, 1979; Silver et al, 1990). Batson and colleagues (Batson, 1987; Batson, Early \& Salvarani, 1997) found that watching another person in distress may cause both feelings of empathy and personal distress in perceivers, depending on their perspective. Empathy can be defined as an other-oriented emotional reaction (similar to compassion and pity) that evokes an altruistic motivation to alleviate the other's distress. Personal distress can be described as a self-oriented negative emotional reaction (similar to fear) that evokes an egoistic motivation to relieve one's own distress. Thus, both empathy and personal distress may evoke prosocial behavior in perceivers, resulting, however, from different motivational mechanisms. On the basis of the above mentioned studies, one could predict that ill persons who convey a moderate level of distress, might evoke prosocial behavior in perceivers.

The interpersonal consequences of coping with a life-threatening disease have been hardly examined in the context of interactions with strangers. Only two studies investigated the influence of patients' coping behavior on perceivers' reactions. Schwarzer and Weiner (1991) examined the effects of coping with HIV on emotional and behavioral reactions of others, using a vignette methodology. They found that active as compared to passive coping of persons with HIV was related to stronger feelings of pity. However, the pure effect of active coping is still unknown, because Schwarzer and Weiner (1991) did not compare active coping with a control condition, but with an extremely negative form of passive coping. Thus, it is possible that their respondents reacted with stronger feelings of pity, due to the strong difference between active and passive coping.

The only study that investigated the interpersonal consequences of coping in a realistic setting, was conducted by Silver et al. (1990). They examined the effect of coping self-presentation of female breast cancer patients on social support provision and negative reactions of others. Silver et al. (1990) assumed that perceivers would react more negatively towards patients who coped poorly with their disease and conveyed high levels of distress, compared to patients in the other conditions. Indeed, respondents felt less attracted to this target, sat at greater distance from her, reported more distress following the interaction and reported less desire for future interaction. Conversely, Silver et al. (1990) predicted that perceivers would react positively to a target who indicated that she was coping well with her disease. As predicted, this 'good coping' self-presentation was judged 
positively on almost all outcome measures. Interestingly, Silver et al. (1990) expected that a 'balanced coping' portrayal, a combination of conveying distress and indicating that one is coping well, would also result in favorable reactions from perceivers. Indeed, participants who were confronted with a "balanced coping' portrayal reacted positively on all outcome measures. Finally, it was assumed that perceivers would react negatively towards patients who did not provide information about their coping activities. An explanation would be that perceivers in this condition would use their (negative) stereotypes about victims. In fact, when no information about coping activities was provided, perceivers' reactions were similar to the reactions to the target who coped poorly and conveyed high levels of distress.

Although the Silver et al. (1990) study is an important step towards better understanding the interpersonal consequences of coping behavior, some critical remarks should be made. First, the pure effect of 'conveying distress' on perceivers' reactions is still unclear. The target in Silver et al.'s poor coping condition not only conveyed distress, but also displayed feelings of jealousy and indicated to have difficulty to relate to others. It is still unclear to what extent respondents reacted negatively because of targets' distress or because of those other negative aspects. In a similar vein, Silver et al.'s good coping manipulation contained aspects of active coping, but was also mixed with other positive aspects that presented the target as a pleasant interaction partner (e.g. 'I act as if any encounter that I have with a person is of the highest importance - I try to focus in on them and really be caring', Silver et al. (1990), p. 413). Thus, it is also unclear what aspects of Silver et al.'s good coping manipulation were judged positively by their respondents. Second, the generalization of the results seems limited. The participants in this study were students and the study has never been replicated for other diseases. Moreover, Silver et al. (1990) did not investigate reactions of male participants towards patients' coping self-presentation. In fact, their study only provides information about womens' reactions to coping of female patients with cancer. However, we have well-founded reasons to assume that the interpersonal consequences of coping may be different for men and women.

\section{Gender differences in emotional reactions and prosocial behavior}

Communication with persons who suffer from a life-threatening disease, may require skills such as emotional sensitivity, caring and concern for others. These role requirements are generally seen as belonging more to the female gender role than to the male gender role (Eagly \& Crowley, 1986; Eagly \& Wood, 1991). There is empirical evidence that women and men do differ in their emotion expression and in their helping behavior. In general, women are found to be more emotionally expressive than men (Kring \& Gordon, 1998; Timmers, Fischer \& Manstead, 1998), with the exception of expressing anger (Grossman \& Wood, 1993). In addition, the latter authors found that people's stereotypic judgments about gender and emotional experience were in line with these results: Participants thought that typically women generally experience emotions more 
intensely than men, with the exception of anger (Grossman \& Wood, 1993). A meta-analysis of Eagly and Crowley (1986) shows that men and women also differ in their helping behavior. The female gender role encourages helping behavior that is caring and nurturant, whereas the male gender role stimulates helping behavior that is heroic and chivalrous.

These gender differences in emotional expressions and helping behavior can be explained by social role theory (Eagly, 1987; Eagly \& Crowly, 1986; Eagly \& Wood, 1991). This theory postulates that sex differences in social behavior are in part caused by people's tendency to behave consistently with their gender roles. In addition, sex differences may also stem from differences in skills and attitudes derived from men's and women's prior role enactment. The female gender role consists of communal attributes, such as being emotional expressive, friendly, nurturant, altruistic, interpersonally sensitive and caring for others. The male gender role consists of agentic qualities, such as being independent, assertive, masterful, self-confident, dominant and instrumentally competent (Eagly \& Wood, 1991).

In general, we expect that men and women will react differently to patients who display distress. We expect that patients who convey distress evoke prosocial reactions in women, because this coping behavior appeals more to the communal qualities of the female gender role. On the other hand, we expect that men react negatively to patients who convey distress, because this appeals to behavior that is inconsistent with their male gender role. Conversely, we have no reasons to assume that active coping efforts to deal with a serious disease will be judged differently by men and women. We believe that an active coping portrayal will lead to stronger prosocial reactions (cf. Schwarzer \& Weiner, 1991), irrespective of perceivers' gender.

\section{The present studies}

The present studies examine the interpersonal consequences of coping with HIV, using different research methods and a variety of outcome measures. Reactions to patients' coping have been hardly studied from the perspective of the perceiver. Therefore, Study 5.1 was conducted to examine how perceivers value different coping strategies of ill patients, using a free response format. Study 5.2 investigated the influence of two different coping strategies (conveying distress and active coping) on perceivers' emotional and behavioral reactions, using a vignette technique. Study 5.3 was a replication of the second study in a realistic experimental setting, using additional behavioral measures. 


\section{STUDY 5.1}

The interpersonal consequences of coping behavior of ill persons have been hardly examined in the context of interaction with strangers. To date, it is still unknown how perceivers value different coping strategies of seriously ill persons. Therefore, the goal of Study 5.1 was to explore what coping strategies of persons with HIV or cancer are preferred by healthy perceivers, and what coping strategies are not appreciated. In addition, gender differences in perceivers' preferences for different coping strategies were examined.

\section{METHOD}

\section{Participants}

Partcipants were 271 students of senior secondary vocational education (169 women and 96 men). The gender of six participants was unknown. The mean age of the participants was 18.0 years $(S D=1.6)$. Five participants were excluded from data analysis, because of indicating not having participated seriously.

\section{Procedure}

The experiment was conducted during class in the presence of the teacher and the experimenter. The experimenter explained that every participant would receive a scenario and several questions about a situation in a particular workplace. It was pointed out that participants should read the scenario carefully and try to imagine this situation. Eight different versions of the booklet with scenario and questions were distributed at random. After the data collection participants were debriefed.

\section{Scenario}

The booklet first provided a detailed description of the situation. Participants had to imagine that their company, a commercial business, had merged with another company and that they would have to share their office and collaborate with Peter, who used to work for the other company. A colleague, acquainted with Peter, would provide some information about Peter. After this introduction participants 62 read the manipulated information about their new colleague. This manipulation consisted of information about type of disease (HIV vs. cancer), seriousness of the disease (low seriousness vs. high seriousness) and sexual orientation of the target (homosexual vs. heterosexual). 
First, participants answered questions about their emotional and behavioral reactions to the imagined cooperation with the target. At the end of the questionnaire, two open-ended questions were asked. First, respondents were asked to write down what ways of coping of the target they would prefer. Second, respondents were asked to write down what ways of coping of the target they would not appreciate. Respondents had half a blank page to answer each question.

Two separate coding schemes were developed for desirable and undesirable coping. These coding schemes were developed on the basis of distinct themes in the answers of the respondents and on the basis of theoretical considerations from the coping literature (Dunkel-Schetter et al., 1992; Fleishman \& Fogel, 1994; Lazarus \& Folkman, 1984). The coding scheme for desirable coping contained 14 categories and the coding scheme for undesirable coping consisted of 15 categories. Two judges, social scientists with experience in coding qualitative data, were trained in using the coding categories and coded the answers to both questions. Inter-rater reliabilities were fairly high (Cohen's kappa 'desirable coping' $=.82$; Cohen's kappa 'undesirable coping' $=.82$ ). Disagreements were resolved after discussion.

\section{RESULTS}

Table 5.1 gives an overview of the coding categories for desirable coping and the proportion of respondents that spontaneously mentioned these categories. In general, participants prefer that ill persons continue with their normal life $(48.5 \%)$, communicate about their disease $(47.7 \%)$ and try to focus on the positive $(39.8 \%)$. Other frequently mentioned ways of desirable coping are healthy behavior (14.0\%), acceptance of the disease (13.3\%) and avoidance (10.6\%).

Our analyses will now focus on gender differences and differences between illnesses for each desirable coping category. Consistent with our expectation, women had a significant stronger preference for communication about the disease than men, $\chi^{2}(1, N=258)=8.77, p<.01$. Women also had a stronger preference for acceptance of the disease, compared to men, $\chi^{2}(1, N=258)=5.75, p$ $<.05$. No gender differences were found on other desirable coping categories.

Perceivers of persons with HIV more frequently mentioned safe behavior as a desirable coping strategy, compared to perceivers of persons with cancer (Fisher's exact test $p=.003)^{10}$. In addition, giving education about the disease was also mentioned more frequently by perceivers of persons with HIV, compared to perceivers of persons with cancer (Fisher's exact test $p=.007$ ). No other differences were found between perceivers of persons with HIV or cancer. Neither sexual orientation of the target nor seriousness of disease did influence perceivers' preferences for patients' coping behavior. 
Table 5.1 Desirable coping from the perspective of the perceiver (Percentage of respondents who spontaneously mention certain coping category) (Study 5.1)

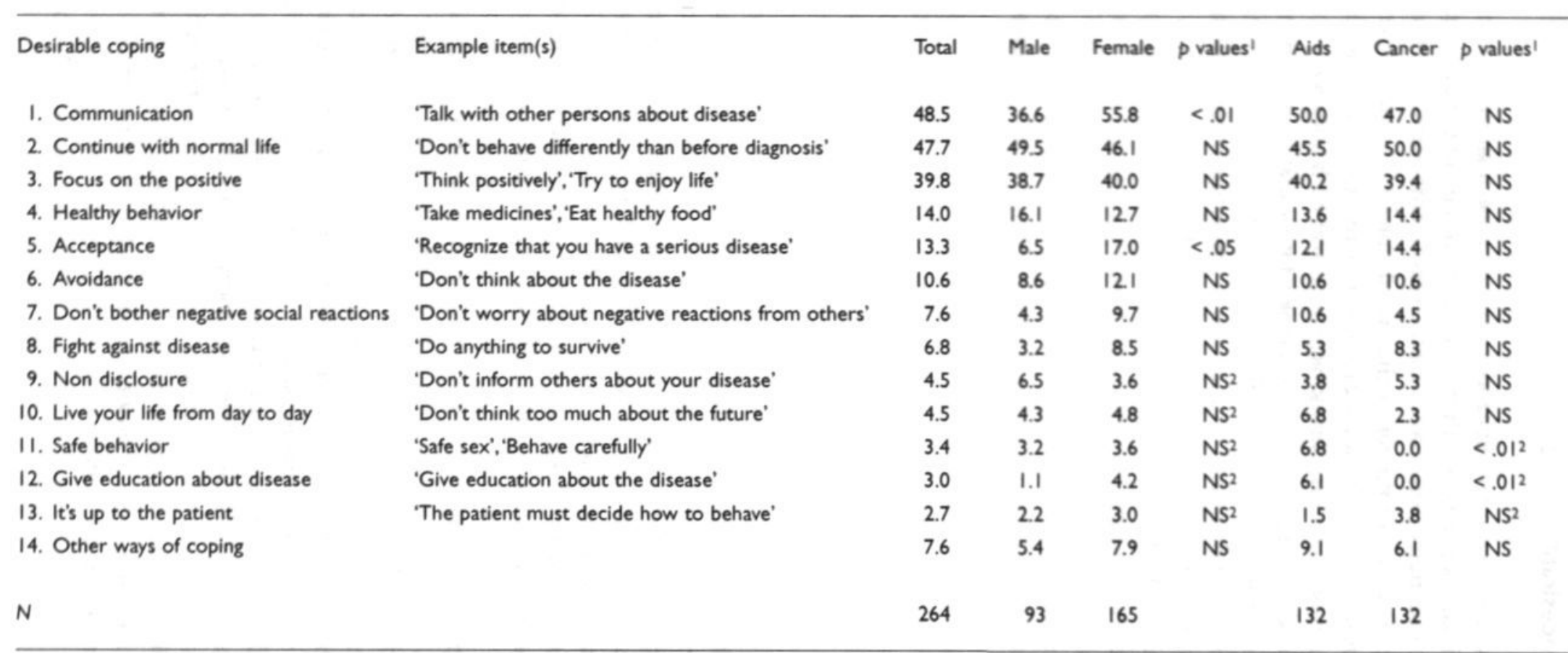

I Chi-square analyses were used unless otherwise indicated. NS, not significant, $p>.05$.

2 Fisher exact test was conducted, because of expected cell frequencies of $\leq 5$. 
Table 5.2 Undesirable coping from the perspective of the perceiver (Percentage of respondents who spontaneously mention certain coping category) (Study 5.1)

\begin{tabular}{|c|c|c|c|c|c|c|c|c|}
\hline Undesirable coping & Example item(s) & Total & Male & Female & $p$ values 1 & Aids & Cancer & $p$ values \\
\hline I. Self-pity & 'Behave pitiful','Arouse pity in other person' & 34.6 & 35.2 & 35.0 & NS & 29.7 & 39.7 & NS \\
\hline 2. Depression & 'Being sad all day long' & 23.6 & 15.9 & 28.1 & $<.05$ & 24.2 & 23.0 & NS \\
\hline 3. Social isolation & 'Seclude oneself from society' & 21.7 & 21.6 & 22.5 & NS & 18.0 & 25.4 & NS \\
\hline 4. Non disclosure & 'Don't inform others about your disease' & 19.7 & 18.2 & 20.6 & NS & 18.8 & 20.6 & NS \\
\hline 5. Rumination & 'Think about the disease too much / all day long' & 17.3 & 17.1 & 16.3 & NS & 14.0 & 20.6 & NS \\
\hline 6. Denial of disease & 'Take no account of disease', 'Repression' & 12.2 & 4.5 & 16.3 & $<.01$ & 14.1 & 10.3 & NS \\
\hline 7. Communication & 'Talk with other persons about disease' & 10.2 & 15.9 & 7.5 & $<.05$ & 14.1 & 6.3 & $<.05$ \\
\hline 8. No continuation of normal life & 'Behave like a patient', 'Stop working' & 7.9 & 3.4 & 10.0 & NS & 8.6 & 7.1 & NS \\
\hline 9. Unhealthy behavior & 'Don't take medicines', 'Neglect oneself' & 7.5 & 13.6 & 4.4 & $<.01$ & 10.2 & 4.8 & NS \\
\hline 10. No fight against disease & 'Give up hope','Don't fight against the disease' & 3.5 & 3.4 & 3.8 & NS2 & 3.1 & 4.0 & NS2 \\
\hline II. Unsafe behavior & 'Unsafe sex' & 2.8 & 1.1 & 3.8 & NS2 & 5.4 & 0.0 & $<.052$ \\
\hline 12. Shame & 'Feeling shame' & 2.8 & 0.0 & 4.4 & NS2 & 3.1 & 2.4 & NS2 \\
\hline 13. Aggressive bahavior & 'Being angry' & 2.4 & 1.1 & 2.5 & NS2 & 3.1 & 1.6 & NS2 \\
\hline 15. Other ways of coping & & 5.1 & 4.5 & 5.6 & NS & 8.6 & 1.6 & $<.05$ \\
\hline$N$ & & 254 & 88 & 160 & & 128 & 126 & \\
\hline
\end{tabular}

' Chi-square analyses were used unless otherwise indicated. NS, not significant, $p>05$.

2 Fisher exact test was conducted, because of expected cell frequencies of $\leq 5$.

${ }^{3}$ Not reported, because of expected cell frequencies $\leq 1$. 
Table 5.2 shows the coding categories for undesirable coping and the proportion of respondents that spontaneously mentioned these coping categories. In general, respondents did not appreciate self-pity (34.6\%), depression (23.6\%) and social isolation ( $21.7 \%)$. Other coping behavior that was negatively valued by the respondents was non-disclosure $(19.7 \%)$, rumination $(17.3 \%)$, denial of disease (12.2\%) and communication (10.2\%).

Again, clear gender differences emerged. Men more frequently mentioned communication about the disease as an undesirable coping strategy than women, $\chi^{2}(1$, $N=254)=4.28, p<.05$. This gender difference in preference for communication about the disease is complementary to the findings for desirable coping. Further, women more frequently mentioned depression $\left(\chi^{2}(1, N=254)=4.67\right.$, $p<.05)$ and denial of disease $\left(\chi^{2}(1, N=254)=7.32, p<.01\right)$ as undesirable responses than men. On the other hand, men more frequently mentioned unhealthy behavior as undesirable coping behavior, $\chi^{2}(1, N=254)=6.88, p<$ .01 . No gender differences were found on other undesirable coping categories.

Communication about the disease $\left(\chi^{2}(1, N=254)=4.11, p<.05\right)$ and unsafe behavior (Fisher's exact test $p=.014$ ) were more frequently mentioned as undesirable coping by perceivers of persons with HIV than perceivers of persons with cancer. The proportion of negatively valued coping behavior that did not fit in one of the coding categories was larger for perceivers of persons with HIV than for perceivers of persons with cancer, $\left(\chi^{2}(1, N=254)=6.42, p<.05\right.$. No other differences were found between perceivers of persons with HIV or cancer. Again, sexual orientation of the target and seriousness of disease did not influence perceivers' ideas about undesirable coping.

\section{DISCUSSION}

The present study has mapped desirable and undesirable coping strategies from the perspective of perceivers who are unfamiliar to the ill person. Results indicate that perceivers prefer that patients continue with their normal life and try to have a positive attitude towards life. In contrast, perceivers seem to reject self-pity and negative mood states. In other words, it seems that perceivers prefer that ill persons do not indulge in their sick role behavior. This finding underlines the selfpresentational dilemma of ill persons (Silver et al, 1990) and suggests that ill persons should be careful with confronting relative strangers with their suffering.

Overall, perceivers mention the same main coping categories for persons with HIV and cancer. Differences in desirable and undesirable coping seem to be connected with differences in disease characteristics between both diseases. Perceivers of persons with HIV are more concerned about safe behavior than perceivers of persons with cancer. Further, perceivers of persons with HIV find it more desirable to give education about their disease and less desirable to communicate about their disease than perceivers of persons with cancer. 
Reactions to patients' coping seem different for male and female perceivers. First, men and women clearly differ in their preference for patients' communication about the disease. Women regard this as a more desirable way of coping than men, whereas men consider this as a more undesirable way of coping than women. This finding can be explained from a social role perspective: Communi-cating about one's disease fits more with the communal qualities of the female gender role and is more inconsistent with the agentic aspects of the male gender role. Second, women mentioned certain ways of emotion regulation (acceptance as desirable, and depression and denial of disease as undesirable) more often than men. This pattem is also consistent with a social role perspective on emotions and behavior: Women are expected to be more emotionally expressive and to have more attention for others' emotional well-being than men.

In the present study we have used a free response format to investigate desirable and undesirable coping strategies from the perspective of the perceiver. However, it is unclear how perceivers actually respond when they are confronted with certain coping behaviors of a person with HIV. This question is addressed in Studies 5.2 and 5.3, in which patients' coping was experimentally manipulated. Special attention will be paid to gender differences in perceivers' reactions.

\section{STUDY 5.2}

In Study 5.2 we investigate the effects of two ways of coping (conveying distress and active coping) and a control condition (no information about coping) on gender differences in perceivers' emotional reactions. The interpersonal consequences of coping with HIV have been hardly investigated and therefore it is important to examine whether our coping manipulations interact with other factors that are known to be related to perceivers' reactions to persons with HIV. For this reason, personal responsibility and seriousness of disease were manipulated as well.

Our first study revealed that women express a greater desire to be informed by patients about their disease than men. During communication about one's disease, it seems almost inevitable to confront perceivers with at least some signs of distress. From a theoretical point of view, conveying some distress seems necessary to receive pro-social responses (see Schroeder et al, 1995). However, the level of distress should be appropriate and not be seen as self-pity, as our first study indicates. On the basis of research in the field of gender and emotion (Grossman \& Wood, 1993; Kring \& Gordon, 1998; Timmers, Fischer \& Manstead, 1998) and the results of our first study, we predict that women will react with stronger feelings of pity to patients who convey distress, whereas men will respond with stronger feelings of anger.

The results of our first study also indicated that perceivers of seriously ill persons prefer active coping strategies and respond negatively to persons who indulge in their sick role behavior. This finding corresponds with results of Schwarzer and Weiner (1991), who found that active coping was related to stronger feelings of pity. In line with these findings, we predict that active coping will be related to stronger feelings of pity and less feelings of anger. 


\section{Participants}

Two hundred twenty-four students of senior secondary vocational education (127 men and 96 women) participated in this study. The gender of one participant was unknown. The mean age of the participants was 18.4 years $(S D=1.2)$. Five participants were excluded from data-analysis, because they indicated not to have participated seriously.

\section{Procedure}

The procedure was identical to the procedure in the first study. In Study 5.2, however, twelve different versions of the booklet were distributed at random. The study consisted of a 3 (Coping with HIV: active coping vs. conveying distress vs. no information) $\times 2$ (Gender of participant: male vs. female) $\times 2$ (Seriousness: low vs. high) $\times 2$ (Personal responsibility: low vs. high) between-subjects design.

\section{Scenario}

Participants received a detailed description of the situation. They had to imagine that their company merged with another company. As a result, they would have to share their office and collaborate with a new colleague (Michael Severijns), who used to work for the other company. Participants had to imagine that one of their present colleagues showed them an interview with Michael in a recent issue of the hospital magazine. The next page of the booklet consisted of this interview with Michael. In the introduction of the interview, it was clearly stated that Michael was infected with HIV and that he regularly visited the HIV department in the hospital. Then, Michael was asked to tell something about himself. He provided general background information about his neighbourhood, hobbies, work and relationship status (living together with his girlfriend) ${ }^{11}$, and confirmed that he was infected with HIV. Subsequently, the interviewer asked how he was infected with HIV. The answer to this question contained our manipulation of personal responsibility for the onset of the disease. In the high personal responsibility condition, Michael had had unsafe sex with a woman at the time of his practical training in Kenia, despite the fact that he was warned for the possible negative consequences of unsafe sex. In the low personal responsibility condition, Michael had had safe sex with the same woman, but found out afterwards that the condom was ripped. Then, the interviewer informed about the actual medical situation of Michael. The answer to this question was the manipulation of seriousness of disease. In the high seriousness condition, Michael told that recent blood results showed that his medical condition was deteriorating. In addition, Michael reported that he suffered from diarhoea and had become skinny. In the low seriousness condition, Michael told that recent blood results indicated that his 
medical condition was fairly good. Michael also stated that he had no disease symptoms and he generally felt well.

Finally, the interviewer asked how Michael was coping with his HIV infection. The answer to this question contained the manipulation of coping. In the conveying distress condition, Michael responded as follows: "I constantly realize that I'm in a temible situation. After all, you have a disease that may not be cured. It was a smack in the face when I heard about my HIV infection, and I still cannot accept my disease. It seems a hopeless situation and I often feel depressed and sad". In the active coping condition, Michael answered: "I try to cope actively with my HIV infection. I'm having the combination therapy and I swallow a combination of AIDS inhibitors at particular moments during the day. I also try to eat healthy food and take enough rest. I try to continue with my life as normal as possible and I do my best to cope actively with my disease". The question about coping was not asked in the control condition.

\section{Dependent variables}

After reading the scenario, participants answered questions about their emotional reactions to the imagined cooperation with the target. All answers were measured on a 7 -point scale $(1=$ not at all, $7=$ very much). Fear was measured by combining the scores of three items, reflecting different Dutch words with the meaning of slight fear (Cronbach's alpha $=.91$ ). Pity was measured by combining the scores on four items with the Dutch meaning of pity (Cronbach's alpha $=.79)$. Anger was measured by combining the scores on the items irritation and annoyance (Cronbach's alpha $=.79$ ). Finally, eight questions checking the effectiveness of our four manipulations were answered. Each manipulation check consisted of the combination of the scores on two questions (Cronbach's alpha's between .67 and .87).

\section{RESULTS}

\section{Manipulation checks}

Each of the manipulation checks was subjected to a 3 (Coping with HIV: active coping vs. conveying distress vs. no information) $\times 2$ (Gender of participant: male vs. female) $\times 2$ (Seriousness: low vs. high) $\times 2$ (Personal responsibility: low vs. high) analysis of variance (ANOVA). All analyses revealed the expected main effects. First, respondents in the high personal responsibility condition thought that the target had higher personal responsibility $(M=6.22)$ than respondents in the low personal responsibility condition $(M=3.53), F(1,221)=192.88, p<$ .001 . Second, respondents in the high seriousness condition indicated that the medical situation of the target was more serious $(M=4.62)$ than respondents in the low seriousness condition $(M=2.97), \mathrm{F}(1,221)=121.75, p<.001$. Third, 
the target was judged as conveying more distress in the conveying distress condition $(M=3.62)$ than in the control condition $(M=3.37)$ or the active coping condition $(M=2.67), F(2,221)=9.65, p<.001$. Post hoc analyses show that the differences between the conveying distress condition and the other two conditions are significant. Fourth, the target was judged as coping more actively with his disease in the active coping condition $(M=5.95)$ than in the control condition $(M=5.59)$ or in the conveying distress condition $(M=4.88), F(2,221)=$ $21.18, p<.001$. Post hoc analyses show that the differences between active coping and the other two conditions are significant. In sum, we conclude that our experimental manipulations have been induced successfully.

\section{Emotional reactions}

A $3 \times 2 \times 2 \times 2$ (coping with HIV $\times$ gender of participant $\times$ seriousness $\times$ personal responsibility) ANOVA on feelings of fear revealed a significant main effect for gender, $F(1,220)=6.16, \mathrm{p}<.05$. Women reported stronger feelings of fear $(M$ $=3.44)$ than men $(M=2.91)$. No other significant effects were found.

A similar ANOVA on feelings of pity revealed a significant main effect for gender as well, $F(1,220)=4.40, \mathrm{p}<.05$. Women reported stronger feelings of pity $(M=4.90)$ than men $(M=4.58)$. In addition, a significant main effect for coping was found, $F(2,219)=3.15, p<.05$. Post hoc analyses revealed that respondents in the conveying distress condition report stronger pity $(M=5.01)$ than respondents in the control condition $(M=4.59)$. No other significant main effects were found. However, two significant interaction effects showed up. An interaction between coping and personal responsibility $(F(2,219)=5.22, p<$ $.01)$ indicates that perceivers respond with relatively little pity to highly responsible patients who cope actively with their disease. An interaction between coping and seriousness of disease $(F(2,219)=3.05, p<.05)$ shows that participants also respond with relatively little pity to patients in a highly serious medical condition who cope actively with their disease.

An ANOVA on feelings of anger did not reveal a significant main effect for gender, although the pattern was in the expected direction, $F(1,222)=2.57, p$ $=.11$. However, the ANOVA revealed a significant interaction between patients' coping and gender of the participant, $F(2,221)=4.65, p<.05$, indicating that men and women react differently to ill persons who convey distress: Men report relatively stronger feelings of anger, whereas women report relatively less feelings of anger. No other main or interaction effects were found.

Our specific hypotheses with regard to gender differences in emotional reactions to patients' conveying distress were tested with a priori contrast analyses (separately for men and women). We tested the effect of 'conveying distress' on emotional reactions in male and female perceivers, by comparing the conveying distress condition with the other two conditions. The weight ' -2 ' was assigned to the conveying distress condition and the weight ' 1 ' was assigned to the other conditions. Table 5.3 shows that men respond with stronger feelings of anger to a target who is conveying distress, $\mathrm{t}(124)=2.53, \mathrm{p}<.05$. On the other hand, 
Table 5.3 Means, standard deviations and contrast analyses for emotional reactions to 'conveying distress' of target with HIV (Study 5.2)

Dependent variables

Condition

T-values of contrasts

\section{Active coping 2. Distress 3. No information ( $\left.\begin{array}{lll}1 & -2 & 1\end{array}\right)$}

Fear

$\begin{array}{llllll}\text { Women } & \text { M } & 3.43 & 3.44 & 3.46 & 0.02 \\ & \text { SD } & 1.77 & 1.44 & 1.47 & \\ & \text { N } & 32 & 32 & 32 & \\ \text { Men } & & & & & 0.58 \\ & \text { M } & 2.99 & 2.81 & 2.98 & \\ & \text { SD } & 1.41 & 1.54 & 1.67 & \end{array}$

Pity

$\begin{array}{llllll}\text { Women } & M & 4.53 & 5.31 & 4.80 & 2.58 * \\ & \text { SD } & 1.22 & 0.91 & 1.28 & \\ & N & 32 & 31 & 32 & \end{array}$

$\begin{array}{rrrrrr}\text { Men } & \text { M } & 4.74 & 4.69 & 4.36 & 0.63 \\ & \text { SD } & 1.15 & 1.17 & 1.18 & \\ & N & 42 & 42 & 42 & \end{array}$

Anger

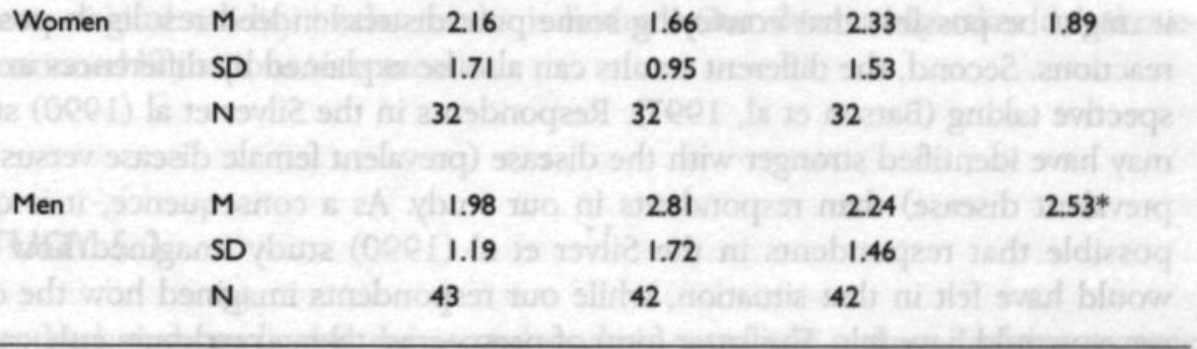

Note $* p<.05$

women respond with stronger feelings of pity $(t(92)=2.58, p<.05)$. Again, our predictions with regard to gender differences were confirmed: conveying distress leads to a more pro-social emotional state in women, but causes a more aggressive emotional state in men.

Our hypotheses with regard to active coping were also tested with contrast analyses. The effect of 'active coping' on pity and anger was tested by comparing this condition with the other two conditions. The weight ' -2 ' was assigned to the 'active coping' condition and the weight ' 1 ' to the other two conditions. Contrary 
to our predictions, the active coping condition did not differ from the other two conditions on pity $(t(220)=.58$, n.s. $)$ and anger $(t(221)=1.21$, n.s. $)$.

\section{DISCUSSION}

Study 5.2 investigated emotional reactions to patients' coping and particularly gender differences in these reactions. In line with research on gender differences in emotional expression (Grossman \& Wood, 1993; Kring \& Gordon, 1999; Timmers et al., 1998), we found that women reported stronger feelings of fear and pity than men. Men also reported stronger feelings of anger than women, although this effect did not reach significance.

Ill persons who convey distress seem to evoke different emotional reactions in men and women: Women report stronger feelings of pity, whereas men respond with stronger feelings of anger. This pattern is consistent with the predictions that we derived from social role theory (Eagly, 1987; Eagly \& Wood, 1991) and research in the field of gender and emotion (Grossman \& Wood, 1993; Kring \& Gordon, 1998; Timmers, Fischer \& Manstead, 1998). In contrast to Silver et al. (1990) who investigated reactions of female perceivers to coping self-presentation of breast cancer patients, we did find that conveying distress results in favorable reactions in female perceivers. We have two different explanations for this discrepancy: First of all, our manipulation of conveying distress was not mixed with other negatively valued aspects as in the manipulation of Silver et al (1990). Thus, it might be possible that conveying some pure distress indeed results in positive reactions. Second, the different results can also be explained by differences in perspective taking (Batson et al, 1997). Respondents in the Silver et al (1990) study may have identified stronger with the disease (prevalent female disease versus less prevalent disease) than respondents in our study. As a consequence, it is quite possible that respondents in the Silver et al (1990) study imagined how they would have felt in that situation, while our respondents imagined how the other person would have felt. The latter form of perspective taking predominantly causes empathy in perceivers, whereas the first form not only causes empathy, but also leads to distress in perceivers (see Batson et al., 1997).

Contrary to our expectations, we were not able to demonstrate generally favourable interpersonal consequences of active coping: Active coping was not related to stronger feelings of pity or less feelings of anger. These findings are in contradiction with results of Schwarzer and Weiner (1991), who found that active coping was related to stronger feelings of pity. In our opinion, Schwarzer and Weiners' favorable effects for active coping can be explained by their extremely 72 negative manipulation of passive coping. Because there was no control condition in their design, they could not disentangle effects of active and passive coping.

The present study also examined whether and how personal responsibility and 
seriousness of disease interact with patients' coping. It seems that active coping leads to less pity, when ill persons are highly responsible for the onset of their disease, and when their medical condition is serious. Our manipulation of active coping is problem-focused by nature: It might be that perceivers find emotionfocused strategies especially appropriate in serious medical conditions and in situations where the target is to blame for the onset of the disease. On the other hand, it seems that perceivers consider patients' conveying distress as more appropriate when the medical condition is more serious. This fit between patients' coping, on the one hand, and personal responsibility and seriousness of disease, on the other hand, only seems to determine perceivers' feelings of pity, and not feelings of fear or anger.

The present study has investigated perceivers' emotional reactions to patients' coping. The results of this second study confirm and extend the pattern of results of our first study. Men and women react differently to ill persons who communicate distress about their disease: Female perceivers respond with stronger prosocial emotions, whereas male perceivers react with stronger emotions of a more aggressive nature. This pattern is clear and consistent, but some questions remain unanswered and some limitations of the second study should be mentioned. First of all, in studies 5.1 and 5.2, we used a vignette methodology. Although we are confident that our vignettes were realistic and vivid, it is still unclear whether perceivers would respond similarly in a more realistic experimental setting. Second, in Study 5.2, we only measured emotional reactions to patients' coping. Thus, it remains unclear if patients' coping is also related to gender differences in perceivers' behavioral reactions. Third, in Study 5.2, reactions to persons with HIV were not compared with reactions to a healthy target. Fourth, in studies 1 and 2, participants were students of senior secondary vocational education. Therefore, the ecological validity of the results is limited. Our third study takes the abovementioned limitations into account.

\section{STUDY 5.3}

The third study replicated the second study in a realistic setting. Participants were invited to our laboratory for a study on 'cooperation and first impressions'. They were led to believe that they would cooperate with another person, who could have a different social, cultural or medical background. Our experimental setting was very realistic, since our research laboratory is adjacent to the academic hospital.

In comparison with the second study, four alterations were carried out. First, to reduce the complexity of the design, we decided to only measure reactions to patients' coping in the low personal responsibility and low seriousness condition. We assumed that perceivers would consider a cooperation with a target in a highly serious condition less realistic. Second, the design was extended with a healthy target. In our opinion, our study would give a fuller picture of perceivers' reactions to patients' coping, if we could also compare perceivers' reactions to 
persons with HIV with their reactions to a healthy target. Third, a substantial number of questions was added to our questionnaire, measuring intentions of pro-social behavior towards the target. In addition, physical distance to the target was measured as well, using a behavioral measurement. Finally, we decided to recruit participants from a local community, in order to be better able to generalize our results.

In this third study, we first investigate gender differences in perceivers' reactions to patients with HIV who convey distress. Again, we predict that women respond with stronger feelings of pity, whereas men will react with stronger feelings of anger. In addition, we expect a similar pattern of results on our measurements of pro-social behavior: We expect that women will report stronger prosocial behavior to persons with HIV who convey distress, whereas men will report less pro-social behavior. The present study also examines differences in reactions towards targets with HIV and healthy targets. On the basis of research in the field of HIV-related stigmatization (Crocker, Major \& Steele, 1998; Dijker. Kok \& Koomen, 1996; Weiner et al., 1988) we expect that people respond with stronger fear, anger and stigmatization to a target with HIV than to a healthy target. Finally, we also examine the effect of 'active coping' on perceivers' emotional and behavioral reactions. Once more, we predict that an active coping portrayal results in stronger feelings of pity and less feelings of anger. Similarly, we expect that active coping will also lead to stronger pro-social behavior and a reduction of stigmatizing reactions.

\section{METHOD}

\section{Selection of participants}

A list of addresses of residents of Maastricht, a moderately large city in the Netherlands, was drawn at random from a database of the Dutch National Telephone Company. A letter was sent to these households, informing about the alleged purpose of the study and announcing that they could be called soon with the request to participate in this study. The study was introduced in the letter as research on 'cooperation and first impressions', in which the participants would cooperate with another person who could have a different social, cultural or medical background. The letter also stated that the study would last for approximately one hour and that participants would be paid the equivalent of $\$ 10$ for their participation. One week later co-workers from Maastricht University called the people on the list and tried to make an appointment with them. If people were willing to make an appointment, the prospective participants were asked to mention their age and highest level of education. This information was recorded so that participants could in advance be stratified over all conditions on the basis of age and educational level12. 
Hundred thirty-six persons participated in this study. Eighty-four participants were male and 52 participants were female. The mean age of the participants was 48.7 years $(S D=11.4)$. Thirty-one percent of the participants had a low, 36 percent a medium and 33 percent a high level of education.

\section{Procedure}

The experiment was conducted in the social sciences laboratory, which is adjacent to the academic hospital. Every hour one participant was scheduled. The experimenter welcomed the participants and explained the alleged goal and procedure of the study. Participants were told that they participated in a study on 'cooperation and first impressions'. The experimenter explained that they would first listen to an interview with Michael, their prospective interaction partner, in order to form a first impression of him. Then they would fill in a questionnaire about their initial reactions to Michael and their future cooperation with him. Subsequently they would go to another room where they would actually meet Michael. The experimenter explained that they would first have an acquaintance conversation. Then they would play with Michael at shuffleboard. The experimenter told that the rules of play were somewhat changed and that they had to throw shuffling discs in turns. Participants were told that they would form a team with Michael and that the best team in this study would win $\$ 40$. The experimenter told that the participants had to fill in a second questionnaire after the cooperation with Michael. This questionnaire would measure their secondary reactions to Michael and would evaluate the cooperation with him.

After the explanation of the procedure, participants listened to the bogus interview with Michael. This interview contained the experimental manipulation. Hereafter they filled in a questionnaire, which measured emotional and behavioural reactions towards Michael. Then participants were taken to the other room, where a shufflingboard was set up and a jacket and plastic bag were placed on the right end of a row of six chairs. The experimenter remarked that personal belongings of Michael were placed on one of the chairs and concluded that Michael apparently went to the toilet. After this observation, he requested the participants to get seated on one of the chairs, in anticipation of Michaels' return. As soon as the participant sat down, the seating position was recorded and the experiment was interrupted. The experimenter informed whether the respondents believed that they would actually meet Michael, which was the case for all participants. Finally participants were debriefed.

\section{Manipulations}

There were four versions of the taped interview with the target person (HIV: conveying distress, HIV: active coping. HIV: no information about coping, Healthy target). All tapes were recorded by the same male co-worker. For the HIV conditions the content of the interview was similar to Study 5.2. Michael provided ge- 
neral background information about himself, explained that he had low personal responsibility for the onset of the disease and indicated that his medical condition was fairly good. Subsequently, coping with HIV was manipulated (conveying distress, active coping or no information about coping).

In the healthy condition, Michael provided the same general background information and indicated that he visited the ear, nose and throat doctor in the hospital some months ago. He explained that his ears were stuffed up a bit and that the docter had succesfully syringed his ears. He emphasized that he has a sharp sense of hearing again and that he is healthy at present. We deliberately manipulated the healthy target in such a way that he had an innocent medical complaint in the past, in order that the items in the questionnaire would be applicable to the HIV conditions as well as the healthy condition.

\section{Dependent measures}

The questionnaire contained questions about participants' emotional and behavioral reactions to the anticipated cooperation with Michael. First, emotional reactions were measured, using the same questionnaire as in Study 5.2. Again, scales were formed for fear (Cronbach's alpha $=.93)$, pity $(C r o n b a c h ' s ~ a l p h a=.83)$ and anger (Cronbach's alpha $=.77$ ), combining the same items as in Study 5.2. The emotional reactions were measured on a 7 -point scale ( $1=$ not at all, $7=$ very much).

Subsequently, different intentions to display pro-social behavior were measured. Participants had to indicate on two VAS scales (each ranging from 3 to 20 minutes) how much time they would like to spend on the acquaintance conversation and the cooperation. The sum of the answers on both questions will be referred to as minutes of cooperation. Then respondents were asked to indicate topics that they would like to discuss with Michael during the acquaintance conversation. The number of discussion topics was recorded. Further respondents were asked to what extent they were willing to lend an ear to Michael. This type of emotional social support was measured on a 7-point scale. Respondents were also asked three questions about their willingness to support Michael in a more instrumental way (e.g. give him a glass of water when he would be coughing). These items, measured on a 7-point scale, were combined into one scale of instrumental social support (Cronbach's alpha $=.75$ ). The end of the questionnaire consisted of four questions checking the effectiveness of our manipulations of conveying distress and active coping. Each manipulation check contained the combination of the scores on two questions (Cronbach's alpha .76 for 'conveying distress' and .77 for 'active coping').

Finally, we used a similar procedure as Macrae, Bodenhausen, Milne and Jetten (1994, Study 2) to measure physical distance, which can be seen as a behavioral expression of stigmatization. Respondents were taken to another room, where a row of six chairs was set up. A jacket and plastic bag were placed on the first seat and the experimenter explained that these were personal belongings of Michael. The experimenter told that Michael apparently went to the toilet and asked the respondents to sit down on one of the seats. The seating position was noted by 
the experimenter $(1=$ seat located next to personal belongings, 5 = seat located on other end of the row).

\section{RESULTS}

\section{Manipulation checks}

The manipulation checks of conveying distress and active coping were each subjected to a 3 (Coping with HIV: Conveying distress vs. active coping vs. no information about coping) x 2 (Gender of participant: male vs. female) ANOVA. Both analyses revealed the expected main effects. The tanget was judged as conveying more distress in the conveying distress condition $(M=4.74)$ than in the active coping condition $(M=2.81)$ or the control condition $(M=2.05), F(2,99)=54.94, p<$ .001 . Post-hoc analyses show that the differences between the conveying distress condition and the other two conditions are significant. The target was seen as coping most actively in the active coping condition $(M=6.25)$, followed by the control condition $(M=5.84)$ and the conveying distress condition $(M=5.44), F(2,98)=$ $6.76, p<01$. However, post-hoc analyses show that the active coping condition only differs significantly from the conveying distress condition. To our opinion, the active coping manipulation is indeed judged as intended, since the mean of the active coping manipulation is almost at the top of the scale. Nevertheless, it seems that participants in the control condition assumed that the target with HIV copes actively with his disease, although this information was not provided.

\section{Emotional and behavioral reactions}

A priori contrasts were calculated to test our specific hypotheses. First, we tested the effect of 'conveying distress' on emotional and behavioral reactions in male and female perceivers. The weight ' -2 ' was assigned to the 'conveying distress' condition, whereas the weights ' 1 ' were assigned to the other HIV conditions and ' 0 ' to the healthy target condition. Table 5.4 reports the results of these analyses. Consistent with our predictions, women reported stronger pro-social behavior to a person with HIV who was conveying distress. Women were more willing to provide emotional social support $(t(46)=2.31, p<.05)$, reported more discussion topics $(t(48)=2.52, p<.05)$ and were inclined to spend more time $(t(46)=$ $1.85, p=.07$ ) when the target with HIV conveyed distress. These positive behavioral effects of conveying distress were not found for male perceivers. In contrast with our hypotheses, we did not find significant gender differences in emotional reactions to patients with HIV who convey distress. However, the pattern of the means is in the predicted direction, with women reporting stronger pity and lower anger to patients who convey distress. 
Table 5.4 Means, standard deviations and contrast analyses for emotional and behavioral reactions (Study 5.3)

Dependent variables

Condition

T-values of contrasts

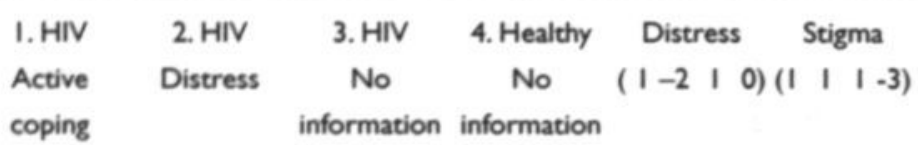

Fear

\begin{tabular}{cccccccc} 
Women & $M$ & 3.14 & 3.21 & 2.50 & 2.33 & 0.68 & 1.16 \\
& SD & 1.42 & 1.87 & 1.55 & 1.76 & & \\
& $N$ & 14 & 13 & 12 & 13 & & \\
\multirow{6}{*}{ Men } & $N$ & & & & & & \\
& $M$ & 2.82 & 2.35 & 2.65 & 1.89 & 1.15 & $2.12^{*}$ \\
& SD & 1.20 & 1.29 & 1.43 & 1.16 & &
\end{tabular}

Pity

\begin{tabular}{cccccccc} 
Women & $M$ & 5.00 & 5.56 & 5.17 & 3.68 & 1.42 & $4.70^{\text {*** }}$ \\
& SD & 1.01 & 0.98 & 0.92 & 0.96 & & \\
& $N$ & 14 & 12 & 12 & 11 & & \\
\multirow{6}{*}{ Men } & & & & & & & \\
& $M$ & 4.95 & 5.15 & 5.01 & 3.61 & 0.60 & $5.14^{* * *}$ \\
& SD & 0.95 & 1.14 & 1.03 & 1.18 & &
\end{tabular}

Anger

\begin{tabular}{cccccccc} 
Women & $M$ & 2.29 & 1.35 & 1.88 & 1.81 & 1.41 & 0.06 \\
& SD & 1.71 & 0.55 & 1.46 & 2.00 & & \\
& $N$ & 14 & 13 & 12 & 13 & & \\
\multirow{6}{*}{ Men } & & & & & & & \\
& $M$ & 2.03 & 1.84 & 2.00 & 1.47 & 0.53 & 1.49 \\
& SD & 1.24 & 1.24 & 1.36 & 1.07 & & \\
& N & 20 & 22 & 22 & 19 & &
\end{tabular}

Seating position

\begin{tabular}{|c|c|c|c|c|c|c|c|}
\hline \multirow[t]{3}{*}{ Women } & $M$ & 2.36 & 2.54 & 2.42 & 2.58 & 0.58 & 0.58 \\
\hline & SD & 0.50 & 0.78 & 0.90 & 0.90 & & \\
\hline & $N$ & 14 & 13 & 12 & 12 & & \\
\hline \multirow[t]{3}{*}{ Men } & $M$ & 2.95 & 2.77 & 2.86 & 2.33 & 0.58 & $2.29 *$ \\
\hline & SD & 0.85 & 0.81 & 0.94 & 0.84 & & \\
\hline & $\mathrm{N}$ & 19 & 22 & 22 & 18 & & \\
\hline
\end{tabular}




$\begin{array}{lccccc}\text { I. HIV } & \text { 2. HIV } & \text { 3. HIV } & \text { 4. Healthy } & \text { Distress } & \text { Stigma } \\ \text { Active } & \text { Distress } & \text { No } & \text { No } & \left(\begin{array}{llll}1 & -2 & \mid & 0\end{array}\right)\left(\begin{array}{llll}1 & \mid & 1 & -3\end{array}\right) \\ \text { coping } & & \text { information information }\end{array}$

Minutes of cooperation

\begin{tabular}{cccccccc} 
Women & M & 27.25 & 29.06 & 23.47 & 27.33 & $1.85 \#$ & 0.39 \\
& SD & 7.02 & 5.37 & 3.03 & 6.62 & & \\
& N & 13 & 13 & 11 & 13 & & \\
& & & & & & & \\
\multirow{6}{*}{ Men } & M & 24.48 & 26.39 & 24.86 & 26.03 & 0.92 & 0.43 \\
& SD & 5.52 & 6.43 & 6.46 & 8.79 & & \\
& N & 18 & 21 & 20 & 19 & &
\end{tabular}

Numer of discussion topics

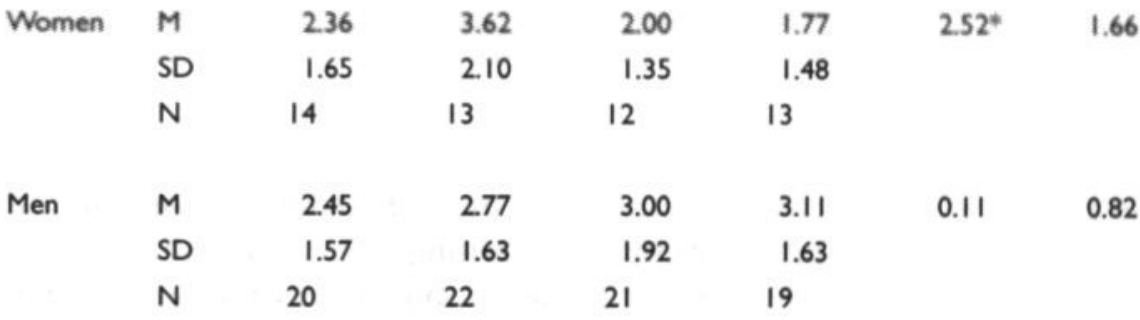

Emotional social support

\begin{tabular}{cccccccc} 
Women & M & 5.77 & 6.50 & 5.83 & 6.38 & $2.31^{*}$ & 1.26 \\
& SD & 1.09 & 0.52 & 0.72 & 0.96 & & \\
& N & 13 & 12 & 12 & 13 & & \\
& & & & & & & \\
\multirow{6}{*}{ Men } & $\mathrm{M}$ & 5.80 & 6.14 & 5.95 & 5.95 & 0.88 & 0.05 \\
& SD & 1.24 & 0.64 & 0.90 & 1.54 & & \\
& $\mathrm{~N}$ & 20 & 22 & 22 & 20 & &
\end{tabular}

Instrumental social support

\begin{tabular}{|c|c|c|c|c|c|c|c|}
\hline \multirow[t]{3}{*}{ Women } & $M$ & 6.36 & 6.58 & 6.19 & 6.33 & 1.11 & 0.17 \\
\hline & SD & 0.89 & 0.49 & 0.89 & 0.80 & & \\
\hline & $N$ & 13 & 12 & 12 & 12 & & \\
\hline \multirow[t]{3}{*}{ Men } & $M$ & 5.75 & 6.14 & 6.29 & 6.43 & 0.45 & 1.48 \\
\hline & SD & 1.11 & 1.20 & 0.91 & 0.63 & & \\
\hline & $\mathrm{N}$ & 20 & 22 & 22 & 20 & & \\
\hline
\end{tabular}

Note \# $p<.10, * p<.05, * * p<.01$. 
Second, we tested our specific predictions concerning different emotional and behavioral reactions to persons with HIV and healthy persons (separately for male and female perceivers). The weight ' -3 ' was assigned to the healthy target condition, whereas the weight ' 1 ' was assigned to the three HIV conditions. A target with HIV evoked stronger feelings of pity than a healthy target in both women $(t(45)=4.70, p<.01)$ and men $(t(79)=5.14, p<.01)$. However, men responded in a more stigmatizing manner to a target with HIV than to a healthy target. They reported stronger fear for a target with $\operatorname{HIV}(t(78)=2.12, p<.05)$ and sat at greater distance from a target with $\operatorname{HIV}(t(77)=2.29, p<.05)$.

Finally, we tested the influence of 'active coping' on emotional and behavioral reactions, by comparing the active coping condition with the other conditions. The weight '-2' was assigned to the 'active coping' condition, whereas the weights ' 1 ' were assigned to the other HIV conditions and ' 0 ' to the healthy target condition. Contrary to our expectations, no significant differences were found on any of our dependent measures.

\section{DISCUSSION}

The present study investigated emotional and behavioral reactions to patients' coping with HIV in a realistic experimental setting. This study demonstrates once more that men and women respond differently to patients who convey distress. In particular, women were willing to provide most emotional social support and to discuss most topics with a patient who conveyed distress. These forms of prosocial behavior appeal to perceivers' emotional sensitivity and communal attributes, qualities that are generally considered as belonging more to the female than to the male gender role. These findings corroborate our previous studies and results of Eagly and Crowley (1986), who found that women are in general helping more in a nurturing way. Contrary to our expectations, the present study did not reveal significant gender effects of conveying distress on emotional reactions, although the pattern of the means was in the predicted direction. The absence of significant effects may in part be attributable to the relatively low number of female participants in each cell. Another possible explanation is the heterogeneity of our sample. For instance, it may be possible that older people have developed better coping skills to deal with their emotions in interactions with seriously ill patients than younger people. Our data suggest that this may indeed be the case for female participants who anticipate interaction with a person with HIV: Pearson correlations show that older women report less fear $(r=-.32, p<.05)$ and stronger pity $(r=.47, p<.01)$. Conversely, age was not related to our measures of prosocial behavior and physical distance.

The present research also demonstrates that perceivers react differently to persons with HIV than to healthy persons. Persons with HIV seem to arouse stronger feelings of pity in perceivers, compared to healthy persons. This finding is consis- 
tent with work of Dijker and Reaijmaekers (1999) who showed that serious diseases evoke stronger feelings of pity in perceivers. Our assumption that participants would report stronger stigmatizing reactions to persons with HIV than to healthy persons, was only supported for male perceivers. Men reported more fear for HIV-infected persons and sat further away from a target with HIV than a healthy target. Perhaps, men take instrumental considerations (e.g. contagiousness of HIV) into account in their interaction with persons with HIV.

Similar to our second study, we were unable to demonstrate favourable effects of active coping on perceivers' emotional reactions. Likewise, our third study did not reveal positive effects of active coping on perceivers' behavioral reactions. In the general discussion we will pay more attention to the absence of favourable effects of active coping. To conclude, the outcomes of the present study suggest that persons with HIV who convey distress may evoke prosocial reactions in female perceivers. However, male perceivers seem less sensitive for such signs of distress and tend to base their reactions to a larger extent to disease characterics.

\section{GENERAL DISCUSSION}

Three studies examined the interpersonal consequences of patients' coping behavior on perceivers' reactions, using different research methods and various outcome measures. These studies support the notion that men and women react differently to ill persons who convey distress. In all three studies women responded in a prosocial way to patients with HIV who convey distress, whereas men reacted in a more negative manner. As we argued before, these findings are consistent with gender role theory (Eagly, 1987), which assumes that sex differences in social behavior are partly caused by people's tendency to behave consistently with their gender roles (Eagly, 1987; Eagly \& Wood, 1991). Patients who convey distress seem to appeal to the female gender role, which consists of communal aspects, such as being friendly, concerned with others and emotionally expressive. In contrast, patients who convey distress seem to oppose to the male gender role, which contains agentic aspects, including independence, being masterful and being instrumentally competent.

However, another possible explanation for our gender differences is still not ruled out. Although it seems obvious that our gender differences reflect actual differences between male and female perceivers, it might still be possible that these gender differences refer to the appropriateness of the behavior of our male target. In other words, it might be possible that female perceivers respond positively to the fact that a male patient displays behavior that is inconsistent with his male gender role. Conversely, male perceivers might respond negatively, because they consider it inappropriate that the male target shows behavior that is opposed to his male gender role. Future research should address this issue by varying the gender of the target as well. Anyhow, our findings illustrate the importance of 
close examination of gender differences in helping behavior and social support provision, recognizing that men and women may respond in different ways.

The results of our studies extend previous findings of Silver, Wortman and Crofton (1990) with regard to conveying distress. Silver, Wortman \& Crofton (1990) reported that female respondents reacted negatively to a female patient who displayed poor coping and high levels of distress. Our first study demonstrates that perceivers indeed consider pityful and negative behavior as undesirable coping. However, our second and third study reveal that a mild form of conveying distress may trigger prosocial reactions in female perceivers. Thus, displaying some distress in social interaction might be a cue for prosocial reactions in women. Nevertheless, male perceivers seem to respond negatively to even small amounts of distress.

Interestingly, one might argue that our effects on 'conveying distress' resemble the favourable effects on 'balanced coping' in the Silver et al. (1990) study. Their manipulation of 'balanced coping' apparently consisted of lower levels of distress, compared to their 'poor coping' condition. Furthermore, their respondents (who were all female) reacted in a prosocial manner to these lower levels of distress. Although prosocial reactions may result from the combination of conveying distress and indicating that one's coping well, it might be argued that communicated distress was crucial in triggering prosocial reactions in female participants.

Contrary to previous studies (Schwarzer \& Weiner, 1991; Silver, Wortman \& Crofton, 1990), we were unable to demonstrate favourable effects of patients' active coping. In our experiments, active coping was presented as problemfocused coping (similar to Schwarzer \& Weiner, 1991). However, patients' emotion regulation may have a stronger impact on perceivers than patients' attempts to fight against the disease. Therefore, active emotion-focused coping may be of greater importance for perceivers than active problem-focused coping. Silver, Wortman and Crofton (1990) used an emotion-focused way of 'good' coping and found indeed positive effects on perceivers' reactions. The favourable effects of active problem-focused coping in the Schwarzer and Weiner (1991) study are difficult to interpret, for they compared active coping with an extremely negative presentation of passive coping. In sum, the specific interpersonal consequences of both active emotion-focused and active problem-focused coping certainly deserve closer attention in future research.

It is important to remember that the generalizability of our results is limited to brief initial encounters with strangers. The influence of patients' coping may be different in longer-lasting contact or in personal relationships with partners, relatives or friends. Conveying distress, for example, may serve as a cue for prosocial reactions in female perceivers in initial contact, but may have opposite effects in the long-term. If patients repeatedly confront others with signs of distress, they may convey too much distress or may be perceived as behaving pitiful, resulting in negative responses from others. Recently, Kuijer et al. (2000) reported a study 82 on social support provision by intimate partners of patients with cancer. They found that intimate partners show more active engagement, if patients are more distressed and partners think that the patient is coping better with the cancer. These results suggested that cancer patients may display signs of distress to get 
their partners' positive attention, as long as they communicate to their partner that they try to cope with the situation (Kuijer et al., 2000). More research is needed to investigate the effects of patients' coping in closer relationships and to examine the effects of patients' coping in longer-lasting social interactions. In addition, the current results should be replicated for other illnesses and future research should examine the interpersonal consequences of other ways of coping as well.

In everyday life seriously ill persons encounter various situations in which they meet relative strangers (e.g. in the workplace, neighbourhood or hospital). In such interaction contexts, people's reactions are to a large extent based on first impressions and stigmatizing reactions are likely to occur. The present studies contribute to our understanding of reactions to patients' coping in social interaction with strangers, a research area that has received surprisingly little attention in the field of health psychology. In addition, our findings shed additional light on the self-presentational dilemma of patients. Our first study suggests that patients are likely to receive negative reactions when they overwhelm perceivers with signs of distress. However, conveying some distress may have positive consequences on emotional and behavioral reactions of women, but not for men. 


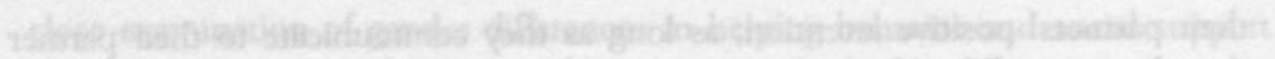

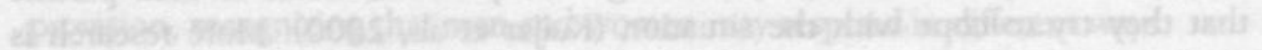

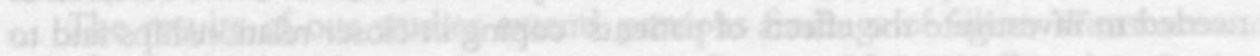

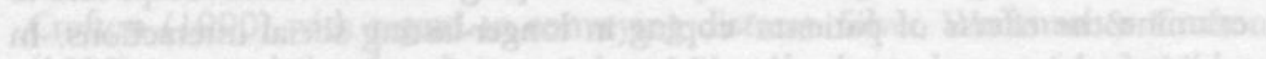

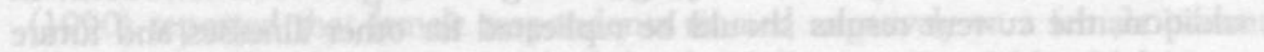

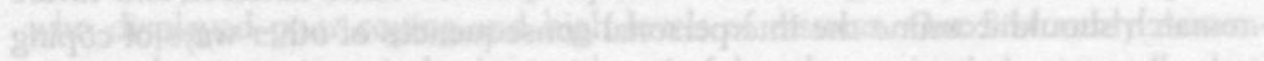

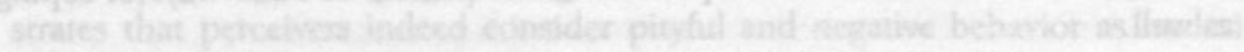

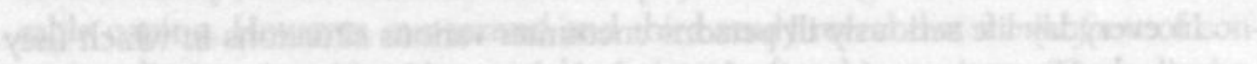

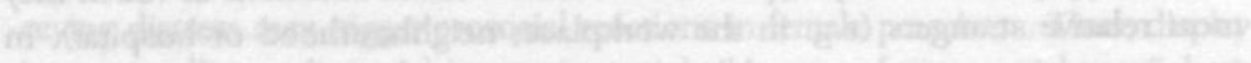

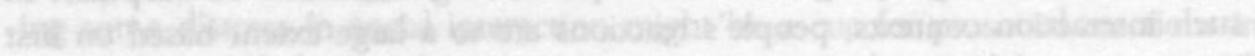

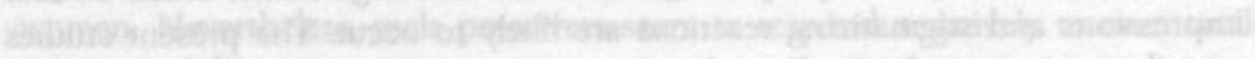

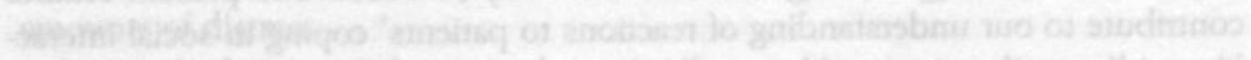

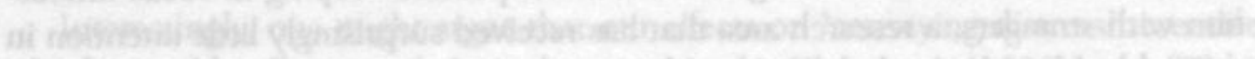

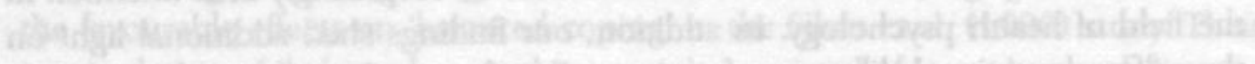

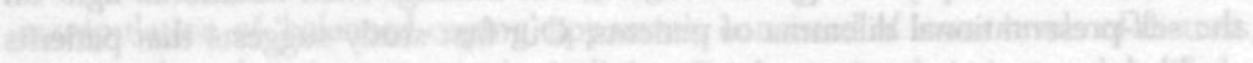

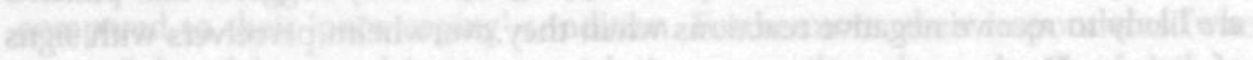

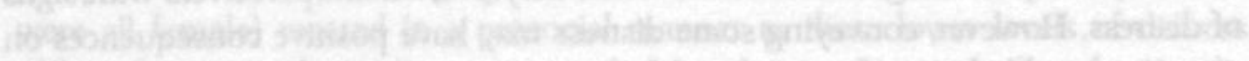

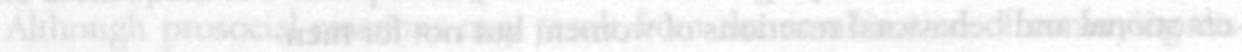

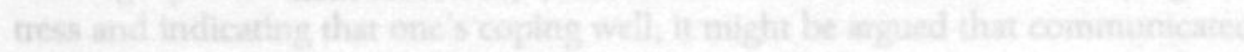
dhetross was grucuat in

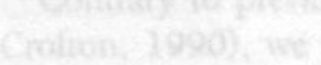

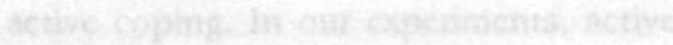

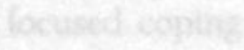

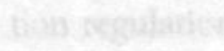

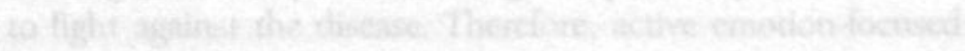

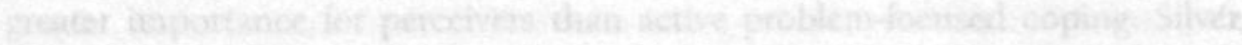

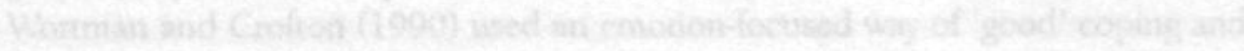

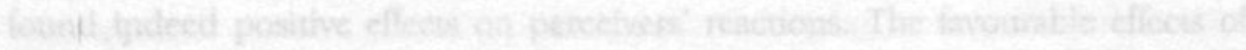

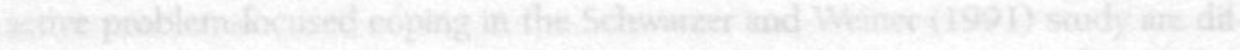

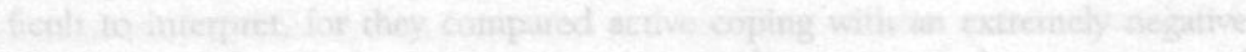

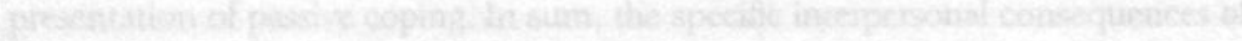

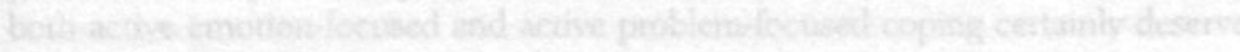

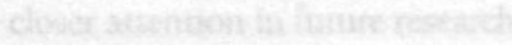

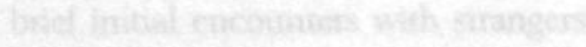

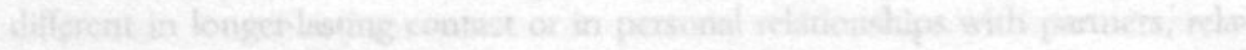

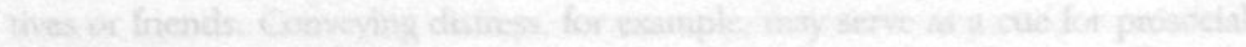

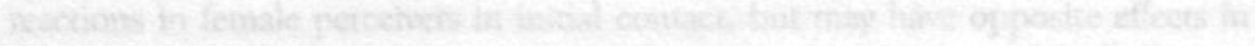

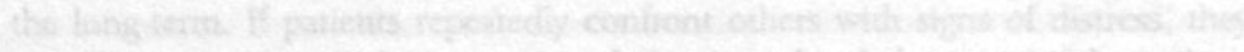

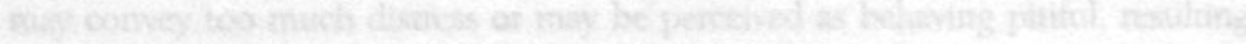




\section{CHAPTER 6}

REDUCING FEAR OF PEOPLE WITH HIV: THE IMPACT OF PREDICTABLE BEHAVIOR AND REASSURING INFORMATION

Submitted for pubication as:

Bos, A. E. R., Dijker,A. J., \& Reuvekamp, M.A.J. (200I). Reducing Fear of People with HIV: The Impact of Predictable Behavior and Reassuring Information. Manuscript submitted for publication. 


\section{INTRODUCTION}

Research on illness representations has revealed that contagiousness and seriousness of disease are the two primary dimensions that lay people use to categorize and interpret diseases (Bishop, 1991a; 1991b). Human Immunodeficiency Virus (HIV) is categorized among the contagious and serious medical conditions. These illness representations have important implications for social reactions towards ill persons. Bishop (1991a) found that contagiousness of disease was a primary determinant of willingness to interact with disease victims. Research in the field of HIV stigma has also revealed that the contagiousness of HIV is an important determinant of stigmatizing reactions towards persons with HIV (Dijker et al., 1996; Herek \& Capitanio, 1998).

Fear is the central emotion that mediates the relationship between perceived contagiousness and behavioral responses to persons with HIV (Dijker et al., 1996; Dijker \& Koomen, 1996). Fear is an emotional response to the appraisal of a concrete and sudden threat that involves physical harm, death or injury (Izard, 1991; Lazarus, 1991; Rosen \& Schulkin, 1998). This adaptive response motivates people to relieve their negative emotional state and adapt defensive behaviors, such as escape or flight (Rosen \& Schulkin, 1998). As mentioned above, HIV is a life-threatening medical condition that is often mistakenly perceived as contagious in everyday contact. Thus, interpersonal contact with a person with HIV may be appraised as a dangerous situation and may motivate a need for safety in perceivers. As a result, fear instigates an action tendency to avoid personal contact and keep one's distance (Frijda, 1986).

Stigmatization may have far-reachting negative consequences for persons with HIV. It may lead to the disruption of personal and social relationships (Herek, 1999; Leary \& Schreindorfer, 1998), and may also have detrimental consequences for the psychological well-being of persons with HIV (Crandall \& Coleman, 1992; Leary $\&$ Schreindorfer, 1998). Throughout the past twenty years, mass-media information campaigns have been launched to reduce stigmatization and fear, and increase prosocial reactions to and compassion for people with HIV in the general public (see for example Kok et al., 1998). Such campaigns have played an important role in informing the general public about HIV transmission. However, the effect of such campaigns on people's actual emotional and behavioral reactions to persons with HIV is unknown. It is conceivable that people are fearful in their initial encounters with persons with HIV, despite the fact that they are well-informed about HIV transmission. This illustrates the importance of examining people's emotional and behavioral reactions to persons with HIV in initial encounters and of investigating strategies that persons with HIV may adopt to reduce perceivers' fear or stigmatization. The present paper investigates the impact of two different fear reduction strategies, namely displaying predictable behavior and providing reassuring information. 
Research on fear dispositions and phobias has shown that cognitive representations of feared objects contain information about target's predictability (Dijker et al., 1997). For example, Merckelbach and colleagues (1987) found that fear ratings of a number of animals were correlated with ratings of unpredictability. Amtz et al. (1993) examined spider-related beliefs in spider phobics. Factor-analysis on the Spider Phobia Beliefs Questionnaire revealed that 'unpredictability and speed' was one of the five spider-related factors. This factor refers to items such as 'is incalculable', 'is uncontrollable' and 'runs very fast'. Information about target's predictability seems particularly relevant to fearful persons, because an unpredictable target may interfere with their need for safety.

Target's predictability is closely related to Riskind and Maddux's (1993; 1994) concept of loomingness. This term refers to 'perceptions of rapid forward movement and instantaneous changes in distance and danger of a potential threat' (Riskind \& Maddux, 1994, p. 432). According to Riskind and Maddux (1994), perceptions of forward-looming movement evoke fear because a rapid visual approach of a stimulus can increase the apparent proximity of a potential threat. Riskind and Maddux (1994) examined the relationship between perceived loomingness and fear of HIV by comparing ratings of high and low HIV-fearful persons on a measure of perceived loomingness. Their study showed that people with high fear of HIV indeed perceived higher levels of loomingness in situations involving HIV than those having low fear.

\section{Attention for threatful stimuli}

Fearful persons tend to focus their attention on the stimulus that signals danger (Izard, 1991). Selective attention for threatful stimuli may serve as a mechanism to protect oneself, because it could facilitate a fast response. Cognitive experimental research has also shown that anxious people often have an attentional bias for threat-related stimuli (see Lavy (1993) for an overview). People with HIV may be seen as a potential threat by HIV fearful persons and may thus become the focus of other people's attention. Perceivers' need for staring may be even stronger when a person with HIV displays unpredictable behavior.

\section{Predictable behavior of persons with HIV}

Dijker et al. (1997) investigated the effect of predictable behavior of people with AIDS on perceivers' emotional and behavioral reactions. Students of secondary vocational education received a vignette about cooperation with a new colleague. Participants were asked to imagine that they worked at a community office involved in the planning of towns, and that they had to cooperate with another colleague on the development of a plan for a town. In the vignette, participants were informed about target's health status (Healthy vs. HIV) and sexual orienta- 
tion (homosexual vs. heterosexual). In addition, information was given about the predictability of target's behavior (low vs. moderate vs. high predictability). After reading the vignette, participants had to complete a questionnaire about their willingness to engage in different forms of indirect physical contact, emotional reactions and attention for the target. The results showed that participants were less willing to engage in indirect physical contact with a person with HIV than a healthy person, when this person behaved in an unpredictable manner. No differential reactions were found when the target displayed moderately or highly predictable behavior. Furthermore, the same pattern of results was found on the measure of fear, but only when male participants expected to work with a heterosexual target and female participants expected to work with a homosexual partner. Finally, participants reported a greater need to stare through the glass wall at a person with HIV than at a healthy person, when the target displayed unpredictable behavior. No differential reactions were found in the moderately or highly predictable conditions. The latter result seems consistent with the assumption that fearful persons have an increased attention towards fearful stimuli. The study of Dijker et al. (1997) shows that predictability information may influence emotional and behavioral reactions towards persons with HIV. However, their findings are based on a single study that has never been replicated. Furthermore, Dijker et al. (1997) investigated the effects of predictable behavior by means of vignettes and not in a real interaction context.

\section{STUDY 6.1}

The goal of our first study was to replicate Dijker et al.'s study in a real interaction context. In order to reduce the complexity of the design, we only examined women's reactions towards a heterosexual male interaction partner, who was either healthy or infected with HIV. Furthermore, we only manipulated two levels of predictability (low vs. high). The present study uses similar outcome measures as Dijker et al. (1997), such as emotional reactions, questions regarding the cooperation and need for staring at the target. Our main research interest, however, is the impact of predictable behavior on reported fear. We assume that predictable behavior will be particularly relevant to participants when the target is infected with HIV. We expect participants to respond with less fear towards a predictable target with HIV than to an unpredictable target with HIV. No differential reactions to predictability are expected when the target is healthy. A similar pattern of results is expected for perceived pleasantness of the cooperation and need for staring at the target. We expect that perceivers anticipate cooperation with an unpredictable target with HIV as least pleasant and have the greatest need to stare at an unpredictable target with HIV. 


\section{Participants}

Partcipants were 55 female undergraduate students, who received the equivalent of $\$ 5$ for their participation. The average age of the participants was 19.42 years $(S D=1.32)$. Three additional participants were excluded from data analysis because they had doubts about the veracity of our manipulation. Participants were randomly assigned to the cells of a 2 (Health status: Healthy vs. HIV) $\times 2$ (Predictability: Predictable behavior vs. Unpredictable behavior) experimental design.

\section{Procedure}

The experiment was conducted in the psychology laboratory. The experimenter welcomed the participants and explained the alleged purpose of the study. Participants were told that the research concerned 'cooperation and first impressions'. The experimenter explained that, first, they were to fill in a general information sheet with background information about themselves. Their future interaction partner (Martijn), who was told to be in an adjacent room with a colleague of the experimenter, was to fill in a general information sheet as well. Both information sheets were to be exchanged and participants were to read the information sheet of Martijn in order to form a first impression. Subsequently, participants were to fill in a questionnaire about their first impressions and attitudes towards the cooperation. After this, Martijn was to join them. The experimenter told the participants that they were expected to cooperate on a town-planning task and showed them a scale-model of a local city area $(1 \times 2 \mathrm{~m})$, which was placed on a table in the same room. He explained that the task consisted of rearranging this city area using lego, pins and colored cardboard, which represented houses, trees and different forms of land use. The experimenter told them there were no fixed guidelines for the town-planning task, but pointed out that the participants could try out some town-planning options before meeting Martijn. Finally, participants were asked to complete a second questionnaire about their impressions and evaluation of the cooperation upon completion of the task.

After the explanation of the procedure, participants completed their general information sheet and the experimenter went to the other room to exchange the information sheets. Upon his return, the participants read Martijn's information sheet, which contained the manipulation of health status (healthy vs. HIV). After that, the experimenter switched on a monitor and participants were told they were allowed to watch Martijn, while he was preparing for the town-planning task in the other room. These video pictures contained our manipulation of predictable behavior (predictable vs. unpredictable). After 60 seconds, the experimenter switched off the monitor and participants were asked to fill in the questionnaire about their first impressions of Martijn and attitudes towards the cooperation. Upon completion of the questionnaire the experiment was interrupted. 
The experimenter asked the participants whether they believed they would actually cooperate with Martijn, which was the case for all but three of the participants. Finally, participants were debriefed.

\section{Manipulations}

Health status (Healthy vs. HIV) was manipulated by means of a personal information sheet. In both conditions, Martijn was presented as a 28-year old man, who lived together with his girlfriend. He had studied economics and liked to go to the cinema and watch football on TV. The last question on the personal information sheet concerned 'particulars'. In the healthy condition, this question was answered with 'No particulars'. In the HIV condition, this question was answered with 'Infected with HIV. I've been on the combination therapy since 1997'.

Predictable behavior (predictable vs. unpredictable) was manipulated by means of video pictures. The actor on these video pictures was an art academy student experienced in acting. The video camera registered how the actor was using the scale-model, while preparing for the town-planning task. The actor had been instructed to bend forward and look at the scale-model, thus hiding his face from the viewer so that respondents would base their reactions on his behavior rather than his facial expression. In order to avoid other unwanted inferences, the actor was not wearing any conspicuous clothes. In both conditions, the actor had been instructed to move the houses on the scale-model. In the predictable condition, the actor moved the houses in a predictable, calm and self-controlled manner. In the unpredictable condition, however, the actor displayed more bodily movement and moved the houses in an unpredictable and impulsive way. The selection of the final version of the videotape was made by the researchers on the basis of correspondence with the concepts and credibility of the behavior.

\section{Pilot testing of the videotapes}

Nineteen female students participated in a pilot test of the videotapes. Their average age was 21.16 years $(S D=1.54)$. Nine students watched the 'predictable' videotape and rated the target on 20 different adjectives (e.g., dominant, impulsive, social), measured on a 7 -point scale $(1=$ not at all, $7=$ very much). Ten students watched the 'unpredicatable' videotape and rated the target on the same adjectives. Predictability was measured by combining the scores on the items calm, predictable, careful, self-controlled, impulsive and active (the latter two items were reversed coded), Cronbach's alpha $=.94$. Observers of predictable behavior rated the target as being more predictable $(M=5.19)$ than observers of unpredictable behavior $(M=2.25), F(1,17)=236.98, p<.001$. The videotapes showed the intended differences on predictability and could therefore be used in the experiment. 
The questionnaire contained questions about emotional and behavioral reactions to the cooperation with Martijn. First, emotional reactions were measured on a 7 point scale ( $1=$ not at all, $7=$ very much). Fear was measured by combining four different items, reflecting Dutch words with the meaning of slight fear (Cronbach's alpha $=.94)$. Pity was measured by combining two Dutch words with the meaning of pity $(r=.41, p<.01)$.

Second, participants answered questions about the cooperation. Participants were asked to indicate the expected pleasantness of nine different aspects of the cooperation task (e.g., 'discuss the town-planning task', or 'put houses on the scale-model'), measured on a 7 -point scale ( $1=$ very unpleasant, $7=$ very pleasant). Pleasantness of the task was measured by combining the nine aspects of the task (Cronbach's alpha $=.75$ ). In addition, participants were asked to indicate on a visual analogue scale (VAS) how much time they would like to cooperate with Martijn. Participants had to place a mark on a horizontal line of $100 \mathrm{~mm}$, labeled ' 10 minutes' at one end and ' 30 minutes' at the other.

Third, participants were asked to rate the target on 20 different adjectives. This list of adjectives was similar to the list of adjectives in the pilot test of the videotapes. Six items (calm, predictable, careful, self-controlled, impulsive and active, the latter two reversed coded) were averaged into a single measure of predictability (Cronbach's alpha $=.81$ ). In addition, four items (friendly, social, kind and unobtrusive) were combined into one measure of likeability (Cronbach's alpha $=.79$ ).

Fourth, two questions were concerned with staring at the target. First, participants were asked to what extent they would like to watch Martijn on the monitor for a couple of more minutes. This question was measured on a 7-point scale (1 $=$ not at all, $7=$ very much). Next, participants were asked to indicate on a VAS how many minutes they would like to watch Martijn on the monitor. They had to place a mark on a horizontal line of $100 \mathrm{~mm}$, labeled ' 0 minutes' at one end and ' 10 minutes' at the other.

Finally, two additional questions were asked to check the effectiveness of our predictability manipulation ('To what extent is Martijn working systematically?' and 'To what extent is Martijn behaving impulsively?, the latter question being reversed-coded). Both questions were averaged into a single manipulation check $(r=.72, p<.001)$.

\section{RESULTS}

Manipulation checks

The scale for predictability was subjected to a 2 (Predictability: Predictable vs. Unpredictable) $\times 2$ (Health status: Healthy vs. HIV) ANOVA. This analysis 
revealed the expected main effect for predictability. Persons in the predictable condition judged the target person as being more predictable $(M=4.71)$ than persons in the unpredictable condition $(M=2.81), F(1,54)=163.85, p<$ .001 . No other effects were found. The additional manipulation check of predictable behavior was also subjected to a 2 (Predictability) $\times 2$ (Health status) ANOVA. Again, the target was judged as more predictable in the predictable condition $(M=5.36)$ than in the unpredictable condition $(M=2.50), F(1,54)=$ $95.48, p<.001$. No other significant effects were found. Altogether, we can conclude that our manipulations have been induced successfully.

\section{Emotional reactions}

A 2 (predictability) $\times 2$ (Health status) ANOVA was performed on feelings of fear. Contrary to our expectations, no significant main or interaction effect was detected (see Table 6.1). However, a similar $2 \times 2$ ANOVA on pity revealed a significant interaction effect, $F(1,54)=5.97, p<.01$. As Table 6.1 shows, participants responded with the strongest degree of pity to the target with HIV who displayed predictable behavior.

\section{Cooperation}

The scale for pleasantness of the task was subjected to the same $2 \times 2$ ANOVA. However, this analysis did not reveal any significant main or interaction effect. A similar $2 \times 2$ ANOVA on minutes of cooperation revealed a significant main effect for health status, $F(1,53)=6.52, p<.05$. Participants were willing to spend more minutes on the town-planning task with the target with HIV $(M=21.93)$ than with the healthy target $(M=19.06)$. No other significant effects were found.

\section{Staring at the target}

The same 2 × 2 ANOVA was conducted on perceivers' need for staring at the target. This analysis revealed a significant interaction effect, $F(1,54)=5.43, p<$ .05 . Table 6.2 shows that participants feel the strongest need to stare at the predictable target with HIV and the unpredictable healthy target. In a similar vein, the number of minutes that participants would like to stare at the target was subjected to a $2 \times 2$ ANOVA. Again, a significant interaction effect was found, $F(1,54)=10.03, p<.01$. The means and standard deviations of this interaction effect are also shown in table 6.2. Participants wish to stare for a relatively longer period of time at the predictable target with $\mathrm{HIV}$ and the unpredictable healthy 92 target.

In order to determine the underlying motivation for participants' need for staring, we calculated correlations between participants' need for staring, on the one hand, and predictability and likeability, on the other (separately for targets with 
Table 6.1 Perceivers' fear and pity as a function of target's predictable behavior and health status (Study 6.1)

Fear

$\begin{array}{llcc}\text { Healthy } & \text { M } & 2.89 & 3.31 \\ & \text { SD } & 1.51 & 1.34 \\ & \text { N } & 14 & 13 \\ \text { HIV } & & & \\ & \text { M } & 3.41 & 3.75 \\ & \text { SD } & 1.67 & 1.17 \\ & \text { N } & 14 & 14\end{array}$

Pity

$\begin{array}{llcc}\text { Healthy } & \text { M } & 3.71 & 3.96 \\ & \text { SD } & .93 & .78 \\ & N & 14 & 13 \\ \text { HIV } & \text { M } & 4.67 & 3.61 \\ & \text { SD } & .64 & .96\end{array}$

Table 6.2 Perceivers' staring as a function of target's predictable behavior and health status (Study 6.1)

Need for staring

$\begin{array}{llcc}\text { Healthy } & \text { M } & 2.64 & 4.00 \\ & \text { SD } & 1.60 & 1.87 \\ & \text { N } & 14 & 13 \\ \text { HIV } & & & \\ & \text { M } & 3.79 & 3.07 \\ & \text { SD } & 1.37 & 1.73 \\ & \text { N } & 14 & 14\end{array}$

Number of seconds staring

Healthy 
HIV and for healthy targets). The results show that participants' need to stare at a target with HIV is positively related to the perceived likeability of this target $(r=$ $.38, p<.05)$. In contrast, participants need to stare at a healthy target was negatively related with perceived likeability $(r=-.42, p<.05)$ and negatively associated with perceived predictability $(r=-.49, p<.05)$. These results suggest that staring at a target with HIV may be particularly related to prosocial motives. Conversely, perceivers seem to feel a stronger need to stare at a healthy target when this person is perceived as unkind and unpredictable. Nevertheless, these results are still somewhat inconclusive, because we failed to find a similar pattem of significant correlations for fear and pity.

\section{DISCUSSION}

The present study investigated emotional and behavioral reactions to predictable behavior of persons with HIV. Our experiment failed to provide evidence for the assumption that predictable behavior of persons with HIV reduces fear in initial contacts with strangers. However, predictable behavior of persons with HIV did have another favourable effect. Our female respondents reported the strongest degree of pity for the person with HIV who displayed predictable behavior.

A possible explanation for these findings is the assumption that need for safety may not be a primary concern for female students in their contact with persons with HIV. This notion is supported by the results on the cooperation questions. The town-planning task was rated equally pleasant for participants who anticipated contact with a target with HIV and participants who expected social interaction with a healthy target. Remarkably, participants were even willing to spend more time with a target with HIV than with a healthy target.

Our data seem to suggest that the prospect of meeting a person with HIV has evoked a prosocial motivation in our female participants. HIV, as a serious medical condition, may appeal to a need to support the other person and respond in a prosocial manner. These behaviors are generally considered to belong to the female gender role. According to gender role theory (Eagly, 1987; Eagly \& Wood, 1991), gender differences in social behavior in part result from people's inclination to behave consistent with their gender role. The female gender role consists of communal attributes such as friendly, nurturing and caring for others. Eagly and Crowley (1986) indeed showed that the female gender role encourages helping behavior that is caring and nurturing. As mentioned previously, female respondents reported greatest pity for our predictable target with HIV. One might argue that unpredictable behavior of persons with HIV may hamper communication and interfere with participants' need to help. Conversely, calm and predictable behavior may make it easier for other persons to provide support. Thus, predictable behavior of persons with HIV may be consistent with a prosocial motivation in female perceivers. 
The present study also examined participants' need for staring. In contrast to our expectations, participants did not report the greatest need to stare at the unpredictable target with HIV. However, participants were willing to stare for the longest time at the predictable target with HIV and the unpredictable healthy target. Additional analyses of this effect lead us to suggest with some caution that perceivers' need to stare at the predictable target with HIV may have resulted from prosocial motivation, while the need to stare at the unpredictable healthy target may be caused by a more negative motivation.

\section{STUDY 6.2}

Study 6.1 has investigated perceivers' responses to predictable behavior of persons with HIV. It was asumed that this implicit behavioral strategy would meet participants' need for safety. It is conceivable, however, that persons with HIV may also consider other people's need for safety in a more explicit manner. Therefore, a cecond chudy wac earried aut to invectigate whether the provicion of reassuring information would reduce fear responses in female participants.

The provision of reassurance seems an interpersonal strategy that is frequently used to reduce other people's worries or fear. For example, O'Shea et al. (1991) examined how senior dental students coped with fearful patients. This study showed that giving reassurance was the most prominent strategy used. In a similar vein, Weijts et al. (1991) found that immediate reassurance was one of the responses of gynecologists to patients' anxiety during gynecological consultations. The impact of reassuring information on actual fear responses has received limited research attention. Young et al. (1993), however, examined the effect of reassurance on fear of AIDS. Students were asked to read magazine articles stressing low or high likelihood of contracting AIDS through casual contact, or a control article that did not discuss the topic of AIDS. Students in the reassuring condition (low likelihood of contracting AIDS) reported lower fear of AIDS than students in the alarming condition (high likelihood of contracting AIDS). This finding suggests that providing reassuring information might reduce fear of AIDS. But is reassurance also an effective fear reduction strategy in a real interaction context?

The second study examines the impact of reassurance on fear responses of female participants in a realistic experimental setting. It was predicted that participants would report less fear for a target with HIV provide reassuring information than for a target providing non-reassuring information. 


\section{Participants}

Forty-seven female undergraduate students were randomly assigned to the cells of a 2 (Health status: Healthy vs. HIV) $\times 2$ (Reassurance: Yes vs. No) experimental design. The average age of the participants was 19.40 years $(S D=1.62)$. The data of five additional students were excluded from data analysis, because they distrusted the veracity of our audio-taped manipulation. One student refused to continue with the experiment, when she discovered that she had to cooperate with a target with HIV. This student was immediately debriefed and dismissed. All participants received the equivalent of $\$ 5$ for their participation.

\section{Procedure}

The procedure of this study was similar to the first. Again, participants were led to believe that they participated in a study on 'cooperation and first impressions' and that they were to cooperate with another person. Once more, participants first filled in a general information sheet with background information about themselves. In contrast to the previous study, the experimenter also recorded a short interview with the participant on audiotape. This interview consisted of three general questions ('Can you tell something about yourself?', 'Do you like the town planning task?' and 'What position do you take up during the cooperation?'). These questions had been given to the participants in advance, which enabled them to prepare for the interview, in order to prevent that they would experience the interview in itself as a fear arousing experience. After the recording of the interview, the experimenter went to the other room to exchange the general information sheets and the audiotapes. Subsequently, participants read the information sheet of Martijn, which contained the manipulation of health status, and listened to the interview that had been held with him, which consisted of our manipulation of reassurance. Then participants were to fill in a questionnaire about their first impressions and attitudes towards the cooperation. After this, the experiment was interrupted, participants were asked about the veracity of the experimental design, and they were debriefed.

\section{Manipulations}

The manipulation of Health status (Healthy vs. HIV) was similar to the health status manipulation in our first study. Reassuring information (Reassurance vs. Non reassurance) was manipulated by means of an audiotaped interview with the target person. The same target person was used in both conditions. The target person was asked the same three questions as the participants in their interview. First, Martijn provided general information about himself, which was similar to the information on the general information sheet. Second, he indicated that he 
liked the town-planning task. Third, Martijn explained the position that he would take up during the cooperation. This answer was the manipulation of reassurance. In the reassurance condition, Martijn provided the following information: 'I realize that, in a moment, I will meet somebody that I have never met before. In such circumstances I find it important to estimate others' needs. If the other person would like to spend some time to get acquainted or would like to agree on a plan for our cooperation, we could do so. Anyway, 1 find it important to take others' needs into account during first contact, in order to have a pleasant cooperation'. In the non reassurance condition, Martijn answered: 'In general, I'm not so occupied with the position that I take up. Usually I follow my feelings and wait and see what happens. I think we should start right away with the town-planning task: then, as a matter of course, you get to know eachother better. I normally react impulsively towards new people and see how it works out. Actually, in initial cooperation, I'm not occupied with how my behavior affects other people's feelings'.

\section{Pilot testing of the audiotapes}

Thirty-four female undergraduates participated in a pilot test of the audiotapes. Their average age was 21.82 years $(S D=1.59)$. Participants were assigned to one of the following four conditions (HIV: reassurance; HIV: non-reassurance; Healthy: reassurance; Healthy: non-reassurance). Students listened to the tape and rated the target on the 20 adjectives that had also been used in the pilot testing of the videotapes in Study 6.1. The scores on the items calm, cautious, serious and predictable were combined into one scale measuring reassuring attributes (Cronbach's alpha $=.72$ ). Further, two questions were asked to check the effectiveness of our reassurance manipulation ('To what extent do you find the first information of Martijn reassuring?' and 'To what extent does Martijn indicate that he will take your feelings into account?', measured on a 7-point scale, $1=$ not at all, $7=$ very much). Both items were combined into one manipulation check $(r=.70, p<.001)$.

A 2 (Health Status) x 2 (Reassurance) ANOVA on the scale for reassuring attributes revealed the expected main effect for reassurance, $F(1,33)=21.13, p<$ .001 . Participants in the reassuring condition ascribed more reassuring attributes to the target $(M=5.03)$ than participants in the non-reassuring condition $(M=$ 4.02). No other significant effects were found. A similar $2 \times 2$ ANOVA on the combined manipulation check also revealed a significant main effect for reassurance, $F(1,33)=49.70, p<.001$. Participants in the reassuring condition rated the information about the target as more reassuring $(M=5.87)$ than participants in the non-reassuring condition $(M=4.25)$. No other significant effects were found. In sum, the results of our pilot study indicate that our two manipulations are perceived as intended. Therefore, the audio-taped manipulations could be used in the experiment. 


\section{Dependent measures}

The questionnaire was similar to the one used in the first experiment. First, emotional reactions were measured (Fear: Cronbach's alpha $=.94$; Pity, $r=.50, p<$ $.001)$.

Second, participants answered questions about the cooperation. Similar to the first study, pleasantness of the task was measured (Cronbach's alpha $=.88$ ). In addition, participants had to indicate on a VAS how much time they would like to spend on the acquaintance conversation with Martijn. This $100 \mathrm{~mm}$-long horizontal line was labeled ' 0 minutes' at one end and ' 10 minutes' at the other end. Likewise, participants had to answer on another VAS how much time they would like to spend on the town planning task. Participants had to place a mark on a $100 \mathrm{~mm}$ horizontal line, labeled ' 0 minutes' at one end and ' 30 minutes' at the other end.

Third, participants had to rate the target on the same list of 20 different adjectives that was used in the first experiment. Four items (calm, cautious, serious and predictable) were averaged into a single measure of reassuring attributes (Cronbach's alpha $=.72$ ). Further, two items (honest and reliable) were combined into one measure of honesty $(r=.60, p<.001)$.

Finally, two questions were asked to crieck tie eifecuveness or 'vur mantination ('To what extent do you find the first information of Martijn reassuring?' and 'To what extent does Martijn indicate that he will take your feelings into account?). Both questions were combined into a single manipulation check $(r=$ $.48, p<.001)$.

\section{RESULTS}

\section{Manipulation checks}

The manipulation check was subjected to a 2 (Health Status: Healthy vs. HIV) $\times 2$ (Reassurance: Yes vs. No) ANOVA. This revealed a significant main effect for reassurance, $F(1,45)=31.85, p<.001$. Participants in the reassurance conditions rated the information of the target as more reassuring $(M=6.30)$ than participants in the non-reassuring conditions $(M=4.92)$. No other effects were found. The same $2 \times 2$ ANOVA was performed on the scale for reassuring attributes, as an additional indication of the success of our manipulation. Once again, the predicted main effect for reassurance was found, $F(1,46)=11.24, p<.01$. Participants in the reassurance condition ascribed more reassuring attributes to the target $(M=4.70)$ than participants in the non-reassurance condition $(M=$ 4.05). No other effects were found. From these results we can conclude that our manipulation of reassurance has been induced successfully. 


\begin{tabular}{llcc}
\hline & & Reassurance & Non-reassurance \\
\hline Healthy & M & 3.57 & 2.40 \\
& SD & 1.27 & 1.14 \\
N & 11 & 12 \\
HIV & & 3.77 & 2.67 \\
& M & 1.15 & 1.31 \\
& SD & 12 & 12 \\
\hline
\end{tabular}

\section{Emotional reactions}

A 2 (Health status) $\times 2$ (Reassurance) ANOVA was performed on participants' reported fear. Contrary to our predictions, a significant main effect of reassurance was found in the opposite direction, $F(1,46)=10.26, p<.01$. Participants in the reassurance condition reported stronger fear $(M=3.67)$ than participants in the non-reassurance condition $(M=2.53)$. No other effects were found. Table 6.3 shows the means and standard deviations of reported fear for the four different conditions. A similar $2 \times 2$ ANOVA on pity revealed no significant results.

\section{Cooperation}

The scale for pleasantness of the task was subjected to the same $2 \times 2$ ANOVA, but revealed no significant effects. A 2 × 2 ANOVA on the number of minutes that participants would like to spend on the acquaintance conversation, revealed a significant main effect for reassurance, $F(1,46)=6.47, p<.05$. Participants in the reassurance condition were willing to spend more time on the acquaintance conversation ( $M=7.24$ minutes) than participants in the non-reassurance condition $(M=4.81$ minutes). No other effects were found. A similar $2 \times 2$ ANOVA on the number of minutes that participants would like to spend on the townplanning task did not reveal any significant effects. 


\section{DISCUSSION}

The second study did not reveal the predicted results with regard to fear reduction. It had been hypothesized in advance that participants would report less fear when the target would provide reassuring information. However, participants in the reassurance conditions reported stronger fear as compared to participants in the non-reassurance conditions.

How can we explain these counterintuitive results? One might argue that something was wrong with the manipulation of reassurance. However, the pilot test of the audiotapes and the manipulation check of Study 6.2 demonstrate that participants perceived the reassurance manipulation as intended. Another possible explanation is that participants suspected self-presentational motives in the reassuring condition. This might explain why participants felt more uncomfortable in the reassuring condition, despite the fact that they perceived the reassuring information correctly. However, a $2 \times 2$ ANOVA on the honesty scale shows a trend in the other direction, $F(1,46)=3.32 . p=.08$. The target in the reassuring conditions seems to be perceived as being more honest $(M=5.47)$ than the target in the non-reassuring conditions $(M=5.08)$. Thus, it seems unlikely that participants suspected self-presentational motives in the reassurance condition.

A plausible explanation for our findings is the assumption that the provision of reassuring information may have made the potential dangers of the interaction context salient. Similar to Study 6.1, our female students did not report differential reactions to cooperation with a person with HIV or a healthy target. Thus, it seems that participants' need for safety was not higher for a target with HIV than for a healthy target. The explicit focus on participants' needs in this novel interaction context, may have activated their safety concerns and increased their feelings of fear. This explanation is corroborated by the fact that fear reports in the reassurance condition were higher for both the healthy target and the target with HIV.

Our second study also revealed that participants were willing to spend more time on an acquaintance conversation in the reassuring conditions, as compared to the non-reassurance conditions. It should be noted, however, that this significant main effect might be due to our manipulation of non-reassurance. The target in the non-reassurance condition explicitly states that he would like to start with the town planning task right away. It may be conceivable therefore that respondents in the non-reassurance conditions responded according to this need of the target.

\section{GENERAL DISCUSSION}

The present studies investigated the impact of two strategies that persons with HIV may adopt to reduce perceivers' fear in initial encounters. It was assumed that interpersonal contact with a person with HIV would kindle a need for safety 
in perceivers. We expected this need for safety to be reduced if persons with HIV showed, in a more explicit or implicit manner, that they took other people's need for safety into account. Study 6.1 was designed to examine the impact of predictable behavior, an implicit behavioral strategy, on fear responses. In Study 6.2, we sought to investigate the effect of reassuring information, an explicit verbal strategy, on ratings of fear.

Contrary to our expectations, neither of the two studies revealed fear reducing effects. Yet, predictable behavior seems to have other favorable effects in interpersonal contact. Our female participants felt the strongest degree of pity for a predictable target with HIV. It is argued that they may have responded according to their female gender role (Eagly, 1987; Eagly $\&$ Wood, 1991) and that predictable behavior of persons with HIV is beneficial to female participants' need to provide support. In contrast, the provision of reassuring information, as investigated in Study 6.2, seems to have purely adverse interpersonal consequences. Our female respondents reported stronger fear towards targets that provided reassuring information. It seems that this information may have drawn participants' attention to possible threats involved in initial contact with strangers.

Some limitations of the present studies should be noted. The studies examined women's reactions towards a male heterosexual target. It might be argued that the prospect of cooperating with a male heterosexual stranger also aroused fear in our female respondents. However, it seems likely that this fear of cooperation with a heterosexual man influenced the fear reports in all four cells to the same extent. Research in the field of HIV-related stigmatization (Bos et al., 1999; Dijker et al., 1997) has shown that emotional and behavioral reactions towards persons with HIV are dependent on the gender of the perceiver and sexual orientation of the person with HIV. Future research on fear reduction strategies should therefore also pay attention to other combinations of perceivers' gender and sexual orientation of the target with HIV.

It is also important to notice that our results are specific to the group of participants (female students) and that the generalizability of our results is limited. In both studies, our participants did not report differential reactions towards cooperation with a healthy target or a target with HIV. Furthermore, results of our first study indicate that our participants were even motivated to respond in a prosocial manner towards a person with HIV. Therefore, it should be concluded that safety concerns might have been less prominent in our participants than we expected. One of the goals of our first study was to replicate Dijker et al.'s (1997) study in a realistic experimental setting, and investigate whether predictability would reduce fear of persons with HIV in initial contact. As mentioned previously, it seems that need for safety was not a primary concern for our participants. Study 6.1 cannot, therefore, give a decisive answer as to whether predictability reduces fear of persons with HIV in initial encounters. In spite of this, our first study shows that predictable behavior of persons with HIV can have other beneficial interpersonal consequences. However, future research should certainly re-examine the impact of predictability on fear responses in initial encounters, by using lower-educated participants, and studying the interactive effects of participants' gender and target's sexual orientation. 


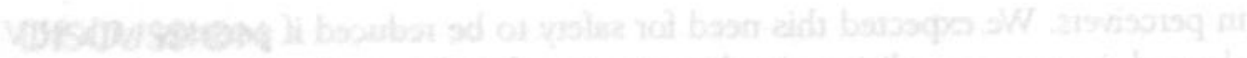

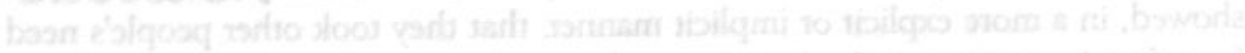

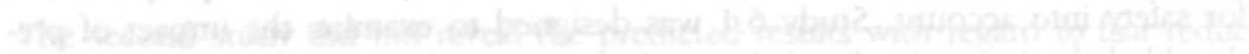

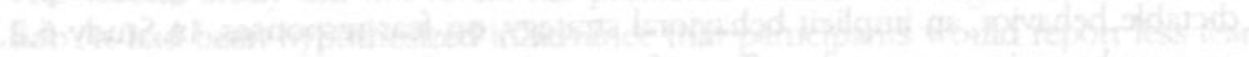

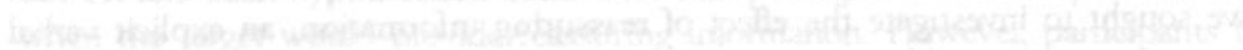
(1)

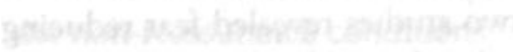

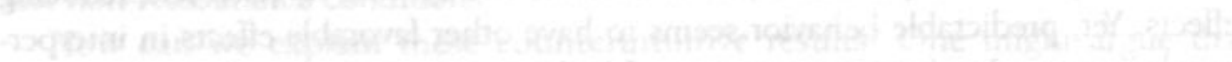

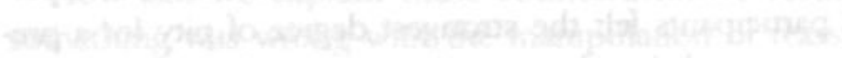

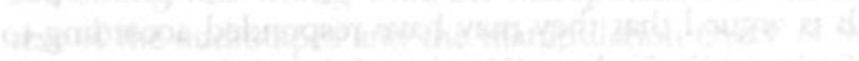

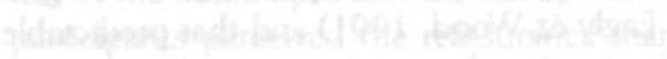

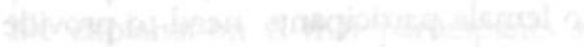

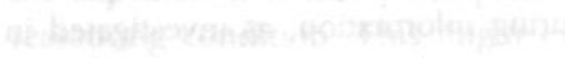

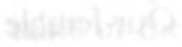

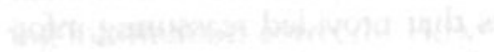

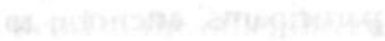

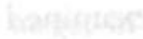

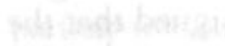

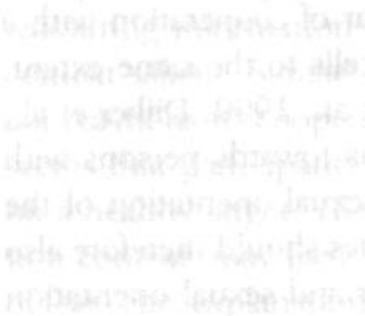

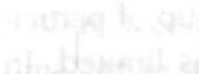




\section{CHAPTER 7}

\section{GENERAL DISCUSSION}




\section{INTRODUCTION}

The studies reported in this dissertation examined determinants of HIV-related stigmatization and investigated the effects of different interaction strategies that persons with HIV may adopt to reduce stigmatizing responses and increase prosocial reactions. This last chapter integrates the findings of the reported studies and discusses their contribution to the field of HIV stigma. In particular, it will focus on determinants of HIV stigma, interaction-level strategies to reduce stigmatization, and gender differences in reactions towards persons with HIV. Subsequently, methodological strengths and limitations of the current studies will be discussed. Finally, attention will be paid to practical implications of the studies.

\section{DETERMINANTS OF STIGMATIZATION OF PERSONS WITH HIV}

The introductory chapter presented a cognitive-emotional model of stigmatization of persons with HIV and discussed empirical evidence for this model. This model assumes that both cognitive and emotional factors are meaningfully related to stigmatization of persons with HIV (see Figure 1.1). Study 2.1 investigated cognitive, emotional and behavioral reactions towards persons with HIV in a large sample of the Dutch population. This study demonstrated that, in addition to cognitive factors, emotional factors determine willingness to have personal contact with persons with HIV. Consistent with the model, fear and anger were related to less willingness to engage in personal contact, whereas pity was associated with stronger willingness to have personal contact. Furthermore, cognitive factors were also meaningfully related to emotional factors. Blaming, a concept comparable to personal responsibility, was related to stronger anger and less pity. These associations are consistent with the model and in line with previous research on attributions and emotions (e.g., Weiner et al., 1988). Risk perceptions were related to stronger fear and stronger anger. The cognitive-emotional model of stigmatization of persons with HIV only presumes a relationship between perceived contagiousness of disease and fear. Risk perceptions about HIV transmission were more strongly associated with fear than with anger. Dijker, Kok and Koomen (1996) also reported that risk perceptions were associated with both fear and anger. Perhaps those who are least informed about the impossibility of HIV transmission in everyday contact are also the ones who respond in a more aggressive manner towards persons with HIV. Consistent with the assumptions of the cognitive-emotional model, Attitude towards homosexuals was positively related with feelings of pity. The predicted negative association between attitude towards homosexuals and anger was considerably weaker (although significant at the $\mathrm{p}<.05$ level).

To conclude, the results of the national survey on HIV stigma seem largely consistent with the cognitive-emotional model of HIV-related stigmatization. However, it should be noticed that cognitive reactions influenced behavioral 
responses to $\boldsymbol{x}$ larger extent than did emotional reactions. In part, this may reflect the nature of this telephone survey, which examined people's responses towards persons with HIV in general, and may have appealed more to participants' cognitions than emotions. In actual social interaction with a person with HIV, emotional reactions may determine people's behavioral responses to a larger extent.

The impact of seriousness of disease on emotional and behavioral reactions towards persons with HIV received special attention in two vignette studies. Study 3.1 demonstrated that seriousness of disease is related to stronger stigmatization. This finding is consistent with other studies that have shown that severity of a medical condition is related to stronger stigmatization (Crandall \& Moriarty, 1995; Dijker \& Koomen, in press). Further, this vignette study indicated that people feel emotional ambivalence when they are confronted with seriously ill persons. Participants reported stronger fear and stronger pity towards an ill person with severe disease symptoms. Thus, social interaction with seriously ill persons seems to arouse opposite motivations. On the one hand, people feel pity and may be motivated to respond in a prosocial manner. On the other hand, people experience fear and may have a desire to avoid ill persons. This ambivalence in perceivers may lead to awkward moments in social interaction and may result in avoidant behavior (Hebl et al., 2000; Katz, 1981). Recently, Dijker and Koomen (in press) also found evidence that seriousness of a condition causes emotional ambivalence. In Study 5.2 , the impact of seriousness of disease on emotional reactions towards persons with HIV was investigated as well. However, this time no evidence for emotional ambivalence was found. The effect of the seriousness-of-disease manipulation may have been influenced by our manipulations of coping with HIV. For example, a significant interaction effect between seriousness of disease and active coping revealed that people responded with least pity when a seriously ill person with HIV displayed active coping. Thus, perceivers may have interpreted information about seriousness of disease in light of patient's coping behavior. To conclude, it seems that Study 5.2 did not have the ideal design to examine the independent effects of seriousness of disease on perceivers' emotional and behavioral responses. More research is needed on the effects of seriousness of disease on emotional and behavioral reactions to ill persons. Such research should also determine the relative impact of seriousness of disease in the process of stigmatization of ill persons.

\section{INTERACTION-LEVEL STRATEGIES TO REDUCE STIGMATIZATION}

The studies reported in Chapters 5 and 6 examined interaction strategies that persons with HIV may adopt to influence perceivers' emotional and behavioral reactions. The use of interaction strategies in social interaction has received limited attention in the field of HIV stigma (see for an exception: Dijker et al., 1997). However, knowledge about strategies to improve social interaction may be useful for persons with HIV. 
Chapter 5 examined the interpersonal consequences of coping with HIV. First, Study 5.1 explored what coping strategies of persons with HIV are preferred by healthy perceivers. This study revealed that perceivers prefer that ill persons do not indulge in their sick role and that they continue with their normal life. Interestingly, women had a significantly stonger preference for communication about the disease than men. In studies 5.2 and 5.3, the effects of two coping strategies, 'conveying distress' and 'active coping', on perceivers' emotional and behavioral reactions were investigated. These results show that women respond in a prosocial manner when a person with HIV conveys distress. Conversely, men responded with stronger anger and stigmatizing responses towards a target with HIV who conveys distress. No favorable interpersonal consequences were found for active coping.

Overall, these results suggest that persons with HIV must be careful not to confront others with their suffering. In general, relative strangers consider self-pity or negative mood states as undesirable coping strategies. Yet, conveying some distress in initial encounters seems to arouse prosocial responses in women, but not in men. These gender differences are consistent with gender role theory (Eagly, $1987)$ and will be discussed thoroughly in the next section. Although conveying some distress may be beneficial in initial contact with women, it is doubtful whether conveying distress also yields positive interpersonal consequences in long-lasting and long-term contact. Silver et al. (1990) demonstrated that conveying large amounts of distress has negative interpersonal consequences. Furthermore, the data of Study 5.1 also suggest that repeatedly confronting other people with one's distress may have negative interpersonal consequences, because selfpity is generally viewed as undesirable coping.

In contrast with previous research (Silver et al., 1990; Schwarzer \& Weiner, 1991), the studies in question have not demonstrated favorable effects of active coping on perceivers' emotional and behavioral reactions. In the current studies, active coping was manipulated as problem-focused active coping (e.g., take medicines, eat healthy food, take enough rest). However, it might be argued that information about patient's emotion regulation is far more important for perceivers in initial encounters. Thus, it might still be possible that emotion-focused active coping has positive interpersonal consequences in initial encounters. Future research should investigate the impact of active emotion-focused coping on perceivers' reactions. Furthermore, it seems fruitful to examine the impact of other coping strategies as well.

\section{Fear reduction stategies}

106 Chapter 6 reported on the impact of two different fear reduction strategies on perceivers' reactions. Study 6,1 examined the impact of patient's predictable behavior on perceivers' reactions. In contrast to previous findings of Dijker, Koomen and Kok (1997), no fear reducing effects of predictable behavior were found. However, 
our female participants responded with strongest compassion towards the target with HIV who displayed predictable behavior. Study 6.2 investigated whether providing reassuring information results in fear reduction. Contrary to our expectations, participants in the reasuring conditions reported stronger feelings of fear.

In advance, it was expected that anticipation of cooperation with a person with HIV would arouse fear in the female students that participated in both studies. However, it seems that need for safety was not their primary concern. On the contrary, Study 6.1 indicates that anticipation of personal contact with a person with HIV has evoked a prosocial motivation in the female participants. This response seems consistent with their female gender role (Eagly, 1987). The female participants reported strongest pity for the predictable person with HIV. Predictable behavior of seriously ill persons may enable perceivers to respond in a prosocial manner, whereas unpredictable behavior may hamper attempts to provide support. The results of Study 6.2 also suggest that need for safety was initially not a major concern of the female participants. Only when reassuring information was provided, women reported increased fear. It is argued that the provision of reassuring information has made the potential danger of the interaction context salient.

In sum, the studies on fear reducing interaction strategies point to the limiting conditions under which interpersonal fear reducing strategies may be effective. The use of explicit verbal strategies may have adverse effects in case the interaction partner is not fearful. In such interaction contexts, predictable behavior seems a useful interaction strategy, because it may evoke stronger feelings of pity. Future research should devote more attention to the effects of predictable behavior on perceivers' emotional and behavioral reactions. First, it seems necessary to replicate Study 6.1 among fearful people to investigate the fear reducing properties of predictable behavior. Second, it seems useful to investigate the interaction contexts under which predictable behavior evokes prosocial responses. Finaly, it would be worthwhile to investigate whether providing reassuring information can be effective in initial contact with fearful persons.

\section{Implications for future research on interaction strategies}

The reported studies are an initial step to better understanding the effects of HIV stigma-reduction strategies in initial encounters. They have advanced our knowledge about the impact of a number of strategies on perceivers' emotional and behavioral reactions. Further, the studies have revealed that structural factors, such as gender or educational level of the perceiver, influence the effectiveness of these strategies. Thus, the impact of certain interaction strategies seems to depend to a large extent on the audience.

The results of the studies reported in this dissertation must be judged in the light of the social and cultural context of the Netherlands. In general, anticipation of personal contact with a person with HIV did not arouse extremely negative emotional or behavioral reactions. This may have several implications for research on interaction strategies for persons with HIV. First, it seems advisable to conduct 
fear reduction strategies in cultures and social contexts where more overt and extreme forms of stigmatization are existing. This may provide better insight into the effectiveness of fear reduction strategies. Second, research on HIV interaction strategies in the Netherlands should use more unobtrusive behavioral measures and include psychophysiological measures as well. Such measures register people's spontaneous and immediate responses towards social interaction with persons with HIV and may also overcome self-presentational bias. The use of such measures will be given more attention in the section on methodological strengths and limitations.

With respect to the content of interaction strategies, the following directions for future research have already been suggested above. First of all, the interpersonal consequences of emotion-focused active coping need to be investigated. Furthermore, fear reduction strategies should be investigated among those who are fearful of social interaction with persons with HIV. Finally, other possible interaction strategies must also be explored and examined as well. Another issue that deserves close attention in future research is the timing of the disclosure. In the studies presented in this dissertation, the HIV status was disclosed immediately and persons with HIV adopted their interaction strategy at the outset of the encounter. What would happen if one first creates a positive interaction context and then discloses one's serostatus? Under what circumstances is immediate disclosure better than delayed disclosure? To what extent does previous behavior of a person with HIV influence perceivers' emotional and beavioral reactions after delayed disclosure? These questions have not been addressed yet and would certainly deserve closer attention of researchers in the field of HIV.

\section{GENDER DIFFERENCES IN RESPONSES TOWARDS PERSONS WITH HIV}

The present studies show a consistent pattem of gender differences in emotional and behavioral reactions towards persons with HIV. First, men and women differ in their reported emotional reactions towards persons with HIV. Men reported stronger anger towards a person with HIV, as compared to women (Studies 2.1, 3.1 and 5.2). Conversely, women reported stronger pity (Studies 2.1 and 5.2) and fear (Study 5.2) than men. These findings are consistent with research on gender differences in emotional expression. In general, women are found to be more emotionally expressive than men, except for the expression of powerful emotions such as anger (Fischer \& Manstead, 2000; Kring \& Gordon, 1998; Timmers et al., 1998). The expression of pity and fear towards persons with HIV may be less

108 appropriate for men, because these emotions imply sensitivity and vulnerability, qualities that are inconsistent with the male gender role, which contains agentic aspects and encourages power and status. In contrast, expressing anger towards ill persons may be less obvious for women, since such hostile emotional reactions 
are inconsistent with the female gender role that consists of qualities as caring and nurturing.

Second, men and women also differ in their behavioral responses towards persons with HIV. Consistent with previous findings (e.g., Herek \& Capitanio, 1993), men displayed stronger stigmatizing behavior towards persons with HIV than did women. Study 2.1 revealed that men were less willing to have personal contact with persons with HIV than women. Moreover, Study 5.3 demonstrated that men sat at a greater distance from a person with HIV than from a healthy target, whereas women did not show differences in seating position. The latter effect is similar to findings of Dijker, Koomen and Kok (1997) in a Dutch vignette study on HIV stigma: Men rated indirect physical contact with a person with HIV as less pleasant than contact with a healthy target, whereas women did not differentiate between a person with HIV or a healthy person.

Third, the current studies show sound gender differences in responses towards homosexual and heterosexual persons. Study 2.1 revealed that male respondents held a more negative attitude towards homosexuals than female respondents. Furthermore, Study 3.1 demonstrated that men reported stronger irritation and stigmatizing responses towards a homosexual person than did women. These findings are in line with a meta-analysis conducted by Kite and Whitley (1996), who found that men generally hold more negative attitudes towards homosexuals than women. These gender differences can be explained by men's greater adherence to gender roles in which homosexuality is less acceptable (Kite \& Whitley, 1996). Studies on gender and emotion have paid little attention to dyadic interaction between heterosexuals and homosexuals (Deaux, 2000). However, Study 3.1 suggests that social interaction between a male homosexual target and a male heterosexual perceiver is likely to evoke negative powerful emotions, such as anger and contempt, in the latter person.

Fourth, the present studies show clear gender differences in reactions towards ill persons who convey distress. Study 5.1 revealed that women had a stronger preference for patients' communication about the disease than men. Furthermore, women reported stronger pity (Study 5.2) and stronger prosocial behavor (Study 5.3) when a male target with HIV conveyed distress. In contrast, conveying distress evoked anger (Study 5.2) and did not increase prosocial behavior (Study 5.3) in male perceivers. These findings are consistent with gender role theory (Eagly, 1987; Eagly \& Wood, 1991). Patients who communicate distress appeal to the caring and nurturing aspects of the female gender role and seem to oppose to the male gender role, which contains agentic aspects and encourages power and status.

In sum, it seems that social interaction with seriously ill persons is more likely to trigger prosocial reactions in women than in men. In the case of HIV, gender differences are even larger because of the association of HIV with homosexuality. Some limitations of these inquiries into gender differences should be noted. The experimental studies have only investigated gender differences towards a male target. It might be possible, for instance, that men respond more positively towards a woman with HIV. Furthermore, in most of the experimental studies, this target was heterosexual. Therefore, it is still unknown how people would respond to these interaction strategies when the target was a homosexual person 
with HIV. However, one might expect men to respond with even stronger anger when to a homosexual man with HIV conveying distress. Future research should certainly vary the gender and sexual orientation of the target. Finally, studies 6.1 and 6.2 have only examined the impact of fear reduction strategies on women's responses. The effects of predictable behavior and reassuring information on men's reactions also deserve more attention in future research.

\section{METHODOLOGICAL STRENGTHS AND LIMITATIONS}

This section discusses methodological strengths and limitations of the present studies. One of the most important strengths is the use of a realistic experimental interaction context in three different studies. Participants were led to believe that they would cooperate with another person who was either infected with HIV or healthy. They received an audiotaped or videotaped manipulation and answered questions about their first impressions regarding the anticipated cooperation with the target. This interaction context may arouse emotional and behavioral responses that resemble perceivers' actual responses in initial encounters with persons with HIV.

An important strength of the studies in Chapter 5 is the use of different research methods (vignette methodology, experiments in realistic interaction context) and different outcome measures (open-ended questions, self-reports of cognitive, emotional and behavioral responses, unobtrusive behavioral measure) to investigate responses towards patient's way of coping. Furthermore, in Study 5.1 perceivers' desirable and undesirable coping was examined not only for persons with HIV, but also for patients with cancer. This makes it possible to compare desirable and undesirable coping of persons with HIV with another life-threatening disease. Besides, in Study 5.3 a healthy control condition was added to the design, in order to compare responses towards persons with HIV with reactions towards a healthy person.

The present research only investigated the effects of interaction strategies on anticipated contact and not during real social interaction. This was done deliberately, in order to be able to examine the effects of different strategies in a controlled setting. Furthermore, it seems especially important to examine initial responses towards cooperation with a person with HIV, given that first impressions may influence the development of further interaction patterns during social interaction. However, social interaction between stigmatized and nonstigmatized individuals is often characterized by discomfort, embarrasment or nonverbal expressions of unease (see Hebl et al., 2000). The impact of the present interaction strategies on such behavioral responses during social interaction is yet unclear and should be examined in the future.

A number of comments must be made with regard to the generalizability of the results. In several studies, the group of participants consisted of (female) stu- 
dents. One must be cautious to generalize these results to other groups in society. However, we have attempted to overcome the limited generalizibility of the studies on coping with HIV. In Study 5.3, participants included men and women from the local community. This study yielded similar results as the previous two coping studies with respect to gender differences in responses to patient's coping. In the national telephone survey on HIV stigma participants were also drawn from the general population. Thus, cognitive, emotional and behavioral reactions towards persons with HIV were examined among men and women, differing in age and educational level. Nevertheless, it should be noted that the external validity of this survey is limited to the social context of the Netherlands.

In studies 3.1., 5.1 and 5.2, participants' responses to persons with HIV were investigated by means of vignettes. Participants received an imaginary situation and were asked to reflect upon their feelings and behavior. One might argue that this method is sensitive to self-presentational bias and that respondents reflect on a hypothetical situation instead of real social interaction. Furthermore, respondents might influence their own exposure to these vignettes (for example, by reading the vignette attentively or by just glancing at it) (Guglielmi, 1999; Kinicki, Hom, Trost, \& Wade, 1995). Despite these limitations, this research method has different advantages and seems useful to investigate people's responses towards persons with HIV. One of the advantages of vignettes is the manipulation of information in a simple and systematic way (Parkinson \& Manstead, 1993). Furthermore, the impact of this information can be examined in the absence of nonverbal characteristics of the stimulus person and other external factors. In addition, imaginary situations seem to fit the anticipating atmosphere of stereotyping and stigmatization. Some of the limitations of vignettes have been overcome in the design of the study. According to Hendrickx (1991), a vivid scenario may increase the reliability of vignettes and scenarios. The vignettes in our studies were made as realistic and vivid as possible. Furthermore, the workplace context was aimed at the students' perception of their environment, because most students of secondary senior vocational education had already been in training. However, in order to overcome the imaginary context of vignettes, Study 5.2 was also replicated in a realistic experimental context.

All outcome measures in the current studies relied on self-reports, with the exception of the unobtrusive behavioral measure used in Study 4. Self-reports are controlled and explicit measures. It might be argued that self-reports are less appropriate to measure subtle forms of prejudice. Furthermore, self-reports are susceptible to self-presentational bias (Guglielmi, 1999). To some extent these issues have been addressed in the design of the studies, for example by emphasizing anonymity and creating a vivid or realistic interaction context. Furthermore, the self-reports in our studies referred to behavioral responses that could be easily verbalized without too much cognitive effort. Besides, global everyday descriptions of feeling states were used to refer to people's inner state. However, it seems useful to include psychophysiological measures and more (unobtrusive) behavioral measures in future research on stigmatization. These automatic and implicit measures may be informative about people's emotional arousal and actual behavior in social interaction. Guglielmi (1999) reviewed psychophysiological meas- 
ures in prejudice research and concluded that 'electrodermal acctivity, heart rate and facial EMG are promising indicators of affective-evaluative responses in prejudice studies' (Guglielmi, 1999, p. 134). It should be noted that psychophysiological measures also have their drawbacks, in that they may create a less natural interaction context.

\section{PRACTICAL IMPLICATIONS}

To what extent do the research findings of our studies contribute to the reduction of stigmatization in the lives of persons with HIV? The present studies may have practical implications for stigma-reduction strategies at both society- and interaction-level.

\section{Society-level strategies}

The nationaf telephone survey on HIV stigma has demonstrated that public reactions to people with HIV are moderately positive in the Netherlands. Risk perceptions for contracting HIV in everyday contact were accurate for most respondents and only a small part of the respondents found it unacceptable to have personal contact with a person with HIV. However, people reported less compassion for persons with HIV than for persons with other chronic or serious diseases. These findings seem to have implications for society-level strategies aimed at reducing stigmatization of persons with HIV in the Netherlands. On the one hand, massmedia campaigns can be used to maintain or improve public reactions to people with HIV. It seems sensible to reinforce knowledge about HIV transmission through casual contact, because negative public reactions might recur if this knowledge declines. Mass-media campaigns may also try to increase compassion for persons with HIV and intensify people's involvement with HIV.

Simultaneously, it seems useful to develop and execute stigma-reduction interventions in situations where persons with HIV may encounter stigmatizing or unsupportive reactions. Such interventions may for example focus on the workplace. Garretsen (2000) investigated employers' reactions towards employing persons with HIV. She noticed that there are still misperceptions and a lack of knowledge on this topic among employers, which may hinder reintegration of persons with HIV in the workplace. As suggested by Garretsen, specific education on social aspects, medical aspects and issues pertaining to industrial law, may have a positive impact on employers' willingness to employ persons with HIV. A stigma-

112 tizing social context for HIV-infected drug users is the drug scene. Roodenburg (1999) interviewed HIV-infected male drug users about their experiences with HIV-related stigmatization. This qualitative study showed that HIV-infected drug users experience stigmatizing reactions in the drug scene. The latter result was 
confirmed in a quantitative study which investigated responses of 48 seronegative drug users to drug users with HIV (Bos, Dijker \& Jansen, 2000). This study revealed that fifty-three percent of the respondents found it unacceptable to have personal contact with seropositive drug users. Furthermore, risk perceptions about HIV transmission were exaggerated and a majority of the respondents also reported feelings of fear and anger. These findings underline the importance of buddies and health care professionals for the provision of social support to drug users with HIV. Furthermore, it seems warranted to direct small-scale educational activities at drug users in order to reduce HIV-related stigmatization.

In sum, it seems fruitful to use mass-media campaigns to maintain (or improve) the moderately positive reactions towards persons with HIV in the general public. Furthermore, it seems necessary to adapt society-level stigma-reduction strategies to social contexts where persons with HIV experience negative social reactions.

Another issue that must be raised with respect to society-level strategies is the relation between HIV prevention programs and stigmatization. Social-psychological research has demonstrated that people respond with stronger stigmatization towards ill persons when they are held responsible for the onset of their disease (e.g., Weiner et al., 1988). HIV prevention programs may foster negative social reactions towards persons with HIV, if they highlight people's personal responsibility for HIV infection. Thus, such programs must be cautious not to put too much emphasis on the personal responsibility for HIV infection. Furthermore, it seems important to address the issue of stigmatization in HIV prevention programs that are specifically aimed at developing countries, ethnic minorities and persons with HIV (Kok, 1999; Van Empelen et al., 2001). In developing countries and among ethnic minorities the stigma surrounding HIV is enormous. The effectiveness of HIV prevention activities will be undermined unless the issue of HIV stigma is tackled in these HIV prevention programs. HIV prevention programs targeting persons with HIV must be careful not to foster stigmatizing responses towards persons with HIV in the general population (Kok, 1999). The stigmatizing consequences of prevention programs targeting persons with HIV will probably be limited if the interventions take place in testing and treatment sites and if the programs are developped in cooperation with persons with HIV (Van Empelen et al., 2001).

\section{Interaction-level strategies}

In this dissertation, we examined the effect of different interaction strategies that persons with HIV may adopt to influence perceivers' emotional and behavioral reactions. Knowledge about the consequences of different interaction strategies might be useful information for persons with HIV. However, such interaction strategies have received limited reseach attention so far. Therefore, the research reported in this dissertation must be regarded as a first, but important step into better understanding the interpersonal consequences of such stigma-reduction strategies. 
The studies reported in Chapter 5 examined the impact of different coping strategies on perceivers' emotional and behavioral reactions. First of all, Study 5.1 provided insight into perceivers' needs with regard to patients' coping with their disease. This study showed that persons with HIV should be careful not to confront strangers with their suffering. In general, perceivers seem to prefer ill persons not to indulge into a sick role and display pitiful behavior. They want ill persons to continue with their normal life and try to focus on the positive. Women, however, considered communication about the disease as more desirable than did men. Studies 5.2 and 5.3 showed that conveying some distress has positive consequences in interpersonal contact with women, but not with men. On a more general level, it might be argued that persons with HIV should be selective in conveying distress to relative strangers. Obviously, it seems sensible to take the possible needs of the interaction partner into account, before conveying distress. Unfortunately, we were not able to demonstrate favorable interpersonal effects of active coping. Future research should investigate the impact of emotion-focused active coping on perceivers' reactions and examine the interpersonal consequences of other coping strategies as well.

The studies reported in Chapter 6 point us to the limiting conditions under which fear reduction strategies may be effective. Providing reassuring information may prove counterproductive, if need for safety is not a primary concern for the interaction partner. However, displaying predictable behavior may evoke stronger feelings of pity, although this interaction strategy had no effects on fear. Thus, it seems that explicit verbal strategies have undesirable consequences in this interaction context, whereas implicit nonverbal strategies are not effective in fear reduction, but have other beneficial consequences.

Interaction strategies seem to be appropriate to influence social responses towards persons with HIV in initial encounters. However, some comments must be made. First, one should mind that persons with HIV are not held responsible for the reduction of stigmatization. Second, the impact of interaction strategies will probably be limited if stigmatization is not simultaneously dealt with at other levels. Both comments demonstrate the importance of fighting stigmatization at different levels, using different methods. Accordingly, interaction strategies must be regarded as an additional way to combat negative emotional and behavioral reactions towards persons with HIV.

The area of interactional stigma-reduction strategies is relatively unexplored and more research is certainly needed to be able to further generalize the results. This dissertation has shown that the impact of interactional stigma-reduction strategies is to some extent dependent on structural and contextual aspects of the social interaction. Future research should vary the sexual orientation of the target as well as the gender of both the target and the perceiver. Furthermore, it is important to study the fear reduction strategies among lower-educated participants or in other cultures where people are more fearful of persons with HIV. 114 Such research efforts not only advance our knowledge about HIV stigma and social interaction, but may also demonstrate which interaction strategies may be used in certain social contexts, in order to reduce stigmatization and increase prosocial responses. 
Allport, G.W. (1954). The nature of prejudice. Reading, MA:Addison-Wesley.

Amir, Y. (1976). The role of inter-group contact in change of prejudice and ethnic relations. In P. A. Katz (Ed.), Towards the elimination of rocism (pp. 245-308). New York, NY: Pergamon.

Arntz, A., Lavy, E., van den Berg, G., \& van Rijsoort, S. (1993). Negative beliefs of spider phobics: A psychometric evaluation of the spider phobia beliefs questionnaire. Advonces in Behaviour Research and Therapy, 15, 257-277.

Bartholomew, L.K., Parcel, G.S., Kok, G., \& Gotdlieb, N.H. (200I). Intervention Mapping, Designing theory - and evidence-based health promotion programs. Mountain View, CA: Mayfield.

Batson, C. D. (1987). Prosocial motivation: Is it ever truly altruistic? In L. Berkowitz (Ed.), Advances in experimental social psychology (Vol. 20, pp. 65-122). New York:Academic Press.

Batson, C. D., Early, S., \& Salvarani, G. (1997). Perspective taking: Imagining how another feels versus imagining how you would feel. Personality and Social Psychology Bulletin, 23, 751 . 758.

Batson, C. D., Polycarpou, M. P., Harmon-Jones, E., Imhoff, H. J., Mitchener, E. C., Bednar, L. L., Klein, T. R., \& Highberger, L. (1997). Empathy and attitudes: Can feeling for a member of a stigmatized group improve feelings toward the group? Journal of Personality and Social Psychology, 72, 105-118.

Belgrave, F. Z. (1984). The effectiveness of strategies for increasing social interaction with a physically disabled person. Journal of Applied Social Psychology, 14, 147-161.

Belgrave, F. Z., \& Mills, J. (198I). Effect upon desire for social interaction with a physically disabled person of mentioning the disability in different contexts. Journal of Applied Social Psychology, II, 44-57.

Bennett, M. J. (1990). Stigmatization: Experiences of persons with acquired immune deficiency syndrome. Issues in Mental Health Nursing, II, $141-154$.

Biernat, M., \& Dovidio, J. F. (2000). Stigma and stereotypes. In T. F. Heatherton, R. E. Kleck, M. R. Hebl \& J. G. Hull (Eds.), The social psychology of stigma (pp. 88-125). New York: Guilford Press.

Bishop, G. D. (199/a). Understanding the understanding of illness: Lay disease representations. In J. A. Skelton \& R. T. Croyle (Eds.), Mental representation in health and illness (pp. 32-59). New York: Springer.

Bishop, G. D. (199/b). Lay disease representations and responses to victims of disease. Basic and Applied Social Psychology, 12, 115-132.

Bishop, G. D.,Alva,A. L., Cantu, L., \& Rittiman, T. K. (1991). Responses to persons with AIDS: Fear of contagion or stigma? Journal of Applied Social Psychology, 21, 1877-1888.

Bos, A., Dijker, A., \& Jansen, M. (2000). Stigma in the drug scene: An investigation of stigmatization of HIV+ drug users in a sample of HIV- drug users. 13th International AIDS Conference. Durban, South Africa.Abstract MoPeD2768.

Bos,A. E. R., Dijker,A. J., \& Koomen, W. (1999). The influence of seriousness of disease symptoms and patients' sexual orientation on emotional and behavioral reactions to ill persons. Gedrag \& Gezondheid, 27, 29-35.

Bos, A. E. R., Dijker,A. J., \& Koomen, W. (200I). Interpersonal Consequences of Coping with HIV: Gender Differences in Perceivers' Emotional and Behovioral Reoctions. Manuscript submitted for publication. 
Bos, A. E. R., Dijker, A. J., \& Reuvekamp, M. A. J. (2001). Reducing Fear of People with HIV:The Impact of Predictable Behovior and Reassuring Information. Manuscript submitted for publication.

Bos, A. E. R., Kok, G., \& Dijker,A. J. (200I). Public Reactions to People with HIVIAIDS in the Netherlands. AIDS Educotion and Prevention, 13, 219-228.

Brewer, M. B. (1988). A dual process model of impression formation. In T. K. Srull \& R. S. Wyer, Jr. (Eds.), Advances in social cognition (Vol. I, pp. I-36). Hillsdale, NJ: Erlbaum.

Brewer, M. B., \& Miller, N. (1984). Beyond the contact hypothesis: Theoretical perspectives on desegregation. In N. Miller \& M. B. Brewer (Eds.), Groups in contoct:The psychology of desegregation (pp. 281-302). Orlando, FL:Academic.

Burris, S. (1999). Studying the legal management of HIV-related stigma. American Behovioral Scientist, 42, $1229-1243$.

Capitanio, J. P., \& Herek, G. M. (1999). AIDS-related stigma and attitudes toward injecting drug users among black and white Americans. American Behovioral Scientist, 42, 1148 1161 .

Chesney, M.A., \& Smith, A.W. (1999). Critical delays in HIV testing and care: The potential role of stigma. American Behavioral Scientist, 42, $1162-1174$.

Coates, D., Wortman, C. B., \& Abbey, A. (1979). Reactions to victims. In I. H. Frieze, D. BarTal, \& J. S. Carroll (Eds.), New opprooches to social problems (pp. 21-52). San Francisco: Jossey-Bass.

Cook, S.W. (1978). Interpersonal and attitudinal outcomes in cooperating interracial groups. Journal of Research and Development in Education, 12, 97-1 13.

Crandall, C. S. (2000). Ideology and lay theories of stigma:The justification of stigmatization. In T. F. Heatherton, R. E. Kleck, M. R. Hebl \& J. G. Hull (Eds.), The social psychology of stigma (pp. 126-150). New York: Guilford Press.

Crandall, C. S. \& Coleman, R. (1992). AIDS-related stigmatization and the disruption of social relationships. Journal of Social and Personal Relationships, 9, 163-177.

Crandall, C. S., Glor, J. \& Britt, T. W. (1997). Aids-related stigmatization: Instrumental and symbolic attitudes. Journal of Applied Social Psychology, 27, 95-123.

Crandall, C. S., \& Moriarty, D. (1995). Physical illness stigma and social rejection. British Journal of Social Psychology, 34, 67-83.

Crawford,A. M. (1996). Stigma associated with AIDS:A meta-analysis. Journal of Applied Social Psychology, 26, 398-416.

Crocker, J. \& Major, B. (1989). Social stigma and self-esteem: The self-protective properties of stigma. Psychological Review, 96, 608-630.

Crocker, J., Major, B. \& Steele, C. (1998). Social stigma. In D.T. Gilbert, S.T. Fiske, \& G. Lindzey (Eds.). The handbook of social psychology (4th ed., Vol. 2, pp. 504-553). Boston, MA: McGraw Hill.

Deaux, K. (2000). Gender and emotion: Notes from a grateful tourist. In A. H. Fischer (Ed.), Gender and Emotion: Social psychological perspectives (pp. 301-318). Cambridge: Cambridge University Press.

Derlega, V. L., Lovejoy, D., \& Winstead, B.A. (1998). Personal accounts of disclosing and conII6 cealing HIV-positive test results. In V. L. Derlega \& A. P. Barbee (Eds.), HIV and social interoction (pp.147-165). Thousand Oaks, CA: Sage publications.

Devine, P. G. (1989). Stereotypes and prejudice: Their automatic and controlled components. Journal of Personality and Social Psychology, 56, 5-18. 
Devine, P. G., Plant, E.A., \& Harrison, K. (1999). The problem of 'us' versus 'them' and AIDS stigma. American Behovioral Scientist, 42, $1212-1228$.

Dovidio, J. F., Major, B., \& Crocker, J. (2000). Stigma: Introduction and overview. In T. F. Heatherton, R. E. Kleck, M. R. Hebl \& J. G. Hull (Eds.), The social psychology of stigma. (pp. I - 28) New York: Guilford Press.

Dijker, A. J., Kok, G. J., \& Koomen, W. (1996). Emotional reactions to people with AIDS. journal of Applied Social Psychology, 26, 731-748.

Dijker,A.J., \& Koomen,W. (1996). Stigmatisering van zieken en gehandicapten: een integratie van cognitieve en emotionele componenten (Stigmatization of ill and handicapped persons: an integration of cognitive and emotional components). Nederlands Tijdschrift voor de Psychologie, 51, 252-260.

Dijker, A.J., \& Koomen, W. (in press). Extending Weiner's attribution-emotion model of stigmatization of ill persons. Basic and Applied Social Psychology.

Dijker,A. J.. Koomen, W. \& Kok, G. (1997). Interpersonal determinants of fear of people with AIDS: The moderating role of predictable behaviour. Basic and Applied Social Psychology. 19, 61-79.

Dijker, A. J. \& Raeijmaekers, F. (1999). The influence of seriousness and contagiousness of disease on emotional reactions to ill persons. Psychology and Heolth, 14, 131-141.

Dunkel-Schetter, C., Feinstein, L. G., Taylor, S. E., \& Falke, R. L. (1992). Patterns of coping with cancer. Health Psychology, II, 79-87.

Eagly, A. H. (1987). Sex differences in social behavior: A social-role interpretation. Hillsdale, NJ: Lawrence Erlbaum.

Eagly, A. H., Chaiken, S. (1993). The psychology of attitudes. Fort Worth: Hartcourt Brace College Publishers.

Eagly, A. H., \& Crowley, M. (1986). Gender and helping behavior: A meta-analytic review of the social psychological literature. Psychological Bulletin, 100, 283-308.

Eagly,A. H., \& Wood,W. (1991). Explaining sex differences in social behavior:A meta-analytic perspective. Personality and Social Psychology Bulletin, 17, 306-315.

Eberhardt, J. L., \& Fiske, S.T. (1996). Motivating individuals to change:What is a target to do? In Macrae, C. N., Stangor, C., \& Hewstone, M., Stereotypes and stereotyping (pp. 369-418). New York, NY: Guilford press.

Finlay, K. A., \& Stephan, W. G. (2000). Improving intergroup relations: The effects of empathy on racial attitudes. Journal of Applied Social Psychology, 30, I720-1737.

Fischer,A. H., \& Manstead,A. S. R. (2000). The relation between gender and emotions in different cultures. In A. H. Fischer (Ed.), Gender and Emotion: Social psychological perspectives (pp.71-96). Cambridge: Cambridge University Press.

Fiske, S. T., \& Neuberg, S. L. (1990). A continuum of impression formation, from categorybased to individuating processes: Influences of information and motivation on attention and interpretation. In M. P. Zanna (Ed.), Advances in experimental social psychology (Vol. 23, Pp. 1-74). New York:Academic Press, Inc.

Fleishman, J.A., \& Fogel, B. (1994). Coping and depressive symptoms among people with AIDS. Health Psychology, 13, 156-169.

Folkman, S., Lazarus, R. S., Gruen, J., \& DeLongis, A. (1986). Appraisal, coping, health status, and psychological symptoms. Journal of Personality and Social Psychology, 50, 571-579.

Frijda, N. H. (1986). The emotions. New York: Cambridge University Press. 
Gaertner, S. L., Dovidio, J. F., Anastasio, P. A., Bachman, B. A., \& Rust, M. C. (1993). The common ingroup identity model: Recategorization and the reduction of intergroup bias. In W. Stroebe \& M. Hewstone (Eds.), European Review of Social Psychology (Vol. 4. pp. I26). Chicester, England:Wiley.

Gaertner, S. L., Mann, J., Murrell,A., \& Dovidio, J. F. (1989). Reducing intergroup bias:The benefits of recategorization. Journal of Personality and Social Psychology, 57, 239-249.

Gagnon, M., \& Godin, G. (2000). The impact of new antiretroviral treatments on college students' intention to use a condom with a new sexual partner. AIDS Education and Prevention, 12, 239-251.

Garritsen, L. (2000). Rapportage onderzoek inzake HIV en werk [Report on HIV and employment]. Heemstede: Stichting Aids Fonds.

Goffman, E. (1963). Stigma: Notes on the management of spoiled identity. Englewood Cliffs, NJ: Prentice-Hall.

Greenberg, J., Pyszczynski, T., \& Solomon, S. (1986). The causes and consequences of a need for self-esteem:A terror management theory. In R. F. Baumeister (Ed.), Public self and privote self (pp. 189-212). New York: Springer.

Grossman, M., \& Wood, W. (1993). Sex differences in intensity of emotional experience: A social role interpretation. Journal of Personality and Social Psychology, 65, 1010-1022.

Guglielmi, R. S. (1999). Psychophysiological assessment of prejudice: Past research, current status, and future directions. Personality and Social Psychology Review, 3, 123-157.

Hastorf, A. H.,Wildfogel, J., \& Cassman, T. (1979). Acknowledgment of handicap as a tactic in social interaction. Journal of Personality and Social Psychology, 37, 1790-1797.

Hays, R. B., McKusick, L., Pollack, L., Hilliard, R., Hoff, C., \& Coates, T. J. (1993). Disclosing HIV seropositivity to significant others. AIDS, 7, 425-431.

Hebl, M. R., Tickle, J., \& Heatherton, T. F. (2000). Awkward moments in interactions between nonstigmatized and stigmatized individuals. In T. F. Heatherton, R. E. Kleck, M. R. Hebl \& J. G. Hull (Eds.), The social psychology of stigma. (pp. 243-272). New York: Guilford Press.

Hendrickx, L. (1991). How versus how often:The role of scenario information and frequency information in risk judgment and risky decision making. Dissertation, Rijsuniversiteit Groningen, the Netherlands.

Herek, G. M. (1999).AIDS and stigma. American Behovioral Scientist, 42, II06-1116.

Herek, G. M., \& Capitanio, J. P. (1993). Public reactions to AIDS in the United States: A second decade of stigma. American Journal of Public Health, 83, 574-577.

Herek, G. M., \& Capitanio, J. P. (1997). AIDS stigma and contact with persons with AIDS: Effects of direct and vicarious contact. Journal of Applied Social Psychology, 27, I-36.

Herek, G. M., \& Capitanio, J. P. (1998a). Symbolic prejudice or fear of infection? A functional analysis of AIDS-related stigma among heterosexual adults. Basic and Applied Social Psychology, 20, 230-241.

Herek, G. M., \& Capitanio. J. P. (1998b). AIDS stigma and HIV-related beliefs in the United States: Results from a national telephone survey. Conference record of the 12 th World AIDS Conference, Geneva, Switzerland.

Herek, G. M., \& Capitanio, J. P. (1999).AIDS stigma and sexual prejudice. American Behovioral Scientist, 42, 1130-1147.

Herek, G. M., Mitnick, L., Burris, S., Chesney, M., Devine, P., Fullilove, M. T., Fullilove, R., Gunther, H. C., Levi, J., Michaels, S., Novick, A., Pryor, J., Snyder, M., \& Sweeney, T. (1998). AIDS and stigma:A conceptual framework and research agenda. AIDS \& Public Policy Journal, 13, 36-47. 
Izard, C. E. (1991). The psychology of emotions. New York: Plenum.

Jaccard, J.,Weber, J., \& Lundmark, J. (1975).A multitrait-multimethod analysis of four attitude assessment procedures. Journal of Experimental Social Psychology, II, 149-154.

Jones, E. E., Farina, A., Hastorf,A., Markus, H., Miller, D., \& Scotc, R.A. (1984). Social stigma:The psychology of marked relationships. New York:W.H. Freeman.

Jost, J.T., \& Banaji, M. R. (1994). The role of stereotyping in system-justification and the production of false consciousness. British Journal of Social Psychology, 33, 1-27.

Kalichman, S. C. (1994). Magic johnson and public attitudes toward AIDS:A review of empirical findings. AIDS Education and Prevention, 6, 542-557.

Katz, I. (1981). Stigma: A social psychological anolysis. Hillsdale, NJ: Lawrence Erlbaum Associates.

Kawakami, K., Dovidio, J. F., Moll, J., Hermsen, S., \& Russin, A. (2000). Just say no (to stereotyping): Effects of training in the negation of stereotypic associations on stereotype activation. Journal of Personality and Social Psychology, 78, 871-888.

Kelly, J.A., Otto-Salaj, L. L., Sikkema, K. J., Pinkerton, S. D., Bloom, F. R. (1998). Implications of HIV treatment advances for behavioral research on AIDS: Protease inhibitors and new challenges in HIV secondary prevention. Health Psychology, 17, 310-319.

Kinicki, A. J., Hom, P.W., Trost, M. R., \& Wade, K. J. (1995). Effects of category prototypes on performance-rating accuracy. Journal of Applied Psychology, 80, 354-370.

Kite, M. E., \& Whitley, B. E. (1996). Sex differences in attitudes toward homosexual persons, behaviors, and civil rights: a meta-analysis. Personality and Social Psychology Bulletin, 22, 336353.

Kok, G. (1999). Targeted prevention for people with HIVIAIDS: Feasible and desirable? Patient Education and Counseling, 36, 239-246.

Kok, G., Kolker, L., De Vroome, E., \& Dijker, A. (1998). 'Safe sex' and 'compassion': Public campaigns on AIDS in the Netherlands. In Th. G. M. Sandfort (Ed.), The Dutch response to HIV (pp. 19-39). London: UCL Press.

Kring,A. M., \& Gordon,A. H. (1998). Sex differences in emotion: Expression, experience, and physiology. Journal of Personality and Social Psychology, 74, 686-703.

Kuijer, R. G., Ybema, J. F., Buunk, B. P., De Jong, G. M., Thijs-Boer, F., \& Sanderman, R. (2000). Active engagement, protective buffering, and overprotection: Three ways of giving support by intimate partners of patients with cancer. Journal of Social and Clinical Psychology, 19, 256-275.

Kunda, Z., \& Oleson, K. C. (1995). Maintaining stereotypes in the face of disconfirmation: Constructing grounds for subtyping deviants. Journal of Personality and Social Psychology, $68,565-579$.

Kunda, Z. \& Oleson, K. C. (1997). When exceptions prove the rule: How extremity of deviance determines the impact of deviant examples on stereotypes. Journal of Personality and Social Psychology, 72, 965-979.

Lane, J. D., \& Wegner, D. M. (1995). The cognitive consequences of secrecy. Journal of Personality and Social Psychology, 69, 237-253.

Larsen, K. S., Reed, M., \& Hoffman, S. (1980). Attitudes of heterosexuals toward homosexuality:A likert-type scale and construct validity. Journal of Sex Research, 16, 245-257.

Larson, D. G., \& Chastain, R. L. (1990). Self-concealment: Conceptualization, measurement, and health implications. Journal of Social and Clinical Psychology, 9, 439-455. 
Lavy, E. (1993). Attentional bias and anxiety: Conceptual issues and empirical data. Dissertation, Rijksuniversiteit Limburg, The Netherlands.

Lazarus, R. S. (1991). Emotion and adaptation. Oxford: Oxford University Press.

Lazarus, R. S., \& Folkman, S. (1984). Stress, oppraisal, and coping. New York: Springer.

Leary, M. R., \& Schreindorfer, L. S. (1998). The stigmatization of HIV and AIDS: Rubbing salt in the wound. In V. J. Derlega \& A. P. Barbee, HIV and social interaction. Thousand Oaks, CA: Sage Publications.

Mackie, D. M., \& Hamilton, D. L. (Eds.). (1993). Affect, cognition, and stereotyping: Interoctive processes in group perception. San Diego, CA:Academic Press.

Macrae, C. N., Bodenhausen, G.V., Milne, A. B., \& Jetten, J. (1994). Out of mind but back in sight: Stereotypes on the rebound. Journal of Personality and Social Psychology, 67, 808-817.

Macrae, C. N., Bodenhausen, G.V., Milne,A. B., \& Wheeler,V. (1996). On resisting the temptation for simplification: Counterintentional effects of stereotype suppression on social memory. Social Cognition, 14, 1-20.

Maes, S., Leventhal, H., \& De Ridder, D. (1996). Coping with chronic diseases. In M. Zeidner \& N.S. Endler (Eds.), Handbook of coping. New York: John Wiley.

Mansergh, G., Marks, G., \& Simoni, J. M. (1995). Self-disclosure of HIV infection among men who vary in time since seropositive diagnosis and symptomatic status. AIDS, 9, 639-644.

McGuire, W. J. (1985). Attitudes and attitude change. In G. Lindzey \& E. Aronson (Eds.), Handbook of Social Psychology (Vol. 2, pp. 233-246). New York: Random House.

Merckelbach, H., van den Hout, M. A., \& van den Molen, M. G. (1987). Fear of animals: Correlations between fear ratings and perceived characteristics. Psychological Reports, 60, 1203-1209.

Miller, C. T., \& Major, B. (2000). Coping with stigma and prejudice. In T. F. Heatherton, R. E. Kleck, M. R. Hebl \& J. G. Hull (Eds.), The social psychology of stigma. (pp. 243-272). New York: Guilford Press.

Monteith, M. J., Sherman, J.W., \& Devine, P. G. (1998). Suppression as a stereotype control strategy. Personality and Social Psychology Review, 2, 63-82.

Mulder, C. L., De Vroome, E. M. M., Van Griensven, G. J. P., Antoni, M. H., \& Sandfort, T. G. M. (1999). Avoidance as a predictor of the biological course of HIV infection over a 7-year period in gay men. Health Psychology, 18, $107-113$.

Neuberg, S. L., Smith, D. M., Hoffman, J. C., \& Russell, F. J. (1994). When we observe stigmatized and 'normal' individuals interacting: Stigma by association. Personality and Social Psychology Bulletin, 20, 196-209.

NSS/Marktonderzoek (1994). Evaluatie Aidscampagne 1994: Eindrapport [Evaluation of the AIDS Campaign 1994: Final report]. Den Haag: NSS/Marktonderzoek.

Orthodox Waardenburg pest homostel met aids-pension weg (1999, May 5). De Volkskrant. Retrieved January 19, 2001, from the World Wide Web:

http://www.volkskrant.nl/nieuws/archief

O'Shea, R. M., Mendola, P., \& Corah, N. L. (1991). Dental students' treatment of anxious patients. Social Science and Medicine, 32, 229-232.

Parkinson, B., \& Manstead, A. S. R. (1993). Making sense of emotion in stories and life. 120 Cognition and Emotion, 7, 295-323.

Pennebaker. J.W. (1990). Opening up: The healing power of confiding in others. New York: Morrow. 
Peters, L., Den Boer, D. J., Kok, G., \& Schaalma, H. P. (1994). Public reactions towards people with AIDS:An attributional analysis. Potient Education and Counseling, 24, 323-335.

Pettigrew, T. F. (1997). Generalized intergroup contact effects on prejudice. Personality and Social Psychology Bulletin, 23, 173-185.

Pryor, J. B., Reeder, G. D. \& Landau, S. (1999). A social-psychological analysis of HIV-related stigma:A two factor theory. American behovioral Scientist, 42, 1193-1211.

Pryor, J. B., Reeder, G. D. McManus, J. (1991). Fear and loathing in the workplace: Reactions to AIDS-infected co-workers. Personality and Social Psychology Bulletin, 17, 133-139.

Pryor, J. B., Reeder, G. D., Vinacco, R., \& Kott, T. L. (1989). The instrumental and symbolic functions of attitudes towards persons with AIDS. Journal of Applied Social Psychology, 19. 377-404.

Reed, G. M., Kemeny, M. E., Taylor, S. E., Wang, H.Y. J., \& Visscher, B. R. (1994). Realistic acceptance as a predictor of decreased survival time in gay men with AIDS. Health Psychology, 13, 299-307.

Reeder, G. D., \& Pryor, J. B. (2000).Attitudes toward persons with HIVIAIDS: Linking a functional approach with underlying process. In G. Maio \& J. Olson (Eds.), Why we evaluate: Functions of attitudes. Mahwah, NJ: Lawrence Erlbaum.

Riskind, J. H., \& Maddux, J. E. (1993). Loomingness, helplessness, and fearfulness: An integration of harm-looming and self-efficacy models of fear. Journal of Social and Clinical Psychology, 12, 73-89.

Riskind, J. H., \& Maddux, J. E. (1994). Loomingness and the fear of AIDS: Perceptions of motion and menace. Journal of Applied Social Psychology, 24, 432-442.

Roodenburg, A. (1999). Kwalitatief onderzoek naar ervaringen van mensen met HIV met stigmatisering [Qualitative research on experiences with stigmatization of persons with HIV]. Maastricht: Capaciteitsgroep Gezondheidsvoorlichting.

Rosen, J. B., \& Schulkin, J. (1998). From normal fear to pathological anxiety. Psychological Review, 105, 325-350.

Schreurs, K. M. G., \& De Ridder, D.T. D. (1997). Integration of coping and social support perspectives: Implications for the study of adaptation to chronic diseases. Clinical Psychology Review, 17, 89-112.

Schroeder, D. A., Penner, L. A., Dovidio, J. F., \& Piliavin, J.A. (1995). The psychology of helping and altruism. New York, NY: Mcgraw-Hill.

Schwarzer, R., \& Weiner, B. (199I). Stigma controllability and coping as predictors of emotions and social support. Joumal of Social and Personal Relationships, 8, 133-140.

Sherif, M., Harvey, O. J., White, B. J., Hood, W. R., \& Sherif, C.W. (1961). Intergroup conflict and cooperation: The Robbers cave experiment. Norman: University of Oklahoma Book Exchange.

Silver, R.C., Wortman, C.B., \& Crofton, C. (1990). The role of coping in support provision: The self-presentational dilemma of victims of life crises. In I.G. Sarason, B.R. Sarason \& G.R. Pierce (Eds.), Social support:An interoctional view. New York:Wiley.

Smart, L, \& Wegner, D. M. (2000). The hidden costs of hidden stigma. In T. F. Heatherton, R. E. Kleck, M. R. Hebl \& J. G. Hull (Eds.), The social psychology of stigma. (pp. 220-242). New York: Guilford Press.

Smith, E. R., \& DeCoster, J. (2000). Dual-process models in social and cognitive psychology: Conceptual integration and links to underlying memory systems. Personality and Social Psychology Review, 4, 108-131. 
Solomon, S., Greenberg. J., \& Pyszczynski, T. (1991). A terror management theory of social behavior: The psychological functions of self-esteem and cultural worldviews. In M. P. Zanna (Ed.), Advances in experimental social psychology (Vol. 24. pp. 93-159). San Diego, CA:Academic Press.

Stangor, C., \& Crandall, C. S. (2000). Threat and the social construction of stigma. In T. F. Heatherton, R. E. Kleck, M. R. Hebl \& J. G. Hull (Eds.), The social psychology of stigma (pp.62-87). New York: Guilford Press.

Stempel, R. R., Moulton, J. F., \& Moss, A. R. (1995). Self-disclosure of HIV-I antibody test results:The San Francisco General Hospital cohort. AIDS Education and Prevention, 7, 116 123.

Stephan, W. G. (1985). Intergroup relations. In G. Lindzey \& E. Aronson (Eds.). Handbook of social psychology (Vol. 2, pp. 599-658). New York, NY: Random House.

Tajfel, H., \& Turner, J. C. (1986). The social identity theory of intergroup behavior. In S. Worchel \& W. Austin (Eds.). Psychology of intergroup relations (2nd ed., pp. 7-24). Chicago: Nelson-Hall.

Tice, D. M. (1993). The social motivations of people with low self-esteem. In R. Baumeister (Ed.), Self-esteem:The puzzle of low self-regard (pp. 37-54). Hillsdale, NJ: Erlbaum.

Timmers, M., Fisher, A., \& Manstead,A. S. R. (1998). Gender differences in motives for regulating emotions. Personality and Social Psychology Bulletin, 24, 974-985.

Van Empelen, P., Kok, G., Van Kesteren, N., Van den Borne, B., Bos, A. E. R., Dijker, A. J., Hospers, H. J., Schaalma, H. P., \& Hogeweg. J.A. (200I). Effectiveness of psychosocial HIV prevention programmes: $A$ review. Manuscript submitted for publication.

Young, R. K., Gallaher, P. E., Marriott, S., \& Kelly, J. (1993). Reading about AIDS and cognitive coping style: Their effects on fear of AIDS and homophobia. Journal of Applied Social Psychology, 23, $911-924$.

Weber, R., \& Crocker, J. (1983). Cognitive processes in the revision of stereotypic beliefs. Journal of Personality and Social Psychology, 45, 961-977.

Wegner, D. M. (1994). Ironic processes of mental control. Psychological Review, 101, 34-52.

Weijts, W., Widdershoven, G., \& Kok, G. (1991). Anxiety-scenarios in communication during gynecological consultations. Patient Education and Counseling, 18, 149-163.

Weiner, B. (1985). An attributional theory of achievement motivation and emotion. Psychological review, 92, 548-573.

Weiner, B. (1993). AIDS from an attributional perspective. In J. B. Pryor and G. D. Reeder (Eds.), The social psychology of HIV infection (pp. 287-302). Hillsdale, NJ: Erlbaum.

Weiner, B. (1996). Searching for order in social motivation. Psychological Inquiry, 7, 199-216.

Weiner, B., Perry, R. B. \& Magnusson, J. (1988). An attributional analysis of reactions to stigmas. Journal of Personality and Social Psychology, 55, 738-748.

Wills, T. A. (1981). Downward comparison principles in social psychology. Psychological Bulletin, 90, 245-27I.

Wright, S. C., Aron, A., McLaughlin-Volpe, T., \& Ropp, S. A. (1997). The extended contact effect: Knowledge of cross-group friendships and prejudice. Journal of Personality and Social Psychology, 73, 73-90. 
1. One might argue that the hostile reactions in Waardenburg are an example of sexual prejudice as well. Indeed, the two homosexual men were already treated negatively upon arrival in Waardenburg. These negative social reactions diminished somewhat over time. However, the hostility intensified tremendously when the plans for the guest-house for AlDS patients were anounced.

2. Throughout this disseration we use the terms HIV and AIDS interchangeably, because the basic underlying process of stigmatization is similar for persons with HIV or AIDS. However, one should bare in mind that AIDS refers to the later stages of the disease and that this may influence people's perception of seriousness and their subsequent behavior (see chapter 3).

3. It should be noted that concealment of HIV in everyday life may be difficult for persons with HIV who adhere to antiretroviral therapies, because of the tight regimen of the therapy.

4. Researchers in this field use different terms to refer to an emotion that motivates prosocial behavior. For example, Batson (1987) uses the term empathy. Eisenberg and colleagues (1989) sympathy and Weiner et al. (1988) pity. In this dissertation I will use the term pity, because the cognitive-emotional model of stigmatization of persons with HIV is based on Weiner's attribution-emotion model of stigmatization.

5. Dijker and Koomen (in press) use the term 'negative valence of behavioral cause' to refer to the concept of norm violation.

6. The factor 'schadenfreude' (malicious delight) is not included the adapted version of Dfijker and Koomen's model, because this emotional reaction has never been investigated with regard to HIV-related stigmatization.

7. Chapters 2, 3, 5 and 6 are based on research articles that have been submitted or accepted for publication. Therefore, the reader may notice some overlap in the theoretical introductions of these chapters and this theoretical overview. However, this overlap allows the reader to read each chapter independently, without cross-referring to other chapters.

8. There were no gender differences with respect to knowledge about HAARI

9. There were gender differences on the mean scores of a number of cognitive, emotional and behavioral reactions towards persons with HIV/AIDS. Men reported stronger blaming, a less positive attitude towards homosexuals, less pity, more anger and less willingness to have personal contact with someone with HIV/AIDS, in comparison with women. In this study, however, we focussed on the contribution of cognitive and emotional factors on willingness to have personal contact with persons with HIV/AIDS. Although men and women differ in their reported level of cognitive, emotional and behavioral reactions, the same cognitive and emotional factors contribute to willingness to have personal contact with someone with HIV/AIDS. In other words, gender does not moderate the influence of our cognitive and emotional predictors on willingness to have personal contact with someone with HIV/AIDS. 
10. Fisher exact tests were used in case of expected cell frequencies of $\leq 5$.

11. The impact of coping behavior of persons with HIV on perceivers' emotional and behavioral reactions is a relatively unexplored research area and little is known about the effect of different coping strategies on perceivers' reactions to persons with HIV. In the present studies a heterosexual target person was used, in order to limit the moderating role of 'attitude towards homosexuals' on perceivers' responses to coping with HIV.

12. Analyses of variance show that the four conditions indeed do not differ from each other with regard to age $(F(3,132)=.35$, n.s. $)$ and educational level $(F(3,132)=.24$, n.s. $)$. 


\section{SUMMARY}

Persons with HIV not only face the physical and psychological consequences of their medical condition, but are often also confronted with negative emotional and behavioral reactions from others. This dissertation examines determinants of stigmatization of persons with HIV and AIDS. Furthermore, it examines the effectiveness of different interaction strategies that persons with HIV may adopt to influence perceivers' emotional and behavioral reactions in initial encounters.

Chapter 1 presents an overview of social-psychological literature on social stigma. Relevant theoretical insights are applied to the stigmatization of persons with HIV. Furthermore, important aspects of social interaction between stigmatized and nonstigmatized individuals are discussed. Finally, a cognitive-emotional model of HIV-related stigmatization is presented and empinical evidence for this model is discussed. This model is based on Dijker and Koomen's (1996) extension of Weiner's attribution-emotion model of stigmatization (Weiner et al., 1988). The cognitive-emotional model of HIV-related stigmatization describes how cognitive and emotional factors are meaningfully related to one another and how they influence stigmatizing behavior towards persons with HIV.

Chapter 2 reports the results of a national telephone survey on HIV. This survey was conducted to (1) assess present-day public reactions towards persons with HIV/AIDS in the Netherlands, (2) to measure how knowledge about highly active antiretroviral therapy (HAART) is related to public reactions towards persons with HIV/AIDS, and (3) to investigate determinants of willingness to have personal contact with people with HIV/AIDS. Dutch adults $(N=751)$ participated in a telephone interview conducted to measure cognitive, emotional and behavioral reactions to people with HIV/AIDS. The results of this survey indicated that public reactions to people with HIV/AIDS are moderately positive in the Netherlands. Knowledge about HAART is related to lower risk perceptions, a positive attitude towards homosexuals, less fear and more willingness to have personal contact with persons with HIV/AIDS. In particular cognitive, but also emotional factors are meaningfully related to willingness to have personal contact with people with HIV/AIDS.

Chapter 3 reports the results of a vignette study among students from colleges of senior secondary vocational education. This study examined the influence of seriousness of disease symptoms and patient's sexual orientation on emotional and behavioral reactions to ill persons. Participants received a vignette containing information about a new colleague, suffering from a disease (HIV or cancer) that differed in seriousness (low or high). An additional manipulation was target's sexual orientation (homosexual or heterosexual). After reading the vignette, participants answered questions about emotions and stigmatizing reactions. The results confirmed the hypothesis that seriousness of disease symptoms is related to stronger stigmatization. Seriousness of disease was related to pity, and to a limited extent to fear. In line with other studies, an interaction between sexual orientation of the target and gender of the participant influenced stigmatization, with men expressing the strongest negative reactions when confronted with a homosexual target. 
Chapter 4 introduces the empirical studies on interaction strategies that persons with HIV may adopt to influence perceivers' emotional and behavioral reactions in initial encounters. First, social-psychological research on reducing prejudice towards stigmatized individuals is discussed. Second, attention is paid to society-level strategies that have been employed to reduce stigmatization of persons with HIV. Third, interaction-level strategies to reduce stigmatization in initial encounters are addressed. Such interaction strategies have seldom been examined for persons with HIV. Finally, this chapter presents an outline of the experiments reported in chapters 5 and 6 .

Chapter 5 describes three studies that examined the role of coping with HIV on perceivers' emotional and behavioral reactions to patients. Using a freeresponse format, Study 5.1 examined what coping strategies of persons with HIV or cancer are preferred by healthy perceivers. This study demonstrated that perceivers prefer ill persons to continue with their normal life and to have a positive attitude towards life. In contrast, perceivers seem to reject self-pity and negative mood states of ill persons. Interestingly, women had a significantly stronger preference for patient's communication about the disease than did men. In Study 5.2, 'conveying distress' and 'active coping' of persons with HIV were experimentally manipulated by means of vignettes. This study revealed clear gender differences in responses towards persons with HIV who convey distress: women reported stronger feelings of pity, while men reported stronger feelings of anger. No favorable effects were found for active coping. Study 5.3 replicated the previous study in a realistic experimental setting with additional behavioral measures. Participants were led to believe that they were to cooperate with a person who was either healthy or infected with HIV. Prior to the alleged cooperation, they listened to an audiotaped interview with this target person, which contained our manipulation of coping. The results confirmed previous findings with respect to gender differences in responses to patient's coping. Women reported stronger pro-social behavior than men, when confronted with a target with HIV who conveyed distress. Once again, no favorable effects were found for active coping. The results of the three studies are discussed in terms of gender roles, emotions and pro-social behavior.

Chapter 6 reports on two studies that were conducted to examine the impact of fear reduction strategies in initial encounters. Study 6.1 investigated the role of predictable behavior, an implicit nonverbal strategy. Female students were led to believe that they were to cooperate with a male target that was either healthy or infected with HIV. Prior to the alleged cooperation, participants secretly watched the target on a monitor while he was preparing for the task in a predictable or unpredictable way. The results showed that there were no differences in reported fear. However, participants reported the strongest degree of pity for a target with HIV who displayed predictable behavior. Study 6.2 examined the effect of reassurance, an explicit verbal strategy. In this second study, female participants listened to a taped interview with a healthy target or a target with HIV, who provided either reassuring or non-reassuring information. Contrary to our expectations, participants in the reassuring condition reported stronger feelings of fear. The results of these two studies are discussed in terms of the limiting conditions 
under which interpersonal fear-reducing strategies may be effective.

Finally, Chapter 7 integrates the findings of the reported studies and discusses the contribution of these studies to the field of HIV stigma. In particular, it pays attention to determinants of stigmatization of persons with HIV, interaction strategies to reduce stigmatization and gender differences in reactions towards persons with HIV. Furthermore, strengths and limitations of the reported studies are discussed. To conclude, practical implications of the studies in this dissertation are discussed. 


\section{SAMENVATTING}

Mensen met HIV hebben niet alleen te maken met de lichamelijke en emotionele gevolgen van hun ziekte, maar worden vaak ook geconfronteerd met stigmatiserende reacties. Hierbij kan men bijvoorbeeld denken aan openlijke signalen van ongemak, het vermijden van de omgang met iemand met HIV of het verbreken van het contact. In het huidige promotie-onderzoek is onderzocht welke factoren stigmatisering van mensen met HIV beïnvloeden. Verder zijn verschillende strategieën onderzocht die mensen met HIV in het eerste contact met anderen zouden kunnen hanteren om stigmatiserende reacties te reduceren en prosociale reacties te bevorderen.

In Hoofdstuk 1 wordt een overzicht gegeven van de sociaal-psychologische literatuur over stigmatisering. Deze inzichten worden zoveel mogelijk toegepast op stigmatisering van mensen met HIV. Vervolgens komen verschillende aspecten van sociale interactie tussen mensen met HIV en hun omgeving aan de orde. Hierbij is zowel aandacht voor motieven van waarnemers om te stigmatiseren, als voor de gevolgen en dilemma's die stigmatisering met zich meebrengt voor mensen met HIV. Het inleidende hoofdstuk wordt besloten met de presentatie van een cognitief-emotioneel model van stigmatisering van mensen met HIV. Dit model is gebaseerd op het cognitief-emotionele model van stigmatisering van zieken en gehandicapten van Dijker en Koomen (1996), dat een uitbreiding is van Weiner's attributie-emotie model van stigmatisering (Weiner et al., 1988). Het cognitiefemotionele model van stigmatisering van mensen met HIV beschrijft hoe verschillende cognitieve en emotionele factoren stigmatiserende reacties ten opzichte van mensen met HIV bepalen en hoe deze cognitieve en emotionele factoren onderling gerelateerd zijn.

In Hoofdstuk 2 worden de resultaten beschreven van een landelijke telefonische enquête naar de beeldvorming over mensen met HIV en AIDS. Het doel van dit onderzoek was drieledig. Het eerste doel was het verschaffen van een actueel beeld over de beeldvorming over mensen met HIV/AIDS in Nederland. Het tweede doel was het nagaan in hoeverre kennis over de combinatietherapie gerelateerd was aan reacties ten opzichte van mensen met HIV. Het laatste doel was het verkrijgen van inzicht in de cognitieve en emotionele determinanten van de bereidheid om persoonlijk contact te hebben met iemand met HIV. Deze telefonische enquête werd aftgenomen onder 751 Nederlanders. De beeldvorming over mensen met HIV/AIDS blijkt redelijk positief te zijn. Verder blijkt kennis over de combinatietherapie samen te hangen met lagere risico inschattingen om HIV in alledaags contact op te lopen, een positievere attitude ten opzichte van homoseksuelen, minder angst en een grotere bereidheid om persoonlijk contact te hebben met iemand met HIV. Tot slot werd gevonden dat cognitieve factoren, en in geringere mate emotionele factoren, op een zinvolle manier samen hingen met de bereidheid om persoonlijk contact te hebben met iemand met HIV.

In Hoofdstuk 3 wordt de invloed van de emst van de ziektesymptomen en de seksuele geaardheid van de patiënt op emoties en gedrag van de waamemer onderzocht. MBO-studenten lazen een scenario met informatie over een nieuwe collega met wie zij op het werk zouden moeten samenwerken. In dit scenario werden de 
ziekte van de collega (HIV of kanker), emst van de ziektesymptomen (weinig of veel) en de seksuele geaardheid van de collega (homoseksueel of heteroselsueel) gevariëerd. Na het lezen van het scenario kregen de studenten vragen voorgelegd over hun emoties en gedrag. Volgens verwachting bleek de emst van de ziektesymptomen gerelateerd te zijn aan sterkere stigmatisering. Bovendien werd gevonden dat de emst van de ziekte een toestand van emotionele ambivalentie in waamemers oproept. Studenten rapporteerden zowel sterkere gevoelens van medelijden als sterkere gevoelens van angst wanneer zij te maken hadden met een collega met emstige ziektesymptomen. In overeenstemming met eerder onderzoek werd een interactie-effect gevonden tussen de seksuele geaardheidheid van de patient en de sekse van de waarnemer, waaruit bleek dat mannen de sterkste negatieve reacties rapporteren wanner zij te maken hebben met een homoseksuele persoon.

Hoofdstuk 4 introduceert de empirische studies uit hoofdstuk 5 en 6 . Deze studies onderzoeken de effecten van verschillende interactiestrategieën die mensen met HIV in het eerste contact met anderen zouden kunnen hanteren om negatieve reacties te reduceren en prosociale reacties te bevorderen. Allereerst wordt sociaal-psychologisch onderzoek naar het reduceren van vooroordelen besproken. Vervolgens wordt aandacht besteed aan strategieën die op maatschappelijk niveau gehanteerd kunnen worden om stigmatisering van mensen met HIV te verminderen. Verder wordt stil gestaan bij de mogelijkheden om stigmatiserende reacties op het interactieniveau te reduceren. Er wordt betoogd dat mensen met HIV in eerste contact ook zelf invloed kunnen uitoefenen op de gevoelens en het gedrag van anderen door het hanteren van bepaalde interactiestrategieën. Tot op heden zijn de effecten van dergelijke interactiestrategieën echter nog nauwelijks onderzocht voor mensen met HIV. Aan het eind van dit hoofdstuk wordt een kort overzicht gegeven van de belangrijkste onderzoeksvragen van de studies uit Hoofdstuk 5 en 6.

Hoofdstuk 5 rapporteert drie studies naar de effecten van coping met HIV op de emoties en het gedrag van waamemers. In studie 5.1 werd onderzocht welke copingstrategieën van mensen met HIV en kanker door waarnemers als wenselijk dan wel onwenselijk werden beschouwd. Uit dit onderzoek komt naar voren dat waarnemers het liefst willen dat mensen met HIV een positieve houding hebben ten opzichte van het leven en niet in een ziekenrol vervallen. Daarentegen blijken waarnemers zelfmedelijden en depressie als zeer onwenselijke vormen van coping te beschouwen. Een interessante bevinding is dat vrouwen het veel wenselijker vinden als een patiënt over zijn ziekte communiceert dan mannen. In studie 5.2 werd de impact van 'actieve coping' en 'leedcommunicatie' van mensen met HIV op emotionele reacties van waarnemers onderzocht. MBO-scholieren kregen een scenario voorgelegd, waarbij zij zich moesten voorstellen dat zij zouden moeten samenwerken met een mannelijke collega met HIV. Informatie over de emst van de ziekteverschijnselen, persoonlijke verantwoordelijkheid voor het krijgen van de ziekte alsmede de coping met HIV werden gemanipuleerd. Het onderzoek laat zien dat mannen en vrouwen verschillend reageren op leedcommunicatie van de mannelijke collega met HIV: Leedommunicatie blijkt bij vrouwen gevoelens van medelijden op te roepen, terwijl mannen hierdoor juist meer geirriteerd raken. Er werden geen gunstige effecten van actieve coping gevonden. In studie 5.3 is het vorige 
onderzoek gerepliceerd in een realistische experimentele interactie context en is gebruik gemaakt van aanvullende gedragsmaten. Deelnemers uit de Maastrichtse bevolking kwamen naar het laboratorium om mee te doen aan een onderzoek over 'samenwerking en eerste indrukken'. Voor de zogenaamde samenwerking luisterden zij naar een interview met de toekomstige interactiepartner (een gezonde persoon of iemand met HIV). Dit bandje bevatte de experimentele manipulatie van coping. Hierna kregen de deelnemers een vragenlijst over hun eerste gevoel en indrukken over de toekomstige samenwerking. Uit het onderzoek kwam naar voren dat vrouwen, in tegenstelling tot mannen, prosociaal reageren wanneer de interactiepartner met HIV over zijn leed communiceert. Er werden wederom geen gunstige effecten van actieve coping gevonden. De drie studies laten een consistent patroon van sekseverschillen zien met betrekking tot reacties op leedcommunicatie van een man met HIV. Deze onderzoeksresultaten worden besproken in het kader van literatuur over sekserollen, emoties en prosociaal gedrag.

In Hoofdstuk 6 worden de resultaten van twee studies naar de effectiviteit van angst-reductie strategieën onderzocht. In studie 6.1 zijn de effecten van voorspelbaar gedrag, een impliciete non-verbale strategie, op reacties van vrouwelijke studenten onderzocht. De deelneemsters dachten dat zij gingen samenwerken met iemand anders (een gezonde persoon of iemand met HIV) en mochten voorafgaand aan de werkelijke ontmoeting op een monitor kijken hoe de ander zich aan het voorbereiden was op de taak. Met behulp van deze videobeelden, waarop een acteur voorspelbaar dan wel onvoorspelbaar gedrag vertoonde, werd de experimentele manipulatie uitgevoerd. $\mathrm{Na}$ het zien van de beelden vulden de deelneemsters een vragenlijst in over hun eerste indrukken en hun gevoel ten opzichte van de samenwerking. In tegenstelling tot de verwachtingen bleek voorspelbaar gedrag niet angst reducerend te werken. Daarentegen bleken de deelneemsters wel de meeste betrokkenheid te voelen voor een persoon met HIV die zich voorspelbaar opstelde. In studie 6.2 werd het effect van geruststelling, een expliciete verbale strategie, op gevoelens van angst onderzocht. In een vergelijkbare experimentele context kregen de deelneemsters een interview met de toekomstige interactiepartner te horen, waarin deze al dan niet geruststellende informatie verschafte. Tegengesteld aan onze verwachtingen, bleken deelnemers in de geruststellende condities (zowel voor een gezonde persoon als iemand met HIV) juist meer angst te rapporteren. Het lijkt er op dat expliciete geruststellende informatie bij de deelneemsters aan dit onderzoek de dreiging juist saillant(er) heeft gemaakt. De resultaten van beide onderzoeken worden besproken in het licht van de situationele context waarbinnen bepaalde angst-reductie strategieën effectief kunnen zijn.

Hoofdstuk 7 integreert de bevindingen uit de gerapporteerde studies en bespreekt de wetenschappelijke bijdrage van deze studies op het gebied van HIV stigma. Ten eerste wordt dieper ingegaan op determinanten van stigmatisering van mensen met HIV. Ten tweede wordt stil gestaan bij interactiestrategieën om stig130 matisering van mensen met HIV te reduceren. Ten derde wordt aandacht besteed aan sekseverschillen in reacties ten aanzien van mensen met HIV. Hierna worden de sterke kanten van de gerapporteerde studies besproken. Tot slot worden de praktische implicaties van de gerapporteerde studies besproken. 


\section{CURRICULUM VITAE}

Arjan Bos was born on November 15, 1970 in Epe. In 1989 he received his VWO diploma at Murmellius Gymnasium in Alkmaar. From 1990 till 1995 he studied psychology at Free University, Amsterdam. In 1995 he obtained his Master's degree in Social Psychology. From October 1995 till November 1996 he worked as a researcher at the department of Work- and Organizational Psychology at University of Amsterdam. From December 1996 till February 2001 he worked at the Department of Health Education at Maastricht University. In this period he conducted his $\mathrm{PhD}$ research on stigmatization of persons with HIV that is reported in this dissertation. Currently he is working as a lecturer in psychology at Open University in Heerlen. 


\section{ACKNOWLEDGEMENTS}

Throughout the years many people have contributed to this $\mathrm{PhD}$ project and this is the place to express my gratitude to all of them. Most of all, I thank Anton Dijker for his role in this project. I appreciated his thoughtful and detailed comments on the research designs and draft papers. He invariably showed commitment and interest in my work, and was always available for discussions on theoretical and empirical issues. I'm also grateful to Gerjo Kok and Wim Koomen for their feedback and interest in this project. In addition, the following people and organizations have contributed to this dissertation in different ways: AIDS Fonds, Josee Driessen, Pepijn van Empelen, Corien Gijsbers, Sascha Honselaar, Nicole van Kesteren, Lydia Kwak, René Lion, Memic, Nora Oosting, John Pryor, Maarten Reuvekamp, Annemarie Roodenburg, Rob Ruiter, Geo Visser and Nanne de Vries. I want to express my gratitude to them all.

I also thank all my colleagues, friends and relatives who have shown their interest in my $\mathrm{PhD}$ project, supported me and made my $\mathrm{PhD}$ time a highly pleasant one. In particular, I am indebted to my parents for their unconditional support. Furthermore, I thank my grandfather, L.M. van Voorene, for sending me hundreds of newspaper articles about HIV throughout the years. Finally, my move to Maastricht has resulted not only in this dissertation, but also had a positive impact on my personal life. Helga and Jaron, how precious you are to me - you contribute significantly to my feelings of happiness. 
The "Kurt Lewin Institute Dissertation Series" started in 1997. Since 1999 the following dissertations have been published:

1999-1: Barbara van Knippenberg

Determinants of the use of hard and soft influence tactics

1999-2: Manon Hoekstra

Gedragsbeïnvloeding door cursussen. Een studie naar de effecten van persoons-, cursus- en omgevingskenmerken

1999-3: $\quad$ Marga de Weerd

Sociaal-Psychologische determinanten van boerenprotest: collectieve actie frames, onvrede, identiteit en effectiviteit

1999-4: Agnes van den Berg

Individual differences in the aesthetic evaluation of natural landscapes

1999-5: Wilco van Dijk

Dashed hopes and shattered dreams: On the psychology of disappointment

1999-6: Frans Oldersma

Downward comparison in close relationships: A blessing in disguise?

1999-7: Dörte Heimbeck

Training and motivation: The function of implementation intentions, goal orientation, and errors for performance

1999-8: Patricia Rodriguez Mosquera

Honor and emotion. The cultural shaping of pride, shame and anger

1999-9: Tjarda van Sliedregt

Het beoordelen van functies nader beoordeeld

1999-10: Marco Yzer

Mass media campaigns to promote safe sex. An evaluation of public campaigns in the Netherlands

1999-11: Ellen de Bruin

Good for you or good for me? Interpersonal consequences of personality characteristics

1999-12: Ellen Giebels

What if this is as good as it gets: Alternative partners and social motives of negotiators

2000-1: Roeline Kuijer

Give-and-take among couples facing cancer. Equity concerns in the context of a serious illness

2000-2: $\quad$ Marieke Wilke

Billijkheid van prestatieverschillen in taakgroepen

2000-3: Cathy van Dyck

Putting errors to good use: On error management culture in organizations

2000-4: Manuela Barreto

Identity and strategy in pro-group behaviour

2000-5: Arieneke Groenenboom

Efficiency and faimess in collective task performance 
2000-6: Birgitta Gatersleben

Sustainabel household metabolism and quality of life: Examining the perceived social sustainability of environmentally sustainable household consumption patterns

2000-7: Wander Jager

Modelling consumer behaviour

2000-8: Claudia Hoeksema-van Orden

Fatigue and performance in groups

2000-9 : Jaap Ouwerkerk

Comparison-based reactions to group performance outcomes

2000-10: Carien Görts

The Significance of Personal Relationships in Cultural Perspective: A Comparison of Individualistic and Collectivistic Culture

2000-11: Monique Timmers

Sex differences in emotion expression

2000-12: Ana Christina Costa

A matter of trust: Effects on the performance and effectiveness of teams in organizations

2000-13: Sander Koole

Positivity in self-evaluation

2000-14: Andreas Rauch

Success Factors of Small and Medium Sized Enterprises

2001-1: Laura Sweeney

Abstraction, representation and Social Cognition

2001-2: $\quad$ Arjan Bos

HIV stigma and social interaction: Examining strategies to influence perceivers' emotional and behavioral reactions in initial encounters. 

Examining strategies to influence perceivers' emotional and behavioral reactions in initial encounters 